\title{
A review on experience feedback and numerical modeling of packed- bed thermal energy storage systems
}

\author{
Thibaut Esence ${ }^{a *}$, Arnaud Bruch ${ }^{\text {a }}$, Sophie Molina ${ }^{\text {a }}$, Benoit Stutz ${ }^{\text {b }}$, Jean-François \\ Fourmigué $^{\mathrm{a}}$ \\ ${ }^{\text {a }}$ Université Grenoble Alpes (UGA), CEA-Liten-DTBH, Laboratoire de Stockage Thermique, F-38000 Grenoble, France \\ ${ }^{\mathrm{b}}$ LOCIE, Univ. Savoie, Campus Scientifique, Savoie Technolac, F-73376 Le Bourget-du-Lac Cedex, France \\ * Tel: (33)4 387801 82; thibaut.esence@cea.fr
}

\begin{abstract}
Solar thermal energy is a clean, climate-friendly and inexhaustible energy resource. It is therefore promising to cope with fossil fuel depletion and climate change. Thermal storage enables to make this intermittent energy resource dispatchable, reliable on demand and more competitive. Nowadays, most of the concentrated solar power plants equipped with integrated thermal storage systems use the two-tank molten salt technology. Despite its relative simplicity and efficiency, this technology is expensive and requires huge amounts of nitrate salts. In the short to medium term, packed-bed thermal energy storage with either liquid or gaseous heat transfer fluid is a promising alternative to reduce storage costs and hence improve the development of solar energy. To design reliable, efficient and cost-effective packed-bed storage systems, this technology, which involves many physical phenomena, has to be better understood.

This paper aims to sum up some key aspects about design, operation, and performances of packed-bed storage systems. In the first part, most representative setups and their experience feedback are presented. The controllability of packed-bed storage systems and the special influence of thermal stratification are pointed out. In the second part, the various numerical models used to predict packed-bed storage performances are reviewed. In the last part, some useful correlations enabling to quantify the main physical phenomena involved in packed-bed operation and modeling are presented and compared. The correlations investigated enable to calculate fluid/solid and fluid/wall heat transfer coefficients, effective thermal conductivity and pressure drop in packed beds.
\end{abstract}

Keywords: Thermal energy storage, Packed bed, Thermocline, Concentrated Solar Power (CSP)

\section{Introduction}

Variable renewable energy sources, like wind and solar, are expected to play a key role to cope with fossil fuel depletion and climate change. With interconnection and demand response, energy storage is one of the most promising ways to enhance the penetration of intermittent energy sources in power grids while ensuring electricity security (Akinyele and Rayudu, 2014; Hohmeyer and Bohm, 2015; Pudjianto et al., 2014). Integration of energy storage system into a power plant enables the operator to avoid frequent start up and shut down of electrical device, and to increase load factor by dispatching production according to demand and current electricity price. This is therefore a way to reduce the levelized cost of energy (LCOE), thus making variable renewables more competitive (Xu et al., 2012b).

At large scale, thermal energy storage (TES) is cheaper and more efficient than most electric storage systems (Philibert, 2011; Sabihuddin et al., 2015). Consequently, TES appears to be particularly suitable for concentrated solar power (CSP) plants which generate heat before converting it into electricity. TES is therefore a key advantage for CSP compared to photovoltaic power plants which directly generate electricity. A detailed analysis of available data on CSP plants throughout the world (CSP Today; CSP World; NREL) shows that about half of CSP plants gets integrated TES. This share is expected to grow in the next future given that most of the currently scheduled CSP plants are going to get storage systems. Furthermore, some countries like Morocco or South Africa implemented financial incentives for evening CSP generation, while others like Chile or Saudi Arabia have made integrated TES mandatory for coming CSP plants (Kraemer).

There are mainly three ways of storing heat: sensible heat storage, latent heat storage, and chemical heat storage (Gil et al., 2009). Although promising in terms of performance, latent heat and chemical heat storage technologies are not commercially mature yet. Latent heat storage for CSP is still at the prototype stage (Xu et al., 2015) while chemical heat storage is still at the laboratory stage (Pardo et al., 2014). Currently, only sensible heat storage is widely used in CSP plants.

The most widespread and state-of-the-art sensible TES technology is two-tank molten salt storage, an example of which is depicted in Fig. 1. It consists in using molten nitrate salts, which have high volumetric heat capacity and high operating temperature, as storage medium. During load periods, cold molten salt is heated in solar receptors and transferred from cold to hot tank. The process is inverted to recover heat and run thermal processes. This technology is well known, easy to handle and very efficient given that hot and cold fluids are well separated (Gil et al., 2009). However, this storage system is relatively expensive and requires a huge amount of costly nitrate salt while world's capacity production of natural nitrate is limited and won't be able to supply a soaring demand (García-Olivares et al., 2012). 


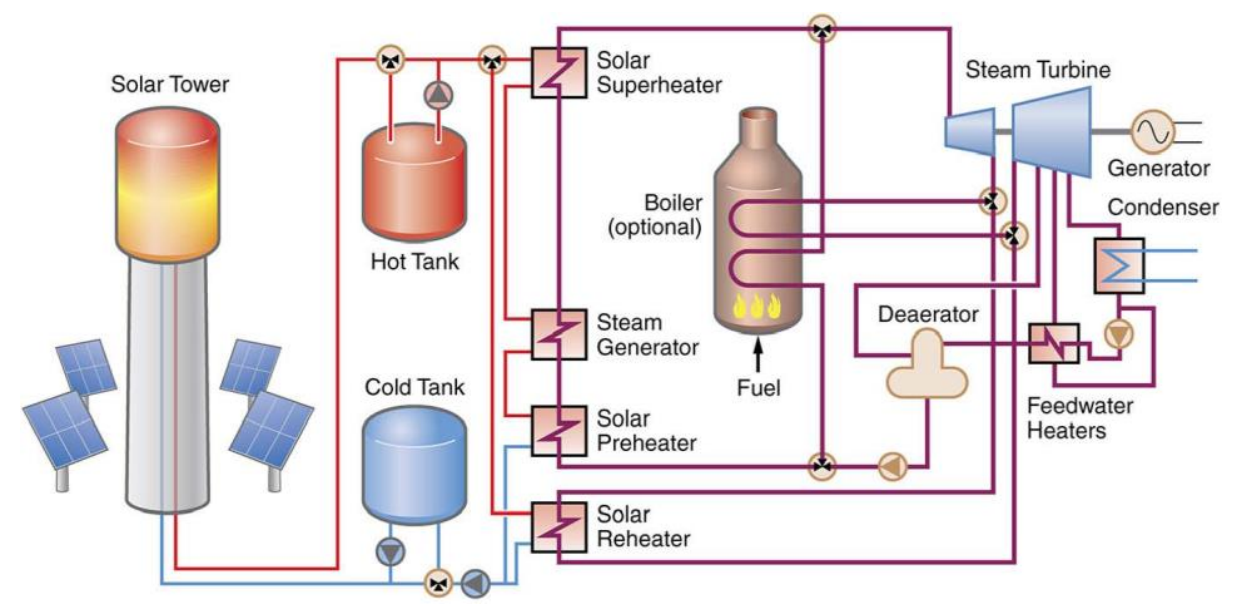

Fig. 1. Two-Tank Direct Thermal Storage System (EPRI, 2010).

To face these difficulties, a possible alternative for sensible TES is single-tank packed-bed storage which consists in using solids as heat storage medium and heat transfer fluid (HTF) in direct contact to convey heat. As depicted in Fig. 2, contrary to two-tank system, packed-bed storage requires a single tank in which hot and cold zones are separated by a transition zone with a thermal gradient called "thermocline". For a fixed theoretical energy capacity, liquid/solid single-tank storage has almost the same size than one of the tanks of two-tank system (Brosseau et al., 2005). Therefore, with typical fillers (i.e. rocks with molten salts or thermal oil), theoretical energy density of packed-bed storage in terms of tank volume is about $50 \%$ higher than the one of two-tank storage (Galione et al., 2015). Moreover, by using cheap solids like rocks and sand, it is possible to reduce the amount of expensive fluid by approximately $70 \%$ (Galione et al., 2015). Theoretical energy density of most packed-bed storages calculated with specific heat of filler materials is about $180-250 \mathrm{MJ} \cdot \mathrm{m}^{-3} \cdot \mathrm{K}^{-1}\left(\mathrm{i} . e .50-70 \mathrm{kWh}\right.$ th $\left./ \mathrm{m}^{3}\right) \mathrm{with}$ a temperature difference of $100{ }^{\circ} \mathrm{C}$.

As a consequence, overall investment cost of packed-bed storage is up to $35 \%$ lower compared to two-tank storage (Brosseau et al., 2005; EPRI, 2010). Using packed-bed storage instead of two-tank storage thus enables to reduce LCOE of CSP plants (Cocco and Serra, 2015).

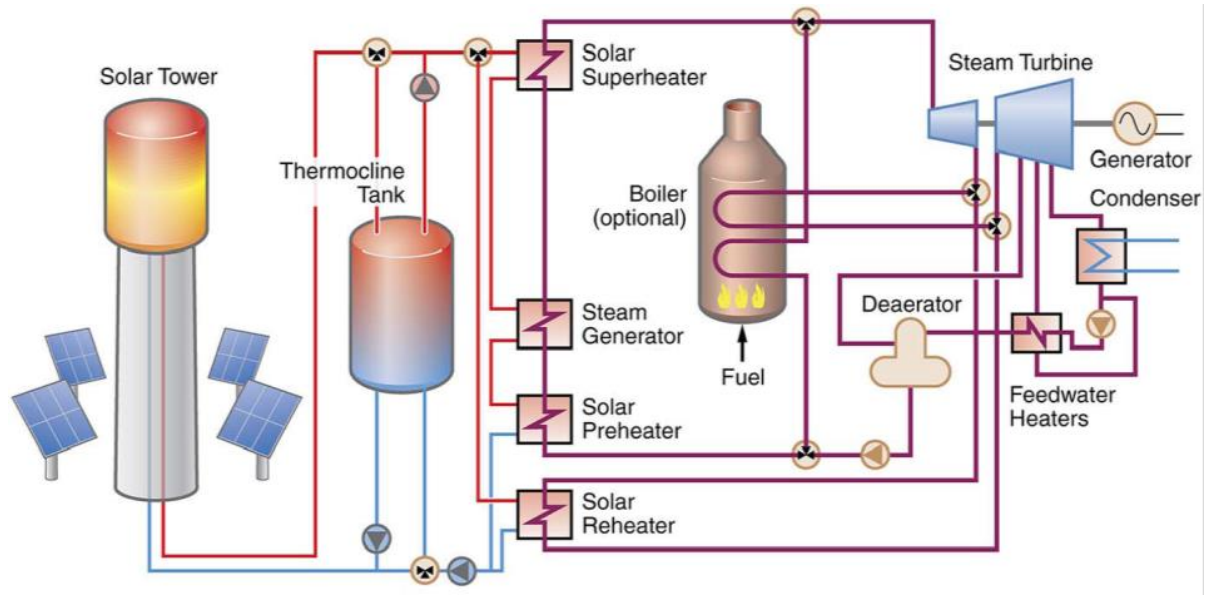

Fig. 2. Single Tank Direct Thermocline System (EPRI, 2010).

Besides, given that the fluid is essentially used as heat transfer medium instead of as storage medium, the choice of the fluid is more flexible. It is therefore possible to use a greater diversity of fluids, either liquid or gaseous.

However, while many two-tank storage systems have been implemented and tested, only a couple of packed-bed storage systems have been experienced at large scale so far. In the first part, this literature review aims to present the main available feedback about behavior, operation and performances of packed-bed storage systems. The second part presents and briefly compares numerical methods from the literature for thermal modeling of the system. The third part deals with correlations for determination of the main physical parameters involved in operation and modeling of packed-bed storage.

\begin{tabular}{|l|l|}
\hline \multicolumn{2}{|c|}{ Nomenclature } \\
\hline A & viscous parameter in Ergun-type equations \\
\hline$A_{s}$ & superficial area of solids $\left(\mathrm{m}^{2}\right)$ \\
\hline$a_{b}$ & external surface area of packed-bed per unit bed volume $\left(\mathrm{m}^{2} \cdot \mathrm{m}^{-3}\right)$ \\
\hline$a_{s}$ & surface area of solid per unit bed volume $\left(\mathrm{m}^{2} \cdot \mathrm{m}^{-3}\right)$, see equation $(4)$ \\
\hline$a_{w}$ & surface area of tank wall per elementary unit wall volume $\left(\mathrm{m}^{2} \cdot \mathrm{m}^{-3}\right)$ \\
\hline
\end{tabular}




\begin{tabular}{|c|c|}
\hline B & inertial parameter in Ergun-type equations \\
\hline $\mathrm{Bi}$ & dimensionless Biot number, see equation (1) \\
\hline $\mathrm{Bi}^{\prime}$ & $\begin{array}{l}\text { dimensionless Biot number as defined by Votyakov and Bonanos, 2014, } \mathrm{Bi}^{\prime}= \\
\mathrm{h} \cdot \mathrm{a}_{\mathrm{s}} \cdot \mathrm{L}^{2} / \lambda_{\text {eff }}\end{array}$ \\
\hline$c_{p}$ & specific heat capacity $\left(\mathrm{J} \cdot \mathrm{kg}^{-1} \cdot \mathrm{K}^{-1}\right)$ \\
\hline $\mathrm{D}$ & diameter $(\mathrm{m})$ \\
\hline $\mathrm{E}$ & thermal effusivity $\left(\mathrm{J} \cdot \mathrm{K}^{-1} \cdot \mathrm{m}^{-2} \cdot \mathrm{s}^{-1 / 2}\right), \mathrm{E}=\sqrt{\rho \cdot \mathrm{c}_{\mathrm{p}} \cdot \lambda}$ \\
\hline $\mathrm{f}$ & term of tortuosity as defined in Hueppe, 2011 \\
\hline$f_{v}$ & friction factor, $\mathrm{f}_{\mathrm{v}}=\Delta \mathrm{P} \cdot \mathrm{D}_{\mathrm{s}}^{2} \cdot \varepsilon^{3} /\left[\mathrm{L} \cdot \mu_{\mathrm{f}} \cdot \mathrm{u}_{\mathrm{sup}} \cdot(1-\varepsilon)^{2}\right]$ \\
\hline $\mathrm{h}$ & convective heat transfer coefficient $\left(\mathrm{W} \cdot \mathrm{m}^{-2} \cdot \mathrm{K}^{-1}\right)$ \\
\hline $\mathrm{Hg}$ & dimensionless Hagen number, $\mathrm{Hg}=\rho_{\mathrm{f}} \cdot \Delta \mathrm{P} \cdot \mathrm{D}_{\mathrm{s}}^{3} /\left(\mathrm{L} \cdot \mu_{\mathrm{f}}^{2}\right)$ \\
\hline $\mathrm{h}_{\mathrm{v}}$ & convective heat transfer coefficient per unit bed volume $\left(\mathrm{W} \cdot \mathrm{m}^{-3} \cdot \mathrm{K}^{-1}\right)$ \\
\hline $\mathrm{L}$ & length of the packed bed in flow direction $(\mathrm{m})$ \\
\hline $\mathrm{m}$ & mass $(\mathrm{kg})$ \\
\hline $\mathrm{Nu}$ & dimensionless Nusselt number, $\mathrm{Nu}=\mathrm{h} \cdot \mathrm{D}_{\mathrm{s}} / \lambda_{\mathrm{f}}$ \\
\hline $\mathrm{Pe}$ & $\begin{array}{l}\text { dimensionless Péclet number as defined by Votyakov and Bonanos, 2014, Pe }=\mathrm{u} \cdot \\
\mathrm{L} /\left[\lambda /\left(\rho \cdot \mathrm{c}_{\mathrm{p}}\right)\right]_{\mathrm{eff}}\end{array}$ \\
\hline $\operatorname{Pr}$ & dimensionless Prandtl number, $\operatorname{Pr}=\mu_{\mathrm{f}} \cdot \mathrm{c}_{\mathrm{p}_{\mathrm{f}}} / \lambda_{\mathrm{f}}$ \\
\hline Q & energy $(J)$ \\
\hline $\mathrm{Q}^{*}$ & dimensionless energy, $\mathrm{Q}^{*}=\mathrm{Q} /\left[\left(\rho \cdot \mathrm{c}_{\mathrm{p}}\right)_{\text {eff }} \cdot \mathrm{V}_{\mathrm{b}} \cdot\left(\mathrm{T}_{\max }-\mathrm{T}_{\min }\right)\right]$ \\
\hline $\mathrm{r}$ & radial coordinate $(\mathrm{m})$ \\
\hline $\mathrm{R}$ & radius $(\mathrm{m})$ \\
\hline $\operatorname{Re}$ & dimensionless Reynolds number, $\operatorname{Re}=\rho_{\mathrm{f}} \cdot \mathrm{u}_{\mathrm{sup}} \cdot \mathrm{D}_{\mathrm{s}} / \mu_{\mathrm{f}}$ \\
\hline $\mathrm{T}$ & temperature $(\mathrm{K})$ \\
\hline $\mathrm{T}^{*}$ & dimensionless temperature, $\mathrm{T}^{*}=\left(\mathrm{T}-\mathrm{T}_{\mathrm{ref}}\right) /\left(\mathrm{T}_{\max }-\mathrm{T}_{\mathrm{ref}}\right)$ \\
\hline $\mathrm{t}$ & time (s) \\
\hline $\mathrm{t}^{*}$ & dimensionless time, $\mathrm{t}^{*}=\mathrm{t} /(\mathrm{L} / \mathrm{u})$ \\
\hline $\mathrm{u}$ & interstitial fluid velocity $\left(\mathrm{m} \cdot \mathrm{s}^{-1}\right), \mathrm{u}=\dot{\mathrm{m}} /\left(\rho_{\mathrm{f}} \cdot \varepsilon \cdot \pi \cdot \mathrm{R}_{\mathrm{b}}^{2}\right)$ \\
\hline $\mathrm{U}$ & overall heat transfer coefficient between the inside and the outside of the $\operatorname{tank}\left(\mathrm{W} \cdot \mathrm{m}^{-2} \cdot \mathrm{K}^{-1}\right)$ \\
\hline $\mathrm{u}_{\text {sup }}$ & superficial fluid velocity $\left(\mathrm{m} \cdot \mathrm{s}^{-1}\right), \mathrm{u}_{\text {sup }}=\varepsilon \cdot \mathrm{u}$ \\
\hline $\mathrm{V}$ & volume $\left(\mathrm{m}^{3}\right)$ \\
\hline $\mathrm{W}$ & velocity of the thermal front $\left(\mathrm{m} \cdot \mathrm{s}^{-1}\right)$, see equation $(10)$ \\
\hline $\mathrm{x}$ & dimensionless time of the Schumann model, $\mathrm{x}=\mathrm{h}_{\mathrm{v}} \cdot(\mathrm{t}-\mathrm{z} / \mathrm{u}) /\left[(1-\varepsilon) \cdot \rho_{\mathrm{s}} \cdot \mathrm{c}_{\mathrm{p}_{\mathrm{s}}}\right]$ \\
\hline $\mathrm{y}$ & dimensionless length of the Schumann model, $y=h_{v} \cdot z /\left(\varepsilon \cdot \rho_{f} \cdot c_{p_{f}} \cdot u\right)$ \\
\hline $\mathrm{z}$ & axial coordinate in flow direction $(\mathrm{m})$ \\
\hline $\mathrm{z}^{*}$ & dimensionless axial coordinate, $\mathrm{z}^{*}=\mathrm{z} / \mathrm{L}$ \\
\hline & Greek symbols \\
\hline$\alpha$ & thermal diffusivity $\left(\mathrm{m}^{2} \cdot \mathrm{s}^{-1}\right), \alpha=\lambda /\left(\rho \cdot \mathrm{c}_{\mathrm{p}}\right)$ \\
\hline$\gamma$ & ratio of volumetric heat capacity $\left(\rho \cdot c_{p}\right)$ to effective volumetric heat capacity of the bed \\
\hline$\delta \Theta$ & dimensionless solid-fluid temperature difference \\
\hline$\varepsilon$ & void fraction \\
\hline$\epsilon$ & emissivity \\
\hline$\Lambda$ & $\begin{array}{l}\text { dimensionless diffusion coefficient as defined by Votyakov and Bonanos, } 2014, \Lambda=1+ \\
\left(\gamma_{\mathrm{s}} \cdot \gamma_{\mathrm{f}} \cdot \mathrm{Pe}\right)^{2} / \mathrm{Bi}^{\prime}\end{array}$ \\
\hline$\lambda$ & thermal conductivity $\left(\mathrm{W} \cdot \mathrm{m}^{-1} \cdot \mathrm{K}^{-1}\right)$ \\
\hline
\end{tabular}




\begin{tabular}{|c|c|}
\hline$\mu$ & dynamic viscosity $(\mathrm{Pa} \cdot \mathrm{s})$ \\
\hline$v_{0}$ & cinematic viscosity evaluated for surface conditions $\left(\mathrm{m}^{2} \cdot \mathrm{s}^{-1}\right)$ \\
\hline$v_{\infty}$ & cinematic viscosity evaluated for free stream conditions $\left(\mathrm{m}^{2} \cdot \mathrm{s}^{-1}\right)$ \\
\hline$\rho$ & density $\left(\mathrm{kg} \cdot \mathrm{m}^{-3}\right)$ \\
\hline$\sigma$ & Stephan-Boltzmann constant, $\sigma=5.67 \cdot 10^{-8} \mathrm{~W} \cdot \mathrm{m}^{-2} \cdot \mathrm{K}^{-4}$ \\
\hline$\tau$ & dimensionless time as defined by Votyakov and Bonanos, $2014, \tau=\mathrm{t} /\left(\mathrm{L}^{2} / \alpha_{\mathrm{eff}}\right)$ \\
\hline \multicolumn{2}{|r|}{ Subscripts } \\
\hline$\infty$ & relating to ambient \\
\hline $\mathrm{b}$ & relating to the whole packed bed \\
\hline eff & effective value \\
\hline eq & relating to/calculated with an equivalent diameter \\
\hline eq,a & $\begin{array}{l}\text { relating to/calculated with the diameter of the sphere of equivalent specific area, see } \\
\text { equation (37) }\end{array}$ \\
\hline eq, $\mathrm{V}$ & $\begin{array}{l}\text { relating to/calculated with the diameter of the sphere of equivalent volume, see equation } \\
(38)\end{array}$ \\
\hline ext & relating to the external surface of the walls \\
\hline $\mathrm{f}$ & relating to fluid phase \\
\hline int & relating to the internal surface of the walls \\
\hline $\max$ & maximal value \\
\hline $\min$ & minimal value \\
\hline $\operatorname{mix}$ & relating to fluid mixing and braiding effect \\
\hline $\mathrm{r}$ & relating to radial direction (perpendicular to flow direction) \\
\hline ref & relating to the reference condition \\
\hline s & relating to filler solids \\
\hline tot & total value \\
\hline $\mathrm{W}$ & relating to the walls of the storage tank \\
\hline $\mathrm{z}$ & relating to axial direction (flow direction) \\
\hline \multicolumn{2}{|r|}{ Superscripts } \\
\hline 0 & with contribution of conduction in each phase (stagnant effective thermal conductivity) \\
\hline $\mathrm{C}$ & with contribution of conduction through contact surfaces between solids \\
\hline $\mathrm{R}$ & with contribution of radiative heat transfer \\
\hline
\end{tabular}

\section{Experimental studies and feedback}

In this part, the main experimental setups are briefly presented and feedback of the experimental studies is discussed in terms of system performances, operation and design. Finally, the main characteristics and some key aspects of filler materials and HTF are presented.

\subsection{Experimental applications}

Some of the most relevant packed-bed storage installations with liquid or gaseous HTF are listed in Table 1 and Table 2 respectively. It should be noticed that some characteristics of the referenced systems are not directly available in the original papers. Some of them were easily deduced and calculated from given data, while the others were estimated from partial data. The former are indicated with one asterisk $(*)$ and the latter with two asterisks $(* *)$.

The first full-scale industrial packed bed for CSP storage was implemented in 1982 in Solar One (Faas et al., 1986; McDonnell Douglas Astronautics Company, 1986). Solar One was a 10-MW $\mathrm{eSP}$ tower plant using water as HTF and integrating a $182-\mathrm{MWh}_{\text {th }}$ storage of more than $3,000 \mathrm{~m}^{3}$ composed of a mixture of rocks and sand with oil up to $290^{\circ} \mathrm{C}$ as HTF. It was rapidly shut down (in 1986) due to accidental admission of water in the tank which caused sudden pressure elevation and tank damage. As preparatory work on Solar One, a similar pilot-scale 5.7- $\mathrm{MWh}_{\text {th }}$ storage was tested (Hallet and Gervais, 1977). From these two experiments only partial data and little feedback are available in the literature. 


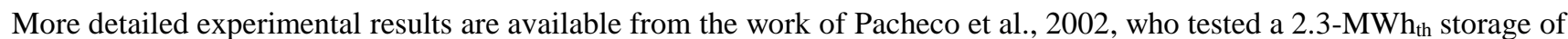
about $40 \mathrm{~m}^{3}$ comprised of rocks and sand with molten salt up to $390{ }^{\circ} \mathrm{C}$ as $\mathrm{HTF}$. Nowadays this reference paper is used by many authors to validate numerical models (Bayón and Rojas, 2013; Flueckiger et al., 2014; Van Lew et al., 2011; Xu et al., 2012b). However, exhaustive operative conditions used during tests were not published, and available temperature profiles suffer from significant and unexplained scattering (Fig. 5).

In addition to these two well-known experimental setups, some other pilot-scale packed-bed storages have been implemented and tested.

Zanganeh et al., 2012, built a 6.5-MWh $\mathrm{Mh}_{\text {th }}$ rock-bed storage running up to $500{ }^{\circ} \mathrm{C}$ with air as HTF. This truncated conical bed was buried to tackle thermomechanical stresses on the walls. The authors used the experimental results to validate a numerical model and to design the full-scale storage of the 3.9-MW th parabolic trough CSP plant of Aït-Baha (Morocco) which started production in 2014 (Airlight Energy). Since Solar One, this is probably the first commercial CSP plant with packed-bed storage. It consists of a pebble bed with air as HTF (Zanganeh et al., 2014) similar to the one presented and designed in Zanganeh et al., 2012. As far as the authors know, no operational data have been published so far.

Kuravi et al., 2013, implemented a structured packed bed of bricks of about $0.1 \mathrm{~m}^{3}$ with air up to $530{ }^{\circ} \mathrm{C}$ as $\mathrm{HTF}$. They confirmed the viability of structured packed beds in terms of fluid distribution and thermal stratification and validated a numerical model with the experimental data.

The experimental studies carried out by CEA (Bruch et al., 2014a; Bruch et al., 2014b; Rodat et al., 2015) investigated the behavior of packed beds of 2.4 and $30 \mathrm{~m}^{3}$ comprised of rocks and sand with thermal oil up to $300{ }^{\circ} \mathrm{C}$ as $\mathrm{HTF}$. The experimental results show smooth temperature profiles, with low experimental scattering, and exhibit a very repeatable and robust stabilized state through various flow and temperature conditions fixed by the operator. The studies highlight in particular the influence of various cycling conditions on packed-bed performances.

This behavior through charge and discharge cycles was also observed by Cascetta et al., 2015, on a $0.5-\mathrm{m}^{3}$ packed bed of alumina beads with air up to $240{ }^{\circ} \mathrm{C}$. The authors investigated the influences of aspect ratio (i.e. height-to-diameter ratio of the bed), air flow rate, temperature level and inertia of the walls (highlighted by radial temperature profiles) on the storage performances.

Except the above mentioned installations, most of the experimental data available in the literature come from laboratoryscale setups. These experiments enable to investigate some phenomena but are often non-representative of the overall behavior of large size installations (Fig. 3).

For example, heat losses are proportionally higher in small tanks due to higher surface-to-volume ratio. Despite thermal insulation, several small size installations showed significant thermal losses which affected experimental results (Hoffmann et al., 2016; Klein et al., 2013; Kuravi et al., 2013; Okello et al., 2014; Shewen et al., 1978). As an example, the experimental system studied by Okello et al., 2014 (about $0.05 \mathrm{~m}^{3}$ ), lost about $25 \%$ of its energy content during a 18-h standby period, while the Solar One's TES (more than 3,000 $\mathrm{m}^{3}$ ) lost only $2.5 \%$ of its energy content in $20 \mathrm{~h}$ (Faas et al., 1986) with similar average temperature.

Besides, absolute and relative dimensions of the tank and the solid particles of the bed influence flow distribution and velocity profiles, thereby affecting heat exchange and thermal stratification in the storage. In small tanks, the relative influence of the walls over velocity profiles is higher than in large tanks due to edge effects. Flow channeling near the walls is also influenced by the tank-to-particle diameter ratio.

Proportion effects may also affect laboratory-scale experiments. While the height occupied by the thermocline, which affects storage behavior and efficiency, is relatively thin in industrial-scale or pilot-scale systems, many laboratory-scale results show thermocline which occupies the whole height of the storage during charge or discharge (Anderson et al., 2014; Bhavsar and Balakrishnan, 1990; Mawire and Taole, 2011; Meier et al., 1991; Shitzer and Levy, 1983; Yang et al., 2014).

In these conditions, experimental results from laboratory-scale systems should be considered with precaution because their behavior and their performances may significantly differ from industrial-scale. 


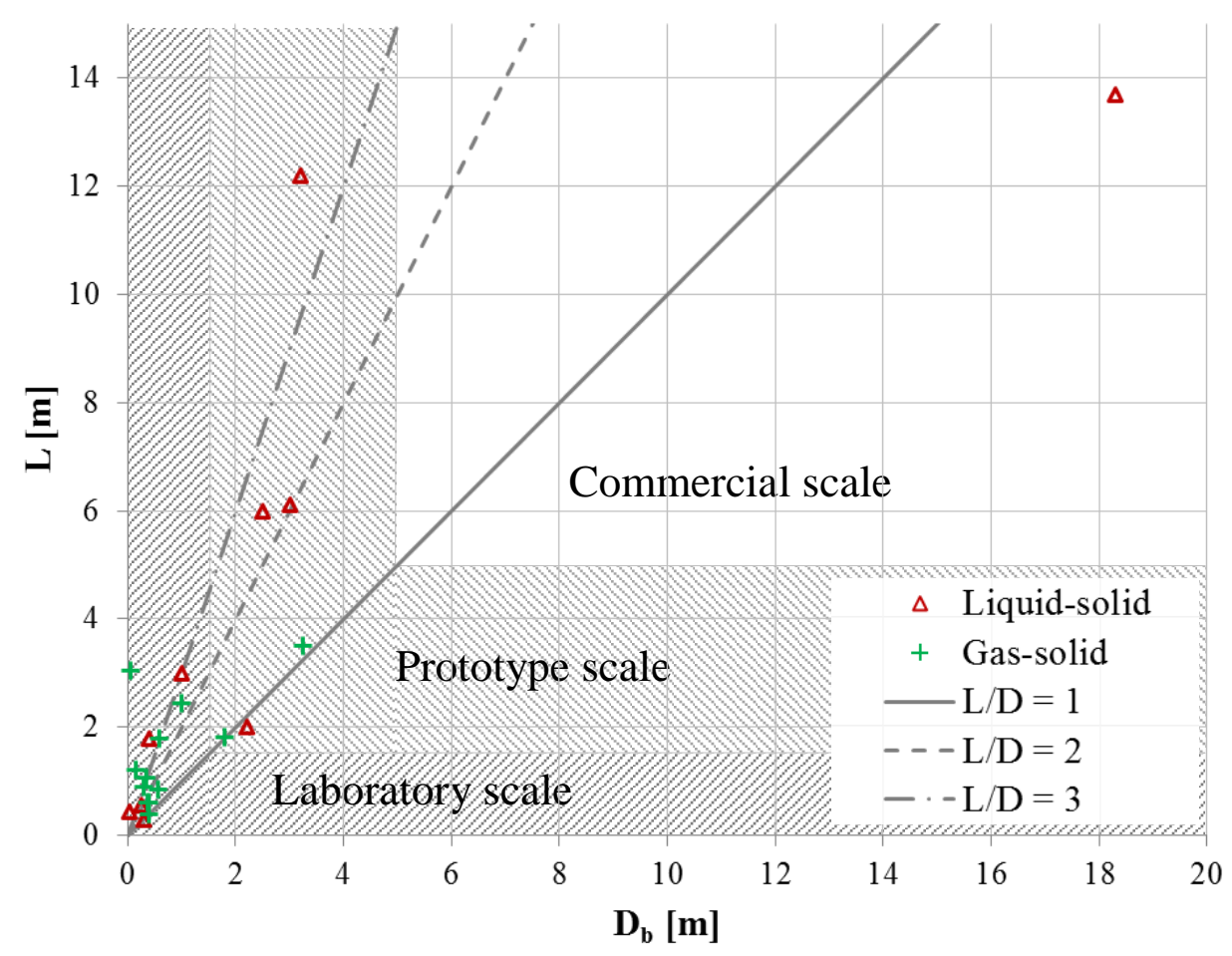

Fig. 3. Dimensions of referenced packed-bed storage systems. 


\begin{tabular}{|c|c|c|c|c|c|c|c|c|c|c|}
\hline Publications & Solid & Fluid & $\mathbf{D}_{\mathbf{b}}(\mathbf{m})$ & $\mathbf{L}(\mathbf{m})$ & $\mathbf{D}_{\mathrm{s}}(\mathbf{m m})$ & $\varepsilon$ & $\mathbf{D}_{\mathrm{b}} / \mathbf{D}_{\mathrm{s}}$ & $\mathbf{T}\left({ }^{\circ} \mathbf{C}\right)$ & $\mathbf{u}$ & $\begin{array}{c}\text { Packed-bed temperature } \\
\text { measurements }\end{array}$ \\
\hline $\begin{array}{l}\text { Hallet and Gervais, } \\
1977\end{array}$ & $\begin{array}{l}\text { River gravels (granite) } \\
\text { and silica sand }\end{array}$ & Caloria HT 43 (oil) & 3.2 & 12.2 & $25 / 1.5$ & 0.25 & 128 & $218-302$ & $0.3-3.3 \mathrm{~mm} / \mathrm{s} *$ & $\begin{array}{c}\text { Fluid } \\
\text { Axial / Radial }\end{array}$ \\
\hline $\begin{array}{l}\text { Faas et al., 1986; } \\
\text { McDonnell Douglas } \\
\text { Astronautics } \\
\text { Company, } 1986\end{array}$ & Rocks and sand & Caloria HT 43 (oil) & 18.3 & 13.7 & $25 /-$ & 0.22 & 732 & $200-290$ & - & $\begin{array}{l}\text { Fluid } \\
\text { Axial }\end{array}$ \\
\hline $\begin{array}{l}\text { Bhavsar and } \\
\text { Balakrishnan, } 1990\end{array}$ & Rocks & HP Hytherm 500 (oil) & 2.2 & 2.0 & 50 & 0.30 & 44 & $230-247$ & $0.4 \mathrm{~mm} / \mathrm{s} *$ & $\begin{array}{c}\text { Fluid / Solid } \\
\text { Axial / Radial } \\
\end{array}$ \\
\hline $\begin{array}{l}\text { Mawire et al., 2009; } \\
\text { Mawire and } \\
\text { McPherson, 2009; } \\
\text { Mawire and Taole, } \\
2011\end{array}$ & Sandy stones & CALFLO $^{\mathrm{TM}} \mathrm{LT}$ (oil) & 0.29 & 0.3 & 5 & 0.42 & 58 & $20-240$ & $0.04-0.12 \mathrm{~mm} / \mathrm{s} *$ & $\begin{array}{l}\text { Fluid } \\
\text { Axial }\end{array}$ \\
\hline Mawire et al., 2010 & Silica glass pebbles & Shell Thermia Oil B (oil) & 0.035 & 0.45 & 3 & 0.42 & 12 & $30-160$ & $10-19 \mathrm{~mm} / \mathrm{s} *$ & $\begin{array}{l}\text { Fluid } \\
\text { Axial }\end{array}$ \\
\hline Yang et al., 2014 & Ceramic spheres & $\begin{array}{l}\mathrm{Hitec}^{\circledR}\left(\mathrm{KNO}_{3}-\mathrm{NaNO}_{2}-\mathrm{NaNO}_{3},\right. \\
53-40-7 \text { wt } \%)\end{array}$ & 0.263 & 0.55 & 30 & - & 8.8 & $280-355$ & $3 \mathrm{~mm} / \mathrm{s} * *$ & $\begin{array}{l}\text { Fluid } \\
\text { Axial }\end{array}$ \\
\hline Rodat et al., 2015 & $\begin{array}{l}\text { Silica gravels and silica } \\
\text { sand }\end{array}$ & Therminol $^{\circledR} 66$ (oil) & 2.5 & 6.0 & $30 / 3$ & 0.27 & 83 & $100-250$ & $0.5-1.7 \mathrm{~mm} / \mathrm{s}$ & $\begin{array}{l}\text { Fluid / Solid } \\
\text { Axial / Radial }\end{array}$ \\
\hline Hoffmann et al., 2016 & Quartzite rocks & Rapeseed oil & 0.4 & 1.8 & 40 & 0.41 & 4.5 & $160-210$ & $0.5 \mathrm{~mm} / \mathrm{s} *$ & $\begin{array}{c}\text { Fluid } \\
\text { Axial / Radial }\end{array}$ \\
\hline
\end{tabular}

Table 1. Main characteristics of some liquid/solid packed-bed storage applications from the literature.

\begin{tabular}{|c|c|c|c|c|c|c|c|c|c|c|}
\hline Publications & Solid & Fluid & $\mathbf{D}_{\mathrm{b}}(\mathbf{m})$ & $\mathbf{L}(\mathbf{m})$ & $\mathbf{D}_{\mathrm{s}}(\mathbf{m m})$ & $\varepsilon$ & $\mathbf{D}_{\mathrm{b}} / \mathbf{D}_{\mathrm{s}}$ & $\mathbf{T}\left({ }^{\circ} \mathbf{C}\right)$ & $\mathbf{u}$ & $\begin{array}{c}\text { Packed-bed temperature } \\
\text { measurements }\end{array}$ \\
\hline $\begin{array}{l}\text { Hollands et al., 1984; } \\
\text { Shewen et al., 1978 }\end{array}$ & River gravels & Air & $1.8 \times 1.8$ & $0.38-1.82$ & 18.1 & 0.42 & 99 & $20-67$ & $16-32 \mathrm{~cm} / \mathrm{s} * *$ & $\begin{array}{l}\text { Fluid / Solid } \\
\text { Axial / Radial }\end{array}$ \\
\hline $\begin{array}{l}\text { Coutier and Farber, } \\
1982\end{array}$ & Rocks & Air & 0.57 & 0.84 & $18-28$ & - & $20-32$ & - & - & $\begin{array}{c}\text { Fluid / Solid } \\
\text { Axial / Radial }\end{array}$ \\
\hline $\begin{array}{l}\text { Shitzer and Levy, } \\
1983\end{array}$ & Crushed quarry rocks & Air & 1.0 & 2.45 & $18-45$ & 0.34 & $22.2-55.6$ & $30-75$ & $21-49 \mathrm{~cm} / \mathrm{s} * *$ & $\begin{array}{l}\text { Fluid / Solid } \\
\text { Axial } \\
\end{array}$ \\
\hline $\begin{array}{l}\text { Beasley and Clark, } \\
1984\end{array}$ & Soda lime glass spheres & Air & 0.375 & 0.62 & 12.6 & 0.364 & 30 & $25-70$ & $44-323 \mathrm{~cm} / \mathrm{s} * *$ & $\begin{array}{c}\text { Fluid / Solid } \\
\text { Axial / Radial } \\
\end{array}$ \\
\hline Zanganeh et al., 2012 & Sedimentary rocks & Air & $2.5-4$ & 2.9 & $20-30$ & 0.342 & $83-200$ & $20-500$ & $3.5 \mathrm{~cm} / \mathrm{s} * *$ & $\begin{array}{l}\text { Fluid } \\
\text { Axial }\end{array}$ \\
\hline Klein et al., 2013 & Ceramic balls & Flue gas / air & 0.40 & 0.62 & 19 & 0.39 & 21 & $25-900$ & $130-250 \mathrm{~cm} / \mathrm{s} * *$ & $\begin{array}{c}\text { Fluid / Solid } \\
\text { Axial / Radial } \\
\end{array}$ \\
\hline Kuravi et al., 2013 & Bricks & Air & $\begin{array}{c}0.508 \times \\
0.203\end{array}$ & 1.07 & $\begin{array}{c}50.8 \times 203 \times \\
178\end{array}$ & 0.20 & - & $20-530$ & $580-670 \mathrm{~cm} / \mathrm{s} * *$ & $\begin{array}{l}\text { Fluid / Solid } \\
\text { Axial / Radial }\end{array}$ \\
\hline Okello et al., 2014 & Crushed rocks & Air & $\begin{array}{l}0.40 \\
0.40\end{array}$ & $\begin{array}{l}0.40 \\
0.90 \\
\end{array}$ & 14.6 & 0.38 & 27 & $20-350$ & $\begin{array}{l}17 \mathrm{~cm} / \mathrm{s} * * \\
31 \mathrm{~cm} / \mathrm{s} * *\end{array}$ & $\begin{array}{l}\text { Fluid } \\
\text { Axial } \\
\end{array}$ \\
\hline
\end{tabular}




\begin{tabular}{|c|c|c|c|c|c|c|c|c|c|c|}
\hline Anderson et al., 2014 & Alumina spheres & Air & 0.572 & 3.05 & 6 & 0.40 & 20 & $25-120$ & $485-975 \mathrm{~cm} / \mathrm{s} *$ & $\begin{array}{l}\text { Fluid } \\
\text { Axial }\end{array}$ \\
\hline Zanganeh et al., 2014 & Rocks & Air & $5-6$ & 4.0 & - & - & - & $250-550$ & - & $\begin{array}{c}\text { Fluid } \\
\text { Axial / Radial }\end{array}$ \\
\hline Cascetta et al., 2015 & Sintered alumina beads & Air & 0.58 & 1.80 & $7-9$ & 0.39 & $64.5-83.0$ & $38-239$ & $115-300 \mathrm{~cm} / \mathrm{s} * *$ & $\begin{array}{c}\text { Fluid } \\
\text { Axial / Radial }\end{array}$ \\
\hline
\end{tabular}

Table 2. Main characteristics of some gas/solid packed-bed storage applications from the literature.

* recalculated value

** estimated value from partial data 


\subsection{Packed-bed storage behavior and operation}

In this part, the typical behavior and performances of packed-bed storage systems is presented based on experimental feedback of the literature.

Packed-bed charging and discharging consist in shifting hot and cold regions in the tank by circulating HTF through the solid storage medium. For exergy and process efficiency purposes, the storage should be kept well stratified, i.e. with hot and cold regions well separated by a thin thermocline with steep thermal gradient (Haller et al., 2009; Qin et al., 2012). The better the stratification, the larger the amounts of hot and cold fluid (Fig. 4), and hence the higher the storage exergy capacity and the longer the operation of heat production process and thermal process at nominal temperatures. In CSP plants, the heat production process and the thermal process are respectively solar receiver and power block.

Plug flow is the ideal way of circulating HTF in order to prevent mixing and to keep a well stratified storage (Hollands et al., 1984). That's why a uniform distribution which prevents jet effects is essential to preserve stratification and to improve storage efficiency. Reducing flow heterogeneities and natural convection, which cause mixing during fluid circulation, is also one of the roles of the solid filler material (Gil et al., 2009; Yang et al., 2014). Furthermore, to some extent, reducing fluid velocity lowers the spreading of the thermocline (Cascetta et al., 2015; Yang and Garimella, 2010b) by reducing fluid mixing, Biot number of the solids (i.e. the influence of the thermal gradient inside solids and hence thermal inertia of the solids) and by coming close to ideal process with thermal equilibrium between fluid and solids. However, given that reducing fluid velocity raises the residence time, this statement remains true as long as time dependent phenomena which lead to destratification of the storage, like heat losses or heat conduction through the bed, remain second order phenomena (Yang and Garimella, 2010a, Votyakov and Bonanos, 2015).

Given that hot and cold fluids coexist in the storage, buoyancy effects may occur. In order to preserve thermal stratification, especially during standby periods, this phenomenon is exploited through the layout of the storage: hot fluid is injected and extracted by/from the top and cold fluid by/from the bottom of the storage (Close, 1965; Zanganeh et al., 2012).

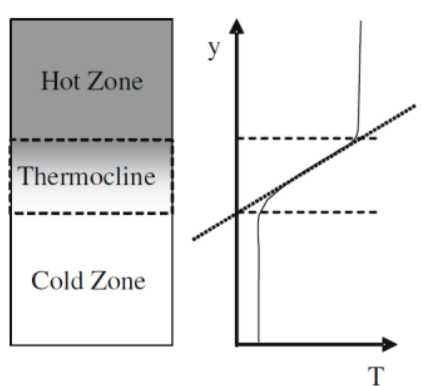

(a)

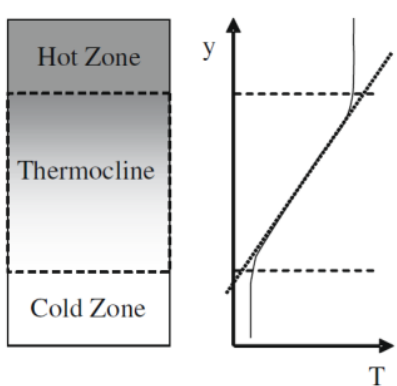

(b)

Fig. 4. Differing degrees of stratification within a storage tank with the same amount of stored heat (a) left, highly stratified, (b) right, moderately stratified (Haller et al., 2009).

During charging or discharging process, the thermocline moves respectively downwards or upwards inside the storage and slightly spreads due to non-infinite heat transfer between solid and HTF, thermal diffusion and fluid mixing. Upstream from the thermocline, a new zone at relatively uniform temperature is generated. This typical behavior has been experimentally observed or theoretically predicted by numerous authors (Anderson et al., 2014; Beasley and Clark, 1984; Bhavsar and Balakrishnan, 1990; Bruch et al., 2014a; Cascetta et al., 2015; Coutier and Farber, 1982; Hallet and Gervais, 1977; Klein et al., 2013; Kuravi et al., 2013; McDonnell Douglas Astronautics Company, 1986; Meier et al., 1991; Okello et al., 2014; Pacheco et al., 2002; Shewen et al., 1978; Shitzer and Levy, 1983; Van Lew et al., 2011; Yang et al., 2014; Zanganeh et al., 2012). Some representative results from installations with different sizes, filler materials and temperature levels are depicted through Fig. 5 to Fig. 7.

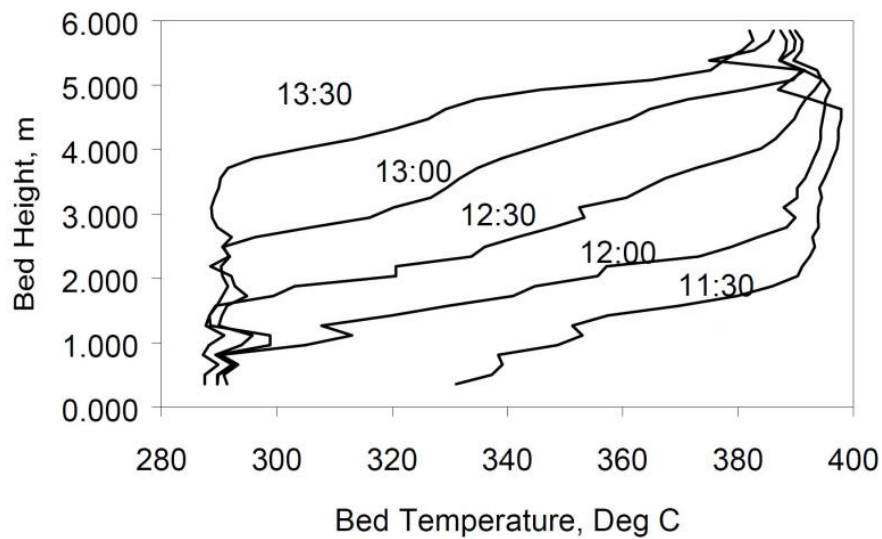

Fig. 5. Measured temperature profiles during discharge of a $4.3-\mathrm{m}^{3}$ packed bed of rocks and sand with molten salts as HTF (Pacheco et al., 2002). 


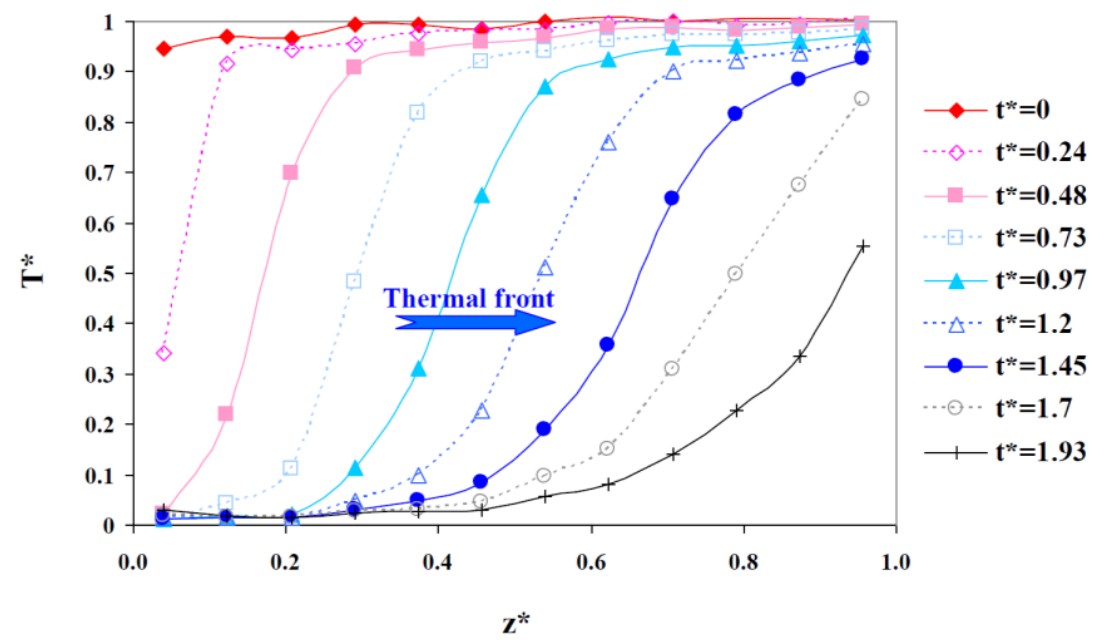

Fig. 6. Dimensionless fluid temperatures during discharge of a $2.4-\mathrm{m}^{3}$ packed bed of rocks and sand with thermal oil as $\mathrm{HTF}$ (Bruch et al., 2014b).

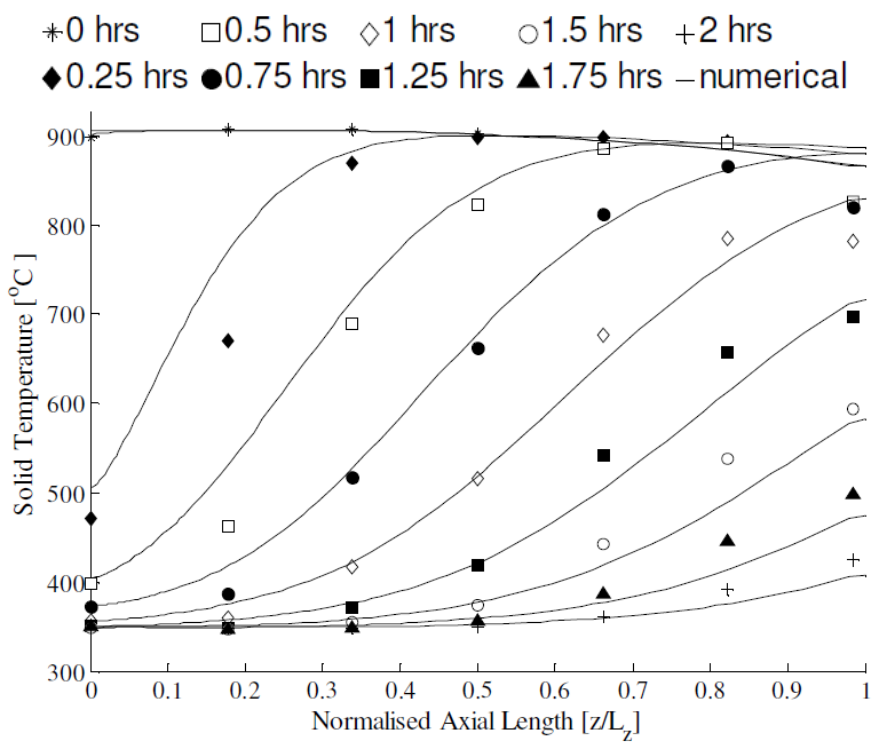

Fig. 7. Measured and simulated centerline solid temperatures during discharge of a $0.08-\mathrm{m}^{3}$ packed bed of ceramic balls with air as HTF (Klein et al., 2013).

As explained by Pacheco et al., 2002, the outlet temperature of packed-bed storage is constant as long as the thermocline remains in the tank. This was experimentally illustrated in charge by Pacheco et al., 2002 (Fig. 8), and in discharge by Bruch et al., 2014b (Fig. 9). Fig. 8 shows the inlet and outlet fluid temperatures of the packed-bed storage during a charging process. While the inlet temperature remains approximately constant (except during a transient stage at the very beginning), the outlet temperature is first constant then gradually increases as the thermocline approaches the exit of the storage at the end of the charging process. The same behavior is illustrated in Fig. 9 which shows inlet and outlet dimensionless temperatures and recovered energy during the discharging process at constant flow rate presented in Fig. 6 . As soon as the thermal gradient reaches the top of the storage $\left(t^{*} \cong 1.45\right.$ ), the outlet temperature and the slope of the energy curve (which is proportional to discharge power due to constant flow rate) decrease. Given that dimensionless energy $Q^{*}$ corresponds to the ratio between recovered energy and the theoretical storage capacity, it can be seen that more than $80 \%$ of energy content has been recovered at the end of the discharging process with a cut-off dimensionless temperature arbitrary fixed at 0.9 . Values of the same order of magnitude had ever been obtained theoretically (EPRI, 2010; Hallet and Gervais, 1977; Van Lew et al., 2011; Xu et al., 2012a; Yang and Garimella, 2010b; Zavattoni et al., 2014) and experimentally (Faas et al., 1986). 


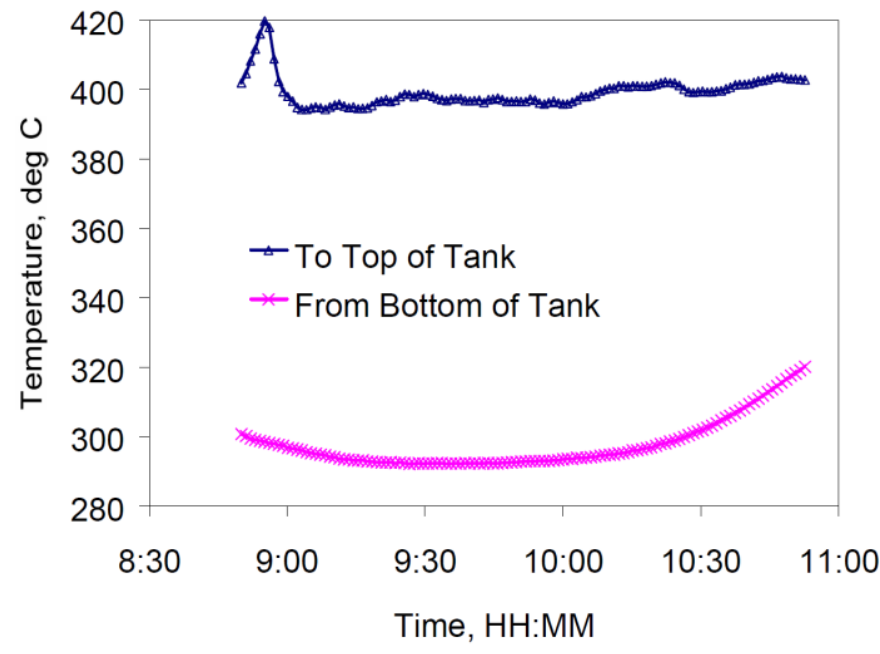

Fig. 8. Measured temperatures of salt pumped from the bottom and returned to the top of the thermocline tank during a charging cycle (Pacheco et al., 2002).

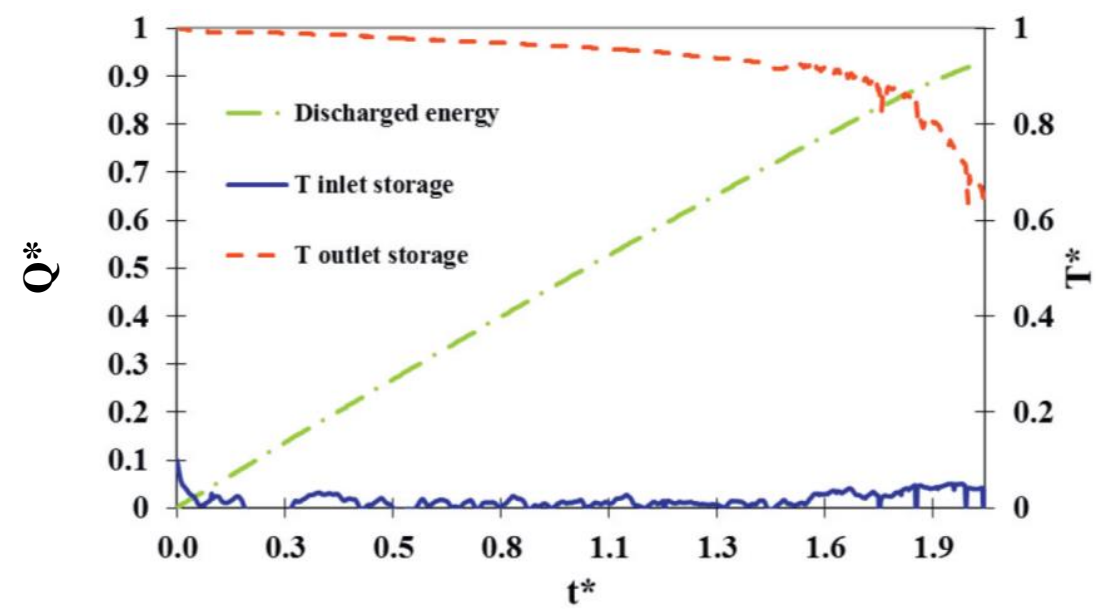

Fig. 9. Dimensionless inlet and outlet tank temperatures and dimensionless extracted energy during the discharging process (Bruch et al., 2014b).

During typical operation, the thermocline has to "stay" inside the storage to keep outlet temperature as constant as possible. Otherwise, heat production and thermal processes would be respectively fed with increasing or decreasing fluid temperature (with related efficiency drop).

On the other hand, if thermocline were not extracted at all from the storage, the tank volume corresponding to the whole thermocline thickness wouldn't be exploited, which would lead to a significant reduction of the actual capacity of the storage. Furthermore, under cyclic operational conditions, non-extraction of at least a part of the thermocline leads to unlimited increase in thermocline thickness due to diffusion and mixing. In this case, the thermocline would end up occupying the whole height of the tank after several charge/discharge cycles and the storage would lose its storage capacity (Bayón et al., 2013).

As a result, a trade-off should be found between maximization of heat production and thermal process efficiencies on the one hand, and optimization of the storage capacity over long-term operation on the other hand.

Long term behavior of packed-bed storage has been poorly investigated so far. This was mainly numerically studied by some authors. As mentioned above, Bayón et al., 2013, have shown that the thermocline region should be partly extracted from the tank at the end of charges and discharges so that the storage doesn't lose its storage capacity over cycles by unlimited expansion of the thermocline. Zanganeh et al., 2012, and Zavattoni et al., 2015, performed respectively first-law and secondlaw numerical analyses of a high-temperature air/rock bed under cyclic operation. After a transition phase depending on initial thermal conditions of the storage, they show a stabilized state with constant performances over cycles. Mertens et al., 2014, numerically showed that steady-state packed-bed storages can withstand variation of charging and discharging processes by drawing upon the heat stored during initial preheating cycles. Therefore, operation of packed-bed storages under cyclic operation is to some extent flexible.

Experimental study with numerous successive charge/discharge cycles has been carried out by Bruch et al., 2014a, on a packed bed of rocks and sand with thermal oil as HTF. As foreseen by Zanganeh et al., 2012, they show a repeatable and robust stabilized periodic state under cyclic operation when constant inlet fluid temperature and thermocline extraction strategy are imposed. The stabilized state, which defines the long-term performances of the storage, is controllable through operational conditions, i.e. the way the thermocline is extracted at the end of cycles, which is represented by $\Delta T_{1} *$ and $\Delta T_{2} *$ in Fig. 10 and Fig. 11. The more the thermocline is extracted at the end of cycles, the greater the effective storage capacity (represented by the greyed area) and the faster the stabilization in terms of both time and number of cycles. This behavior was also observed by Cascetta et al., 2015, on an air/alumina packed-bed storage system and confirms the prediction of Bayón et al., 2013, as the 
stabilized thermal gradient is steeper when the thermocline region is more extracted at the end of cycles. However, as mentioned above, larger extraction of the thermocline leads to colder and hotter outlet fluid temperature at the end of discharging and charging processes, respectively.

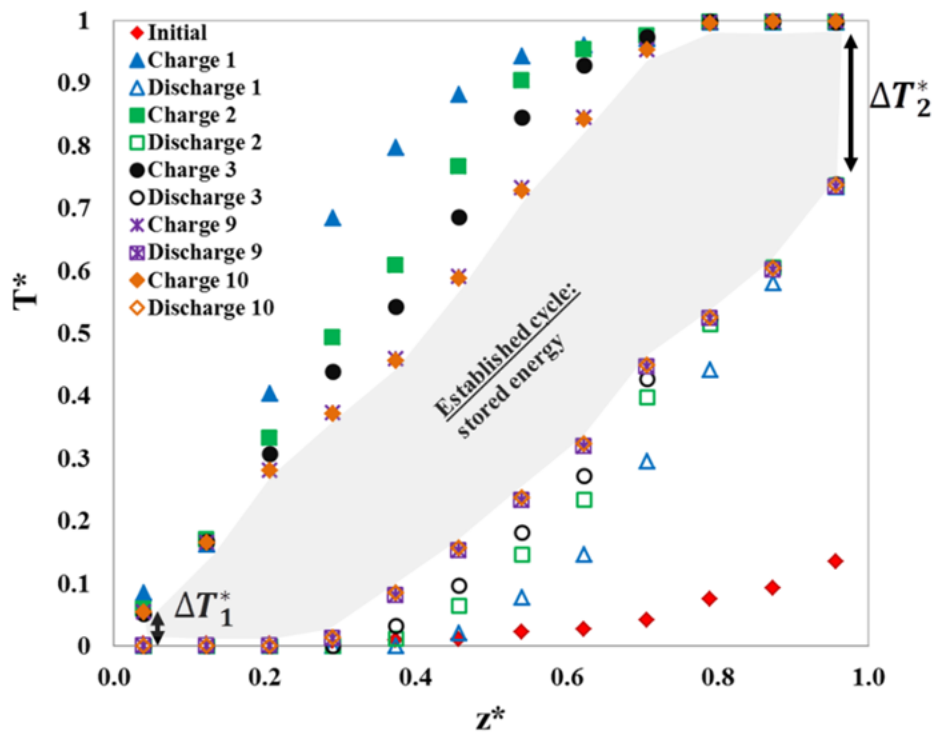

Fig. 10. End-cycle dimensionless temperature profiles in the "intermediate cycle" configuration, i.e. with little extraction of the thermocline region at the end of each charge and discharge (Bruch et al., 2014a).

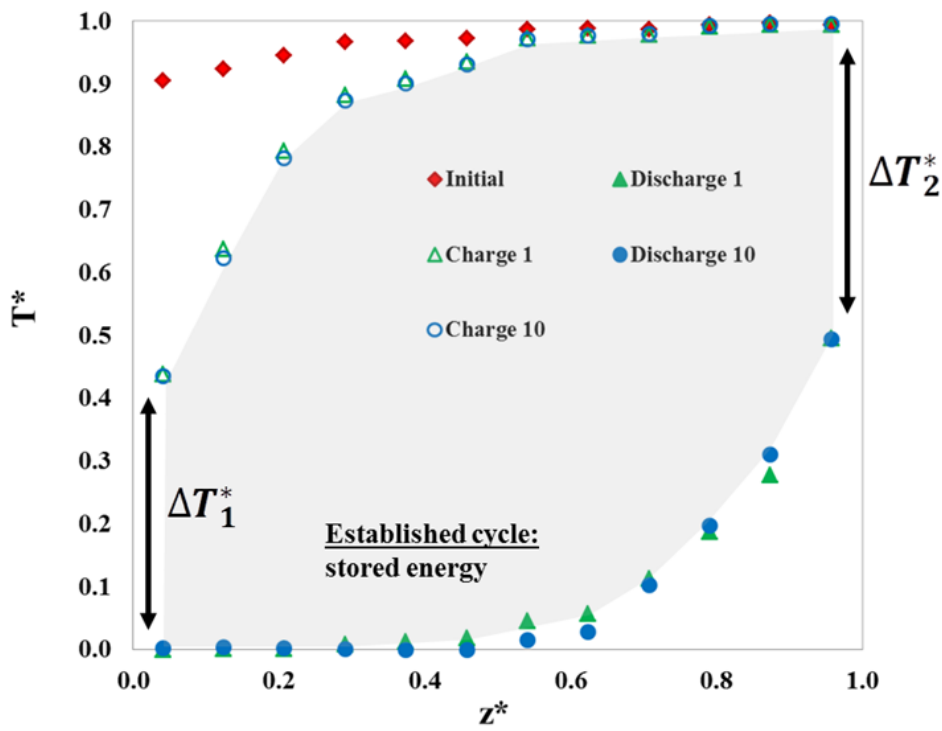

Fig. 11. End-cycle dimensionless temperature profiles in the "long cycle" configuration, i.e. with large extraction of the thermocline region at the end of each charge and discharge (Bruch et al., 2014a).

Furthermore, Bruch et al., 2014b, have shown with a liquid/solid system that the stabilized state depends mostly on the thermocline extraction strategy and is little influenced by fluid flow rate and temperature level. On the range considered by the authors, the flow rate which has been increased up to a factor 2.5 has only a slight influence on the stabilized temperature profiles. According to the authors, this little influence is due to variation of residence time and hence heat losses. Similarly, excepted through the slight influence of heat losses, the temperature level does not influence the stabilized state as long as physical properties of the fluid remain of the same order of magnitude. In addition, the stabilized state is also unaffected by punctual perturbations, like partial load, introduced during or after stabilization: as soon as operational conditions are restored, the storage continues its stabilization or returns to the former stabilized state.

To conclude, operation strategy of packed-bed storage is a key aspect which determines above all its performances and its integration into the desired process. As a consequence, the operator has to define a custom-made operation strategy for thermocline extraction depending on process requirements (Biencinto et al., 2014).

\subsection{Tank design}

To tackle heat losses almost all packed-bed storage applications are insulated. In the case of molten salts, heat-trace cables may be used to make up for thermal losses and prevent salt freezing during standby periods (Pacheco et al., 2002). Standby tests carried out by several authors (Faas et al., 1986; Kuravi et al., 2013; McDonnell Douglas Astronautics Company, 1986; 
Okello et al., 2014; Pacheco et al., 2002; Shewen et al., 1978) show that heat losses occur mainly at the top of the storage because of the higher temperature difference with ambient. Given that this part of the storage contains the most useful part of the stored heat, it should be insulated with particular attention.

Packed beds generally have a height and a diameter of the same order of magnitude (Fig. 3), which increases compactness (i.e. volume-to-surface ratio) of the storage and hence reduces thermal losses (Brosseau et al., 2005; Zanganeh et al., 2012). Depending on fluid flow, the aspect ratio also affects thermal losses through the residence time of fluid which depends on the cross section and the height of the tank.

Most packed-bed storages are cylindrical. This shape is relatively free from mechanical problems (Melanson and Dixon, 1985), minimizes lateral surface area for a given cross section surface and may improve flow uniformity by avoiding corner effects. Some authors have used rectangular cross section to implement structured packed bed (Kuravi et al., 2013) or to use low-cost materials as walls like wooden boards (Hollands et al., 1984; Shewen et al., 1978). A truncated conical tank was studied by Zanganeh et al., 2012. This shape aimed to reduce thermomechanical stresses on the walls and heat losses by increasing the volume-to-surface ratio of the upper (i.e. the hottest) part of the tank.

The aspect ratio of the packed-bed influences stratification and hence efficiency of the storage (Haller et al., 2009) which may be defined as the amount of energy recovered above a certain temperature divided by the amount of energy initially loaded. The thermocline occupies a certain height in the storage tank, thereby reducing its useful capacity. Since thermocline thickness increases more slowly than the tank height (at fixed solid filler size), a large height-to-diameter ratio improves stratification and efficiency (Cascetta et al., 2015; Pacheco et al., 2002; Yang and Garimella, 2010b). A uniformly packed bed with large height-to-diameter ratio also reduces flow heterogeneities since it acts as a flow straightener which evened out nonuniformities introduced upstream (Szekely and Poveromo, 1975).

However, a larger height-to-diameter ratio causes higher pressure losses which may affect the whole process efficiency (Mertens et al., 2014). Furthermore, at industrial scale, the maximum height of packed-bed tanks is practically limited to $16 \mathrm{~m}$ for mechanical reasons (EPRI, 2010; Pacheco et al., 2002). Thermal ratcheting has also to be considered in the dimensioning of the tank. Thermal ratcheting consists in plastic deformation of the tank as a result of cyclic differential thermal expansion of the walls and the solid filler with reorganization of the solids, mainly in non-structured packed beds (Flueckiger et al., 2013; Van Lew et al., 2011). In the long term, this phenomenon can lead to the collapse of the tank (Dogangun et al., 2009). So far, thermal ratcheting of packed-bed storages has not been extensively investigated. However, numerical studies show that a low height-to-diameter ratio is likely to reduce wall stresses caused by thermal ratcheting (Charlas et al., 2010). By the way, the TES of Solar One, which is so far the only very large packed-bed storage which has been built, had a height-to-diameter ratio less than one.

To sum up, the design of packed-bed storage tanks is a trade-off between mechanical, flow distribution, pressure drop, thermal loss and stratification issues. Generally speaking, a cylindrical tank with a height-to-diameter ratio larger than one is often preferable but each system should be specially adapted for the whole process depending on technical requirements and economic constraints.

\subsection{Heat transfer fluid}

In most cases, liquid HTF consists either of thermal oil or molten nitrate salts, while gaseous HTF consists of air (sometimes of flue gas for high temperature tests). Physical properties at average operating temperature of some typical HTF are presented in Table 3. In particular, the volumetric heat capacity $\left(\rho \cdot c_{p}\right)$ enables to assess the heat storage density of materials, while the thermal effusivity $E$ enables to assess their ability to exchange heat.

Liquid HTF have good heat capacity and thermal conductivity, which enables liquid/solid systems to operate at low HTF velocity while keeping a good HTC. Moreover, liquids have high viscosity compared to gasses, which leads to low Reynolds number. As flow dispersion is low at small Reynolds numbers (Yang and Garimella, 2010b), stratification is generally better in liquid/solid systems, thereby improving efficiency of the storage. Besides, due to poor thermal properties of gasses, gas/solid systems require to operate at high flow rate, which increases pressure losses and energy consumption (Kuravi et al., 2013). This should be seriously addressed when using gaseous HTF as it may significantly affect the components' design and the global efficiency of the system.

On the other hand, air is free, non-toxic and non-flammable, which may significantly reduce installation costs and safety concerns. Moreover, air is chemically stable and can operate at very high temperature, thus increasing energy density of the storage and efficiency of the electric conversion. The chemical compatibility between the fluid and the solids is usually less problematic with air than with oils or molten salts.

\begin{tabular}{|c|c|c|c|c|c|c|c|}
\hline Fluid & $\mathbf{T}_{\min } / \mathbf{T}_{\max }\left({ }^{\circ} \mathbf{C}\right)$ & $\rho\left(\mathrm{kg} \cdot \mathrm{m}^{-3}\right)$ & $c_{p}\left(J \cdot \mathrm{kg}^{-1} \cdot \mathbf{K}^{-1}\right)$ & $\lambda\left(\mathbf{W} \cdot \mathbf{m}^{-1} \cdot \mathbf{K}^{-1}\right)$ & $\mu(\mathbf{P a} \cdot \mathbf{s})$ & $\rho \cdot c_{p}\left(k W h \cdot m^{-3} \cdot K^{-1}\right)$ & $E\left(J \cdot K^{-1} \cdot m^{-2} \cdot s^{-1 / 2}\right)$ \\
\hline Caloria HT 43 & $0 / 315$ & 695 & 2700 & 0.16 & $6.8 \cdot 10^{-4}$ & 0.52 & 547 \\
\hline Therminol 66 & $0 / 345$ & 845 & 2380 & 0.10 & $5.7 \cdot 10^{-4}$ & 0.56 & 451 \\
\hline Jarytherm DBT & $0 / 350$ & 870 & 2350 & 0.11 & $4.7 \cdot 10^{-4}$ & 0.57 & 469 \\
\hline Solar salt & $220 / 600$ & 1835 & 1510 & 0.52 & $1.8 \cdot 10^{-3}$ & 0.77 & 1200 \\
\hline Hitec & $142 / 535$ & 1790 & 1560 & 0.33 & $1.8 \cdot 10^{-3}$ & 0.78 & 960 \\
\hline Hitec XL & $120 / 500$ & 1990 & 1445 & 0.52 & $6.3 \cdot 10^{-3}$ & 0.80 & 1224 \\
\hline
\end{tabular}

Table 3. Physical properties of some usual HTF at average operating temperature. 


\subsection{Solid filler material}

Physical properties of some representative sensible heat storage solids are presented in Table 4. These values are estimated since they depend on the quality and the origin of materials.

Packed bed can be made of either structured or non-structured solid filler. Non-structured filler enables to use low cost solids like pebbles. If a single size of spheroidal solids is used, void fraction of the bed is typically around 0.3-0.4 (Nellis and Klein, 2009). A void fraction around 0.25 can be achieved by using two sizes of particle, e.g. by mixing rocks and sand (Bruch et al., 2014a; Faas et al., 1986; Hallet and Gervais, 1977; Pacheco et al., 2002), thereby reducing the quantity of expensive fluid and increasing heat capacity of the storage (Ismail and Stuginsky, 1999; Van Lew et al., 2011) provided that solid material has greater volumetric heat capacity than HTF. However this method increases interstitial velocity of the fluid and pressure loss which may be restrictive when using gaseous HTF. Manufactured materials like ceramic, glass or alumina, usually of spherical shape, may be used in order to run at very high temperature or to prevent fluid/solid chemical interactions. Small solid size is preferable to improve stratification since it increases total fluid/solid heat exchange area and reduces the Biot number of solids (Anderson et al., 2014; Van Lew et al., 2011; Yang and Garimella, 2010b). For stratification purpose, Biot number of the particles has to be as low as possible so that heat transfer is only governed by convection (Adeyanju and Manohar, 2009), resulting in a sharper thermal front and better stratification. As long as fluidization is avoided, reducing particle size also improves flow uniformity by increasing pressure loss (Hollands et al., 1984) and by preventing flow channeling near the walls. In cylindrical beds, this latter phenomenon can be avoided by respecting a minimum tank-to-particle diameter ratio of 30-40 (Meier et al., 1991; Rose and Rizk, 1949). In the case of rectangular cross section, the ratio between the smaller side of the tank and the solid diameter has to be greater than 50 to avoid wall channeling (Hollands et al., 1984).

Structured filler material, like bricks or plates, may be used to shape the bed. Although this is more expensive, this enables to optimize the geometry of the bed in terms of heat exchange, conduction resistance of the solid and pressure losses. Low void fraction can be reached (e.g. 0.2 for Kuravi et al., 2013) while keeping acceptable pressure loss. Furthermore, structured filler material enables to prevent reorganization of solids over thermal cycles, which is very likely to solve the great mechanical concern of thermal ratcheting. For all these reasons, structured filler is particularly suitable with gaseous HTF operated at high temperature.

\begin{tabular}{|c|c|c|c|c|c|}
\hline Solid & $\rho\left(\mathrm{kg} \cdot \mathrm{m}^{-3}\right)$ & $c_{p}\left(J \cdot \mathbf{k g}^{-1} \cdot K^{-1}\right)$ & $\lambda\left(\mathbf{W} \cdot \mathbf{m}^{-1} \cdot \mathbf{K}^{-1}\right)$ & $\rho \cdot c_{p}\left(k W h \cdot m^{-3} \cdot K^{-1}\right)$ & $E\left(J \cdot K^{-1} \cdot m^{-2} \cdot s^{-1 / 2}\right)$ \\
\hline Rocks & 2600 & 900 & 2.0 & 0.65 & 2163 \\
\hline Concrete & 2200 & 850 & 1.5 & 0.52 & 1675 \\
\hline Bricks & 3200 & 800 & 1.6 & 0.71 & 2024 \\
\hline Ceramic & 3550 & 900 & 1.3 & 0.89 & 2038 \\
\hline Alumina & 4000 & 900 & 11 & 1.0 & 6293 \\
\hline
\end{tabular}

Table 4. Order of magnitude of physical properties of some sensible heat storage solids.

\section{Numerical models for packed-bed storage}

Numerous numerical models for packed-bed storage have been presented in the literature as summarized by Ismail and Stuginsky, 1999. All of them are derived from energy equations applied to the components of the storage system and assume no mass exchange and no heat production inside the storage. The heat exchange between the fluid and the solid is assumed proportional to the average difference in temperature (Newton's law). The physical properties of the materials may be considered constant and uniform or not depending on the authors. The additional assumptions and deriving simplifications (presented in Table 5) lead to various kinds of numerical model. First, the models may be grouped into two main categories depending on whether significant thermal gradient inside the solids is considered or not. Then, differentiation can be made according to the number of dimensions (1D or 2D) and to the number of phases (fluid, solid, walls) accounted for.

\subsection{Models with negligible thermal gradient inside solids}

This approach is used when the conduction resistance in the solids of the packed bed is negligible compared to the convection resistance (Saez and McCoy, 1982). This assumption is assessed thanks to the dimensionless Biot number (Bergman et al., 2011):

$$
\mathrm{Bi}=\frac{\mathrm{h} \cdot \mathrm{V}_{\mathrm{s}} / \mathrm{A}_{\mathrm{s}}}{\lambda_{\mathrm{s}}} \leq 0,1
$$

\subsubsection{The Schumann model}

The Schumann's model is a reference for many authors. This one-dimensional two-phase model of heat transfer in porous media was originally developed by Schumann, 1929. It consists in two energy equations, one for the fluid (2) and the other for the solid (3), linked by a convective heat exchange term. 


$$
\begin{gathered}
\varepsilon \cdot \rho_{\mathrm{f}} \cdot \mathrm{c}_{\mathrm{p}_{\mathrm{f}}} \cdot\left(\frac{\partial \mathrm{T}_{\mathrm{f}}}{\partial \mathrm{t}}+\mathrm{u} \cdot \frac{\partial \mathrm{T}_{\mathrm{f}}}{\partial \mathrm{z}}\right)=\mathrm{h} \cdot \mathrm{a}_{\mathrm{s}} \cdot\left(\mathrm{T}_{\mathrm{s}}-\mathrm{T}_{\mathrm{f}}\right) \\
(1-\varepsilon) \cdot \rho_{\mathrm{s}} \cdot \mathrm{c}_{\mathrm{p}_{\mathrm{s}}} \cdot \frac{\partial \mathrm{T}_{\mathrm{s}}}{\partial \mathrm{t}}=\mathrm{h} \cdot \mathrm{a}_{\mathrm{s}} \cdot\left(\mathrm{T}_{\mathrm{f}}-\mathrm{T}_{\mathrm{s}}\right)
\end{gathered}
$$

In previous equations, $a_{s}$ is the surface area of solid per unit bed volume, expressed in $\mathrm{m}^{2} \cdot \mathrm{m}^{-3}$. This shape factor can be determined as follows:

$$
\mathrm{a}_{\mathrm{s}}=\frac{\mathrm{A}_{\mathrm{s}, \text { tot }}}{\mathrm{V}_{\mathrm{b}}}=\frac{6 \cdot(1-\varepsilon)}{\mathrm{D}_{\mathrm{eq}, \mathrm{a}}}
$$

The Schumann model is valid under some conditions presented in Table 5. An analytical solution of this model was proposed by Schumann and presented in the form of graphs (Fig. 12 and Fig. 13). This analytical solution is valid when the volumetric heat capacity of the fluid is negligible compared to the one of the solids (i.e. for gas/solid systems), the solids are initially at a zero uniform temperature and the material properties, the inlet fluid temperature and the fluid flow rate are assumed constant.

Shitzer and Levy, 1983, simplified the writing of this analytical solution and extended its validity to cases in which inlet fluid temperature is time dependent.

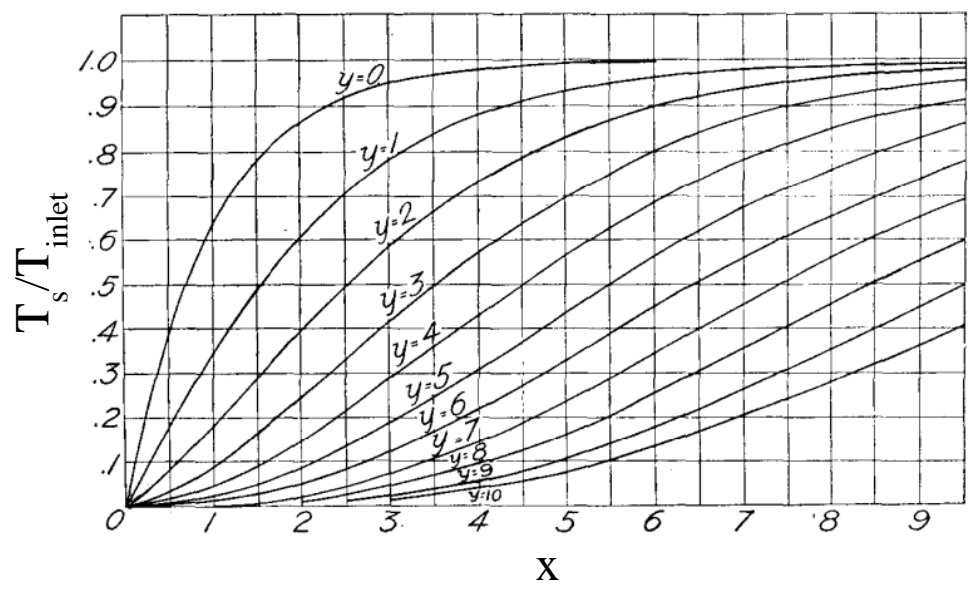

Fig. 12. Analytical solution of the Schumann model for the solid temperature depending on the dimensionless time $x$ and the dimensionless length $y$ (Schumann, 1929).

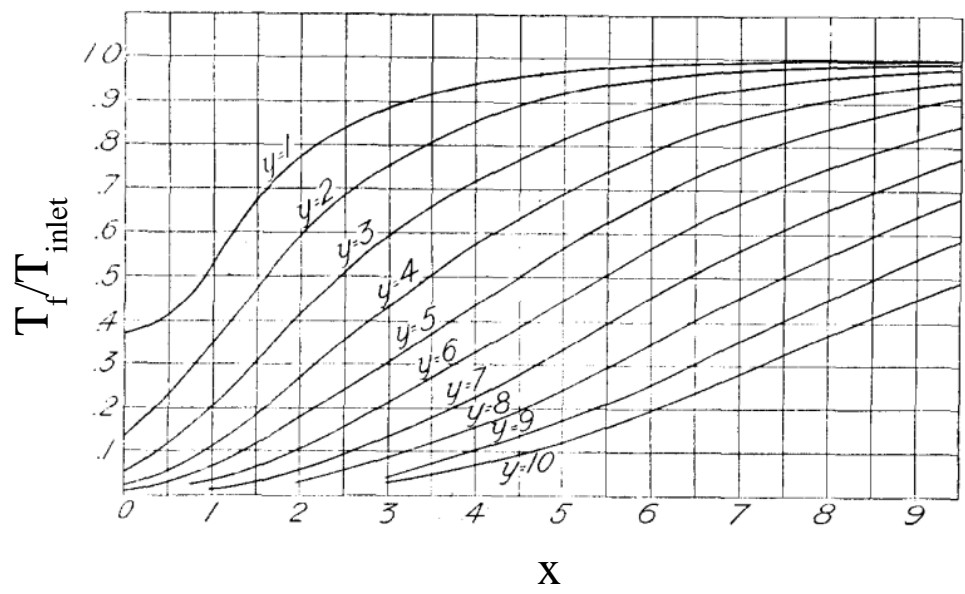

Fig. 13. Analytical solution of the Schumann model for the fluid temperature depending on the dimensionless time $x$ and the dimensionless length $y$ (Schumann, 1929).

Enhancement of the Schumann model can be performed by taking into account additional phenomena. 
Thermal losses to the outside may be a significant phenomenon and should be taken into account mainly in poorly insulated systems, for storage tanks with large surface-to-volume ratio, for process operation at high temperature or to simulate losses in energy content during standby operation. Based on comparisons between numerical and experimental results for laboratory-, prototype- and commercial-scale packed beds, Hoffmann et al., 2016, showed that heat losses have to be accounted for to simulate efficiently laboratory-scale systems, while it is not always necessary for prototype- and commercialscale systems. Given that contact area between the solids and the walls of the storage is usually small compared to the one between the fluid and the walls, this term is often neglected in the equation of solid. However, with gaseous HTF, heat transfer between the solids and the walls may become non-negligible due to radiation (Klein et al., 2013), particularly at high temperature, i.e. more than 200-300 ${ }^{\circ} \mathrm{C}$ (Balakrishnan and Pei, 1979b; Krupiczka, 1967; Kunii and Smith, 1960; Schröder et al., 2006). With liquid HTF, radiation can be neglected due to the opacity of the fluid (Kunii and Smith, 1960).

Thermal losses can be expressed through an overall heat transfer coefficient $(U)$ which accounts for internal and external thermal resistances, and conduction resistance of the walls. In order to be expressed in a volumetric form, this coefficient has to be coupled with the shape factor of the packed bed $\left(a_{b}\right)$ which corresponds to the heat exchange area between the bed and the outside divided by the bed volume (Ismail and Stuginsky, 1999).

A diffusion term including effective thermal conductivity which enables to apply the Fourier's law in the packed bed (Weidenfeld et al., 2004) may also be added to account for thermal destratification. It should be noticed that the convection term in the original Schumann model already leads to spreading of the thermocline during circulation of the fluid due to noninfinite HTC (Hollands et al., 1984). Diffusion is usually a second order phenomenon during circulation of the fluid but becomes essential to simulate degradation of the thermocline during standby periods (Gunn and Vortmeyer, 1982; Handley and Heggs, 1969). Diffusion and effective thermal conductivity will be further discussed in 4.3 .

The heat capacity of tank's walls may also have a significant influence, especially for laboratory-scale or pilot-scale systems (Bruch et al., 2014a; Hoffmann et al., 2016). The walls' contribution can be accounted for through a modified solid density $\left(\rho_{s}{ }^{\prime}\right)$ which includes the walls' heat capacity (Bruch et al., 2014a). This modified density may be expressed by (5).

$$
\rho_{\mathrm{s}}^{\prime}=\rho_{\mathrm{s}}+\frac{\mathrm{m}_{\mathrm{w}} \cdot \mathrm{c}_{\mathrm{p}_{\mathrm{w}}}}{(1-\varepsilon) \cdot \mathrm{c}_{\mathrm{p}_{\mathrm{s}}} \cdot \mathrm{V}_{\mathrm{b}}}
$$

If heat losses (only through fluid phase), solid and fluid effective conductivities, and walls' heat capacity are added to the Schumann model, a more general two-phase one-dimensional model can be obtained and expressed by (6) and (7) with the modified or added terms in bold characters.

$$
\begin{aligned}
& \varepsilon \cdot \rho_{\mathrm{f}} \cdot \mathrm{c}_{\mathrm{p}_{\mathrm{f}}} \cdot\left(\frac{\partial \mathrm{T}_{\mathrm{f}}}{\partial \mathrm{t}}+\mathrm{u} \cdot \frac{\partial \mathrm{T}_{\mathrm{f}}}{\partial \mathrm{z}}\right)=\frac{\mathbf{\partial}}{\partial \mathbf{z}} \cdot\left(\boldsymbol{\lambda}_{\mathbf{e f f}, \mathbf{f}} \cdot \frac{\partial \mathrm{T}_{\mathbf{f}}}{\partial \mathrm{z}}\right)+\mathrm{h} \cdot \mathrm{a}_{\mathrm{s}} \cdot\left(\mathrm{T}_{\mathrm{s}}-\mathrm{T}_{\mathrm{f}}\right)+\mathbf{U} \cdot \mathbf{a}_{\mathbf{b}} \cdot\left(\mathbf{T}_{\infty}-\mathbf{T}_{\mathbf{f}}\right) \\
& (1-\varepsilon) \cdot \boldsymbol{\rho}_{\mathrm{s}}^{\prime} \cdot \mathrm{c}_{\mathrm{p}_{\mathrm{s}}} \cdot \frac{\partial \mathrm{T}_{\mathrm{s}}}{\partial \mathrm{t}}=\frac{\partial}{\partial \mathrm{z}} \cdot\left(\boldsymbol{\lambda}_{\mathrm{eff}, \mathrm{s}} \cdot \frac{\partial \mathrm{T}_{\mathbf{s}}}{\partial \mathrm{z}}\right)+\mathrm{h} \cdot \mathrm{a}_{\mathrm{s}} \cdot\left(\mathrm{T}_{\mathrm{f}}-\mathrm{T}_{\mathrm{s}}\right)
\end{aligned}
$$

\subsubsection{One-dimensional single-phase models: simplification of the Schumann model}

Single-phase models, directly derived from the Schumann model, were mainly introduced by the work of Vortmeyer and Schaefer, 1974, and consist in modeling the packed bed with a single equation. The calculated temperatures are those of the solid phase provided that required assumptions are perfectly respected (Vortmeyer, 1989).

Two kinds of single-phase models involving different assumptions and simplifications depending on whether the fluid is liquid or gaseous may be considered. With gaseous HTF, it is reasonable to assume that the internal energy of the fluid is negligible compared to the one of the solids $\left(\rho_{f} c_{p f} \ll \rho_{s} \cdot c_{p s}\right)$. Therefore, a Schumann-type model similar to (2) and (3) with additional diffusion terms (with uniform effective thermal conductivities) but without the internal energy term of the fluid may be considered. As demonstrated by Vortmeyer and Schaefer, 1974, based on this model a single-phase one-dimensional model (8) may be obtained by only assuming that the second derivatives in space of the fluid and the solid temperatures are equal $\left(\partial^{2} T_{s} / \partial^{2} z=\partial^{2} T_{f} / \partial^{2} z\right)$, which can be reasonably assumed in most packed bed storage systems (Vortmeyer and Schaefer, 1974):

$$
(1-\varepsilon) \cdot \rho_{\mathrm{s}} \cdot \mathrm{c}_{\mathrm{p}_{\mathrm{s}}} \cdot \frac{\partial \mathrm{T}_{\mathrm{s}}}{\partial \mathrm{t}}+\varepsilon \cdot \rho_{\mathrm{f}} \cdot \mathrm{c}_{\mathrm{p}_{\mathrm{f}}} \cdot \mathrm{u} \cdot \frac{\partial \mathrm{T}_{\mathrm{s}}}{\partial \mathrm{z}}=\left[\lambda_{\mathrm{eff,s}}+\lambda_{\mathrm{eff,f}}+\frac{\left(\varepsilon \cdot \rho_{\mathrm{f}} \cdot \mathrm{c}_{\mathrm{p}_{\mathrm{f}}} \cdot \mathrm{u}\right)^{2}}{\mathrm{~h} \cdot \mathrm{a}_{\mathrm{s}}}\right] \cdot \frac{\partial^{2} \mathrm{~T}_{\mathrm{s}}}{\partial \mathrm{z}^{2}}
$$

With liquid HTF, the heat capacity of the fluid cannot be neglected. Vortmeyer and Schaefer, 1974, therefore considered a Schumann-type model similar to (2) and (3) with additional diffusion terms (with uniform effective thermal conductivities). Based on this model and by assuming that the fluid and the solid phases have the same time and space derivatives $\left(\partial T_{s} / \partial t=\partial T_{f} / \partial t\right.$ and $\left.\partial T_{s} / \partial z=\partial T_{f} / \partial z\right)$, the authors developed the following one-dimensional model: 


$$
\begin{aligned}
{\left[(1-\varepsilon) \cdot \rho_{s} \cdot c_{p_{s}}\right.} & \left.+\varepsilon \cdot \rho_{f} \cdot c_{p_{f}}\right] \cdot \frac{\partial T_{s}}{\partial t}+\varepsilon \cdot \rho_{f} \cdot c_{p_{f}} \cdot u \cdot \frac{\partial T_{s}}{\partial z} \\
& =\left[\lambda_{e f f, s}+\lambda_{e f f, f}+\frac{\left[(1-\varepsilon) \cdot \rho_{s} \cdot c_{p_{s}} \cdot w\right]^{2}}{h \cdot a_{s}}\right] \cdot \frac{\partial^{2} T_{s}}{\partial z^{2}}+\frac{(1-\varepsilon) \cdot \rho_{s} \cdot c_{p_{s}} \cdot w \cdot \lambda_{e f f, s}}{h \cdot a_{s}} \cdot \frac{\partial^{3} T_{s}}{\partial z^{3}}
\end{aligned}
$$

In equation (9), the last term is small and could be neglected since it is a third derivative. The term $w$ is the velocity of the thermal front in $\mathrm{m} / \mathrm{s}$. As a consequence of the condition on the derivatives, $w$ is assumed the same for the fluid-phase and the solid-phase. Unless measuring the thermal front velocity, it is possible to calculate it from an overall energy balance:

$$
\mathrm{w}=\frac{\varepsilon \cdot \rho_{\mathrm{f}} \cdot \mathrm{c}_{\mathrm{p}_{\mathrm{f}}} \cdot \mathrm{u}}{(1-\varepsilon) \cdot \rho_{\mathrm{s}} \cdot \mathrm{c}_{\mathrm{p}_{\mathrm{s}}}+\varepsilon \cdot \rho_{\mathrm{f}} \cdot \mathrm{c}_{\mathrm{p}_{\mathrm{f}}}}
$$

This method assumes thermal equilibrium between the fluid and the solid. If (10) is employed to calculate $w$, the model is therefore restricted to packed beds in which the temperature of the fluid and the solid are close to each other. Vortmeyer and Schaefer, 1974, pointed out that this model cannot be applied to steady-state processes due to the fact that the part of the dispersion term due to liquid-solid heat transfer is related to the thermal front velocity $w$.

It should be noticed that thermal destratification due to non-infinite HTC is included in the diffusion term of single phasemodels. As a consequence, the additional simplifications of single phase-models enable to reduce computational effort but don't enable to dispense with determination of the HTC.

\subsubsection{Perturbation model}

The perturbation model was originally developed by Kuznetsov, 1995, and further applied to packed-bed analysis by Votyakov and Bonanos, 2014. This model comes from a Schumann model in which conduction in fluid and solid phases were added. The underlying principle of the perturbation model is that, although different, temperatures of fluid and solid phases are considered close to each other compared to the reference temperature used to make the equations dimensionless. The solid phase temperature can therefore be considered as a perturbation in the temperature field of the fluid phase. As a result, the fluid phase temperature can be calculated thanks to the single dimensionless equation (11). Then, temperature of the solid phase can be calculated with (12) from the temperature of the fluid and characteristics of the packed bed. To be valid, this model has to meet some conditions which mainly limit its application to liquid HTF (cf. Table 5).

$$
\begin{gathered}
\frac{\partial \mathrm{T}_{\mathrm{f}}^{*}}{\partial \tau}+\gamma_{\mathrm{f}} \cdot \mathrm{Pe} \cdot \frac{\partial \mathrm{T}_{\mathrm{f}}^{*}}{\partial \mathrm{z}^{*}}=\Lambda \cdot \frac{\partial^{2} \mathrm{~T}_{\mathrm{f}}^{*}}{\partial \mathrm{z}^{* 2}} \\
\mathrm{~T}_{\mathrm{s}}^{*}=\mathrm{T}_{\mathrm{f}}^{*}+\delta \theta=\mathrm{T}_{\mathrm{f}}^{*}+\frac{\gamma_{\mathrm{s}} \cdot \gamma_{\mathrm{f}} \cdot \mathrm{Pe}}{\mathrm{Bi}^{\prime}} \cdot \frac{\partial \mathrm{T}_{\mathrm{f}}^{*}}{\partial \mathrm{z}^{*}}
\end{gathered}
$$

The perturbation model is more precise than single phase models and has an analytical solution in some conditions (constant inlet temperature and flow rate). A semi-analytical solution of this model was also developed for cases in which inlet fluid temperature and flow rate are time dependent (Mabrouk et al., 2015).

\subsubsection{One-dimensional three-phase models}

In order to account more finely for the influence of the walls, a dedicated energy equation may be added (Beasley and Clark, 1984; Hoffmann et al., 2016). This equation takes into account heat capacity and axial conduction in the tank's walls. If this equation is added to the general two-phase one-dimensional model presented above ((6) and (7)), the new one-dimensional three-phase model is expressed by (13) - (15). In (13) and (15), internal and external wall heat transfer coefficients are associated with shape factors calculated respectively with internal and external surface area of the walls $\left(a_{w, i n t}\right.$ and $\left.a_{w, e x t}\right)$.

$$
\varepsilon \cdot \rho_{\mathrm{f}} \cdot \mathrm{c}_{\mathrm{p}_{\mathrm{f}}} \cdot\left(\frac{\partial \mathrm{T}_{\mathrm{f}}}{\partial \mathrm{t}}+\mathrm{u} \cdot \frac{\partial \mathrm{T}_{\mathrm{f}}}{\partial \mathrm{z}}\right)=\frac{\partial}{\partial \mathrm{z}} \cdot\left(\lambda_{\mathrm{eff}, \mathrm{f}} \cdot \frac{\partial \mathrm{T}_{\mathrm{f}}}{\partial \mathrm{z}}\right)+\mathrm{h} \cdot \mathrm{a}_{\mathrm{s}} \cdot\left(\mathrm{T}_{\mathrm{s}}-\mathrm{T}_{\mathrm{f}}\right)+\mathbf{h}_{\mathbf{w}, \mathbf{i n t}} \cdot \mathbf{a}_{\mathbf{b}} \cdot\left(\mathbf{T}_{\mathbf{w}}-\mathbf{T}_{\mathrm{f}}\right)
$$




$$
\begin{gathered}
(1-\varepsilon) \cdot \rho_{\mathrm{s}} \cdot \mathrm{c}_{\mathrm{p}_{\mathrm{s}}} \cdot \frac{\partial \mathrm{T}_{\mathrm{s}}}{\partial \mathrm{t}}=\frac{\partial}{\partial \mathrm{z}} \cdot\left(\lambda_{\mathrm{eff}, \mathrm{s}} \cdot \frac{\partial \mathrm{T}_{\mathrm{s}}}{\partial \mathrm{z}}\right)+\mathrm{h} \cdot \mathrm{a}_{\mathrm{s}} \cdot\left(\mathrm{T}_{\mathrm{f}}-\mathrm{T}_{\mathrm{s}}\right) \\
\boldsymbol{\rho}_{\mathbf{w}} \cdot \mathbf{c}_{\mathbf{p}_{\mathbf{w}}} \cdot \frac{\partial \mathbf{T}_{\mathbf{w}}}{\partial \mathbf{t}}=\frac{\partial}{\partial \mathbf{z}} \cdot\left(\boldsymbol{\lambda}_{\mathbf{w}} \cdot \frac{\partial \mathbf{T}_{\mathbf{w}}}{\partial \mathbf{z}}\right)+\mathbf{h}_{\mathbf{w}, \text { int }} \cdot \mathbf{a}_{\mathbf{w}, \text { int }} \cdot\left(\mathbf{T}_{\mathbf{f}}-\mathbf{T}_{\mathbf{w}}\right)+\mathbf{h}_{\mathbf{w}, \mathbf{e x t}} \cdot \mathbf{a}_{\mathbf{w}, \mathbf{e x t}} \cdot\left(\mathbf{T}_{\infty}-\mathbf{T}_{\mathbf{w}}\right)
\end{gathered}
$$

\subsubsection{Two-dimensional models}

Consideration of non-negligible edge effects like flow heterogeneities or radial thermal gradient due to significant lateral heat losses leads to the development of two-dimensional models. Parameters like temperature, fluid velocity or bed void fraction can vary according to radial direction. Two-dimensional models also enable to consider anisotropic effective conductivity, particularly in structured packed beds.

Given that heat exchange between the packed bed and the walls or outside occurs only at boundaries, these phenomena are taken into account through boundary conditions (usually Neumann boundary conditions). Although it is not always necessary, the equation for the walls also may be two-dimensional (Klein et al., 2013). A two-dimensional model similar to the one-dimensional model presented in (13) - (15) and written with cylindrical coordinates could be expressed by (16) - (18). In these equations, the radial component of the fluid velocity is assumed negligible.

$$
\begin{gathered}
\varepsilon \cdot \rho_{\mathrm{f}} \cdot \mathrm{c}_{\mathrm{p}_{\mathrm{f}}} \cdot\left(\frac{\partial \mathrm{T}_{\mathrm{f}}}{\partial \mathrm{t}}+\mathrm{u} \cdot \frac{\partial \mathrm{T}_{\mathrm{f}}}{\partial \mathrm{z}}\right)=\frac{\partial}{\partial \mathrm{z}} \cdot\left(\lambda_{\mathrm{eff}, \mathrm{f}, \mathrm{z}} \cdot \frac{\partial \mathrm{T}_{\mathrm{f}}}{\partial \mathrm{z}}\right)+\frac{\mathbf{1}}{\mathbf{r}} \cdot \frac{\mathbf{\partial}}{\partial \mathbf{r}}\left(\mathbf{r} \cdot \boldsymbol{\lambda}_{\text {eff,f,r }} \cdot \frac{\partial \mathrm{T}_{\mathbf{f}}}{\partial \mathbf{r}}\right)+\mathrm{h} \cdot \mathrm{a}_{\mathrm{s}} \cdot\left(\mathrm{T}_{\mathrm{s}}-\mathrm{T}_{\mathrm{f}}\right) \\
(1-\varepsilon) \cdot \rho_{\mathrm{s}} \cdot \mathrm{c}_{\mathrm{p}_{\mathrm{s}}} \cdot \frac{\partial \mathrm{T}_{\mathrm{s}}}{\partial \mathrm{t}}=\frac{\partial}{\partial \mathrm{z}} \cdot\left(\lambda_{\mathrm{eff}, \mathrm{s}, \mathrm{z}} \cdot \frac{\partial \mathrm{T}_{\mathrm{s}}}{\partial \mathrm{z}}\right)+\frac{\mathbf{1}}{\mathbf{r}} \cdot \frac{\mathbf{\partial}}{\partial \mathbf{r}}\left(\mathbf{r} \cdot \boldsymbol{\lambda}_{\mathrm{eff}, \mathbf{s}, \mathbf{r}} \cdot \frac{\partial \mathrm{T}_{\mathbf{s}}}{\partial \mathbf{r}}\right)+\mathrm{h} \cdot \mathrm{a}_{\mathrm{s}} \cdot\left(\mathrm{T}_{\mathrm{f}}-\mathrm{T}_{\mathrm{s}}\right) \\
\rho_{\mathrm{w}} \cdot \mathrm{c}_{\mathrm{p}_{\mathrm{w}}} \cdot \frac{\partial \mathrm{T}_{\mathrm{w}}}{\partial \mathrm{t}}=\frac{\partial}{\partial \mathrm{z}} \cdot\left(\lambda_{\mathrm{w}, \mathrm{z}} \cdot \frac{\partial \mathrm{T}_{\mathrm{w}}}{\partial \mathrm{z}}\right)+\frac{\mathbf{1}}{\mathbf{r}} \cdot \frac{\mathbf{\partial}}{\partial \mathbf{r}}\left(\mathbf{r} \cdot \boldsymbol{\lambda}_{\mathrm{w}, \mathbf{r}} \cdot \frac{\partial \mathrm{T}_{\mathrm{w}}}{\partial \mathbf{r}}\right)
\end{gathered}
$$

More complete two-dimensional models may be implemented thanks to CFD commercial codes like Ansys Fluent (Chang et al., 2015; Yang and Garimella, 2010b). Thanks to these codes, continuity and momentum equations can be solved and some phenomena like compression work due to volume expansion/shrinkage, viscous effects and kinetic energy changes can be accounted for, even if negligible (Chang et al., 2015).

\subsection{Models with non-negligible thermal gradient inside the solids}

The condition (1) which enables to consider negligible thermal resistance inside solids compared to convective resistance may be unfulfilled when the solids are too large, the solid conductivity is too low or the HTC is too high. In this case, the temperature of solids cannot be reasonably assumed uniform. The literature shows that two approaches may be used to face this issue: either calculating the temperature field inside the solids by using a devoted equation or using an effective HTC which accounts for conduction resistance inside the solids without modifying the structure of the models presented above. The former is described below, while the latter will be treated in 4.1.3.

\subsubsection{One-dimensional intraparticle conduction models}

In this kind of model, which accounts for thermal gradient inside the solids and was introduced by Handley and Heggs, 1969, the solids are assumed to be spherical (with the same volume than real particles) and the packed bed is modeled as a superposition of spheres (Fig. 14). In each elementary layer, the model enables to compute the temperature of the fluid phase and the temperature profile inside a representative solid. The overall behavior of the packed bed is considered to be onedimensional. Compared to Schumann-type models, two additional assumptions are necessary to implement this model: the thermal behavior of solids is concentric (central symmetry) and the HTC is uniform around solids. These assumptions are expressed with Neumann boundary conditions. 


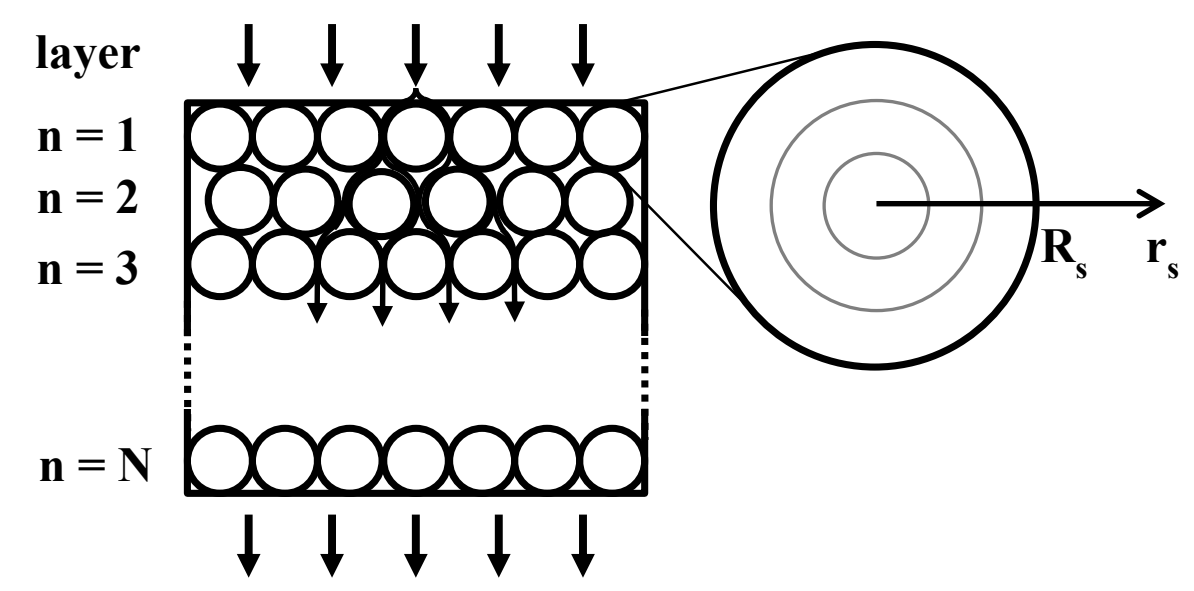

Fig. 14. Principle of the intraparticle conduction model. Reproduced from Meier et al., 1991.

If thermal losses, axial conduction through the fluid phase and the influence of the walls are added to the original model of Handley and Heggs, 1969, the resulting one-dimensional three-phase model can be expressed by (19) - (21). In the solid equation of this model, the fluid-solid heat exchange is accounted for thanks to a Neumann boundary condition. Thermal diffusion through the solid phase of the packed bed is accounted for through the fluid-phase equation by assuming that second space derivatives of the fluid and the solid temperature profiles are close to each other. Therefore, the total effective thermal conductivity of the bed $\left(\lambda_{e f f}\right)$ is used in the fluid-phase equation (Wakao et al., 1979).

$$
\begin{gathered}
\varepsilon \cdot \rho_{\mathrm{f}} \cdot \mathrm{c}_{\mathrm{p}_{\mathrm{f}}} \cdot\left(\frac{\partial \mathrm{T}_{\mathrm{f}}}{\partial \mathrm{t}}+\mathrm{u} \cdot \frac{\partial \mathrm{T}_{\mathrm{f}}}{\partial \mathrm{z}}\right)=\frac{\partial}{\partial \mathrm{z}} \cdot\left(\lambda_{\mathrm{eff}} \cdot \frac{\partial \mathrm{T}_{\mathrm{f}}}{\partial \mathrm{z}}\right)+\mathrm{h} \cdot \mathrm{a}_{\mathrm{s}} \cdot\left(\mathrm{T}_{\mathrm{s}} \mathrm{r}_{\mathrm{r}_{\mathrm{s}}=\mathbf{R}_{\mathrm{s}}}-\mathrm{T}_{\mathrm{f}}\right)+\mathrm{h}_{\mathrm{w}, \text { int }} \cdot \mathrm{a}_{\mathrm{b}} \cdot\left(\mathrm{T}_{\mathrm{w}}-\mathrm{T}_{\mathrm{f}}\right) \\
\boldsymbol{\rho}_{\mathrm{s}} \cdot \mathbf{c}_{\mathrm{p}_{\mathrm{s}}} \cdot \frac{\partial \mathrm{T}_{\mathbf{s}}}{\partial \mathrm{t}}=\frac{\mathbf{1}}{\mathbf{r}_{\mathrm{s}}^{2}} \cdot \frac{\partial}{\partial \mathbf{r}_{\mathrm{s}}}\left(\mathbf{r}_{\mathbf{s}}^{2} \cdot \boldsymbol{\lambda}_{\mathbf{s}} \cdot \frac{\partial \mathrm{T}_{\mathbf{s}}}{\partial \mathbf{r}_{\mathbf{s}}}\right) \\
\rho_{\mathrm{w}} \cdot \mathrm{c}_{\mathrm{p}_{\mathrm{w}}} \cdot \frac{\partial \mathrm{T}_{\mathrm{w}}}{\partial \mathrm{t}}=\frac{\partial}{\partial \mathrm{z}} \cdot\left(\lambda_{\mathrm{w}} \cdot \frac{\partial \mathrm{T}_{\mathrm{w}}}{\partial \mathrm{z}}\right)+\mathrm{h}_{\mathrm{w}, \text { int }} \cdot \mathrm{a}_{\mathrm{w}, \text { int }} \cdot\left(\mathrm{T}_{\mathrm{f}}-\mathrm{T}_{\mathrm{w}}\right)+\mathrm{h}_{\mathrm{w}, \text { ext }} \cdot \mathrm{a}_{\mathrm{w}, \text { ext }} \cdot\left(\mathrm{T}_{\infty}-\mathrm{T}_{\mathrm{w}}\right)
\end{gathered}
$$

\subsubsection{Two-dimensional intraparticle conduction models}

As far as the authors know, there is no two-dimensional intraparticle conduction model in the literature. However, if the two-dimensional approach were applied to the intraparticle conduction model described in (19) - (21), the resulting model would be expressed as follows:

$$
\begin{gathered}
\varepsilon \cdot \rho_{\mathrm{f}} \cdot \mathrm{c}_{\mathrm{p}_{\mathrm{f}}} \cdot\left(\frac{\partial \mathrm{T}_{\mathrm{f}}}{\partial \mathrm{t}}+\mathrm{u} \cdot \frac{\partial \mathrm{T}_{\mathrm{f}}}{\partial \mathrm{z}}\right)=\frac{\partial}{\partial \mathrm{z}} \cdot\left(\lambda_{\mathrm{eff}, \mathrm{z}} \cdot \frac{\partial \mathrm{T}_{\mathrm{f}}}{\partial \mathrm{z}}\right)+\frac{\mathbf{1}}{\mathbf{r}} \cdot \frac{\mathbf{\partial}}{\partial \mathbf{r}}\left(\mathbf{r} \cdot \boldsymbol{\lambda}_{\mathrm{eff}, \mathrm{r}} \cdot \frac{\partial \mathrm{T}_{\mathrm{f}}}{\partial \mathbf{r}}\right)+\mathrm{h} \cdot \mathrm{a}_{\mathrm{s}} \cdot\left(\mathrm{T}_{\mathrm{s}} \mathrm{r}_{\mathrm{s}}=\mathrm{R}_{\mathrm{s}}-\mathrm{T}_{\mathrm{f}}\right) \\
\rho_{\mathrm{s}} \cdot \mathrm{c}_{\mathrm{p}_{\mathrm{s}}} \cdot \frac{\partial \mathrm{T}_{\mathrm{s}}}{\partial \mathrm{t}}=\frac{1}{\mathrm{r}_{\mathrm{s}}{ }^{2}} \cdot \frac{\partial}{\partial \mathrm{r}_{\mathrm{s}}}\left(\mathrm{r}_{\mathrm{s}}^{2} \cdot \lambda_{\mathrm{s}} \cdot \frac{\partial \mathrm{T}_{\mathrm{s}}}{\partial \mathrm{r}_{\mathrm{s}}}\right) \\
\rho_{\mathrm{w}} \cdot \mathrm{c}_{\mathrm{p}_{\mathrm{w}}} \cdot \frac{\partial \mathrm{T}_{\mathrm{w}}}{\partial \mathrm{t}}=\frac{\partial}{\partial \mathrm{z}} \cdot\left(\lambda_{\mathrm{w}} \cdot \frac{\partial \mathrm{T}_{\mathrm{w}}}{\partial \mathrm{z}}\right)+\frac{\lambda_{\mathrm{w}}}{\mathbf{r}} \cdot \frac{\partial}{\partial \mathbf{r}}\left(\mathbf{r} \cdot \frac{\partial \mathrm{T}_{\mathbf{w}}}{\partial \mathbf{r}}\right)
\end{gathered}
$$

\subsection{Comparison between models}

In the literature, a few comparisons of numerical models for packed-bed storage have been carried out. The most complete one was probably performed by Ismail and Stuginsky, 1999. The authors have compared various kinds of numerical model in terms of calculation time and results.

\subsubsection{Calculation time}


Ismail and Stuginsky, 1999, compared several numerical models in terms of calculation time with the same number of time increments and grid points, and the same initial and final conditions for a packed bed comprised of stones with water as HTF. Unless explicitly mentioned, every model takes into account heat losses and conduction in fluid and solid phases. The result obtained by the authors is presented in Fig. 15.

\begin{tabular}{|l|c|}
\hline Model & CPU time \\
\hline 1D 1-phase & 1 \\
\hline $\begin{array}{l}\text { 1D 2-phase without } \\
\text { conduction }\end{array}$ & 4 \\
\hline 1D 2-phase & 7 \\
\hline 2D 1-phase & 20 \\
\hline 1D intraparticle conduction & 81 \\
\hline 2D 2-phase & 180 \\
\hline
\end{tabular}

Fig. 15. Comparison of calculation times with various numerical models (basis 1 for one-dimensional single-phase model). Reproduced from Ismail and Stuginsky, 1999.

Although this study is difficultly exploitable since operational conditions (temperature, flow rate, solid size, material properties, Biot number, etc.) which govern the scope of validity of each model are not given, it enables to estimate the additional calculation time due to each phenomenon accounted for:

- calculation time for two-phase models is 7 to 9 times longer than for one-phase models;

- calculation time for two-dimensional models is 20 to 25 times longer than for one-dimensional models;

- $\quad$ accounting for thermal diffusion multiplies calculation time by 1.7 ;

- $\quad$ accounting for thermal gradient inside solids multiplies calculation time by 11 .

\subsubsection{Parametric studies}

By definition, if the requirements for the applicability of a numerical model are well fulfilled, the results obtained are close to the experimental reality and similar to the results which would be obtained with a less simplified and more general model. However, even if a simplified model gives good results, the estimation through a simplified model of the influence of some phenomena could be misleading.

As an example, Ismail and Stuginsky, 1999, compared the influence of the size of solids in a packed bed comprised of stones and water using three different models: a single-phase model which neglects interface phenomena and thermal gradient inside the solids, a two-phase model which neglects thermal gradient inside the solids, and an intraparticle conduction model which accounts for the two above mentioned phenomena.

Due to the inherent assumptions of the single-phase model, this model doesn't exhibit any influence of the size of solids over the thermal behavior of the packed-bed storage (Fig. 16. a).

In the two-phase model, the increase in solid size leads to a slight decrease in the overall heat exchange between fluid and solids (Fig. 16. b). This is mainly due to the decrease in heat exchange surface area between fluid and solids.

In the intraparticle conduction model, the heat exchange reduction caused by the increase in solid size is even more pronounced because, in addition to the decrease in overall heat exchange surface area, this model also accounts for the increasing conduction resistance inside solids (Fig. 16. c).

In this example, while the singe-phase model gives good results with small particle diameter, it is not relevant to assess the influence of the size of solids, because some involved phenomena are neglected. However, this study should be considered with precaution since the models should be compared within their scope of validity and flow rate and Biot number which would enable to check the validity of each model are not given. 


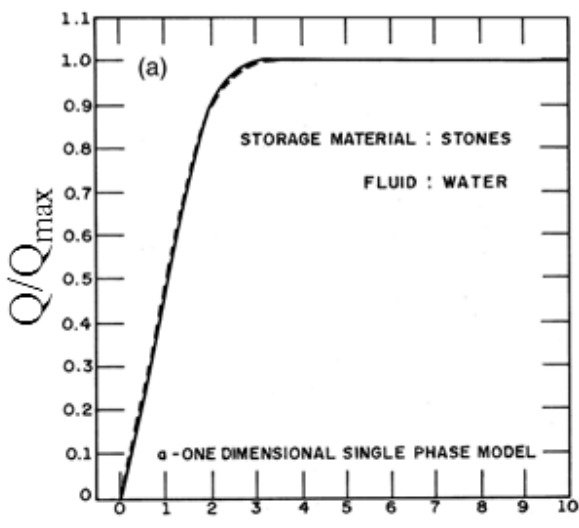

Dimensionless time

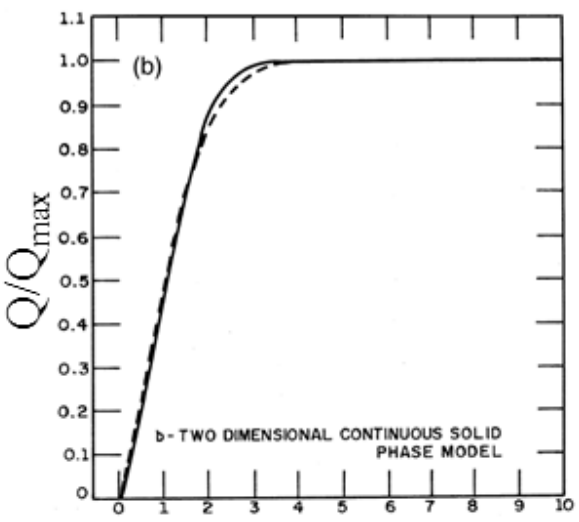

Dimensionless time

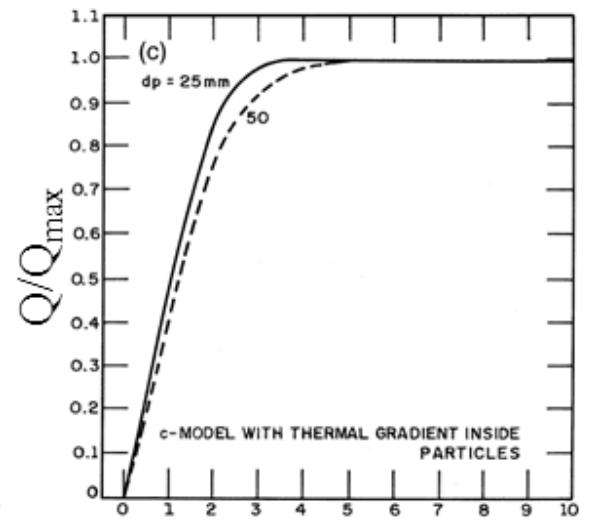

Dimensionless time

Fig. 16. Variation of the energy stored in terms of particle diameter for different bed models: (a) 1D 1-phase, (b) 2D 2-phase and (c) intraparticle conduction models; solid and dotted lines refer to $25 \mathrm{~mm}$ and $50 \mathrm{~mm}$ diameter solids respectively (Ismail and Stuginsky, 1999).

To sum up, various numerical models have been developed in the literature. They come from the simplification of energy equations which are applied to various elements of the storage system. The numerical model should be carefully chosen according to the studied system, the assumptions which can be reasonably done, the phenomena investigated, the desired accuracy and the available computing power. Even if the results are representative of the experimental reality, it should be kept in mind that many models neglect some phenomena and are thereby limited to a particular scope of validity. In addition, experimental data from the literature on packed-bed storages are available only in a narrow range of operating conditions. Thus the scope of significant influence of each phenomenon and the scope of validity of each assumption are not well known. Numerical models should therefore be considered with precaution when they are used for extrapolation or parametric studies. 


\begin{tabular}{|c|c|c|c|c|c|c|c|c|c|}
\hline Assumptions / Conditions & $\begin{array}{l}\text { Schumann } \\
\quad(2),(3)\end{array}$ & $\begin{array}{c}\text { Enhanced } \\
\text { Schumann } \\
(6),(7)\end{array}$ & $\begin{array}{l}\text { 1D single-phase } \\
\text { (gaseous) } \\
(8)\end{array}$ & $\begin{array}{l}\text { 1D single-phase } \\
\text { (liquid) } \\
\text { (9) }\end{array}$ & $\begin{array}{c}\text { Perturbation } \\
\text { model } \\
(11),(12)\end{array}$ & $\begin{array}{l}\text { 1D three-phase } \\
(13),(14),(15)\end{array}$ & $\begin{array}{l}\text { 2D three-phase } \\
(16),(17),(18)\end{array}$ & $\begin{array}{l}1 D \text { intraparticle } \\
\text { conduction } \\
(19),(20),(21)\end{array}$ & $\begin{array}{l}2 \mathrm{D} \text { intraparticle } \\
\text { conduction } \\
(22),(23),(24)\end{array}$ \\
\hline $\begin{array}{l}\text { Negligible thermal gradient } \\
\text { inside the solids }(\mathrm{Bi}<0.1)\end{array}$ & $\mathrm{X}$ & $\mathrm{X}$ & $X$ & $\mathrm{X}$ & $\mathrm{X}$ & $\mathrm{X}$ & $X$ & & \\
\hline Homogeneous porous medium & $\mathrm{X}$ & $\mathrm{X}$ & $\mathrm{X}$ & $\mathrm{X}$ & $\mathrm{X}$ & $\mathrm{X}$ & $\mathrm{X}$ & & \\
\hline $\begin{array}{l}\text { 1D system with fluid circulating } \\
\text { according to plug flow }\end{array}$ & $X$ & $\mathrm{X}$ & $\mathrm{X}$ & $\mathrm{X}$ & $\mathrm{X}$ & $\mathrm{X}$ & & $X$ & \\
\hline $\begin{array}{l}\text { Adiabatic storage with no } \\
\text { thermal influence of the walls }\end{array}$ & $X$ & & $\mathrm{X}$ & $\mathrm{X}$ & $\mathrm{X}$ & & & & \\
\hline $\begin{array}{l}\text { Negligible diffusion compared to } \\
\text { convection }\end{array}$ & $X$ & & & & & & & & \\
\hline $\begin{array}{l}\text { Fluid and solid temperature } \\
\text { second derivatives in space close } \\
\text { to each other }\end{array}$ & & & $\mathrm{X}$ & $X$ & $\mathrm{X}$ & & & & \\
\hline $\begin{array}{l}\text { Negligible volumetric heat } \\
\text { capacity of the fluid compared to } \\
\text { the one of the solid }\end{array}$ & & & $\mathrm{X}$ & & & & & & \\
\hline$\frac{\gamma_{\mathrm{s}} \cdot \gamma_{\mathrm{f}} \cdot \mathrm{Pe}}{\mathrm{Bi}^{\prime}} \ll 1$ & & & & & $\mathrm{X}$ & & & & \\
\hline $\begin{array}{l}\text { Uniform HTC around solids and } \\
\text { concentric temperature profile } \\
\text { inside solids }\end{array}$ & & & & & & & & $X$ & $\mathrm{X}$ \\
\hline
\end{tabular}

Table 5. Assumptions and simplifications for each model. 


\section{Physical properties of porous media}

As depicted in Fig. 17, many physical phenomena govern the packed-bed storage behavior. To implement numerical models and design setups, several parameters have to be determined: fluid/solid and fluid/wall heat transfer coefficients, effective thermal conductivity and pressure loss of the bed. This section aims to present some models and correlations for these parameters.

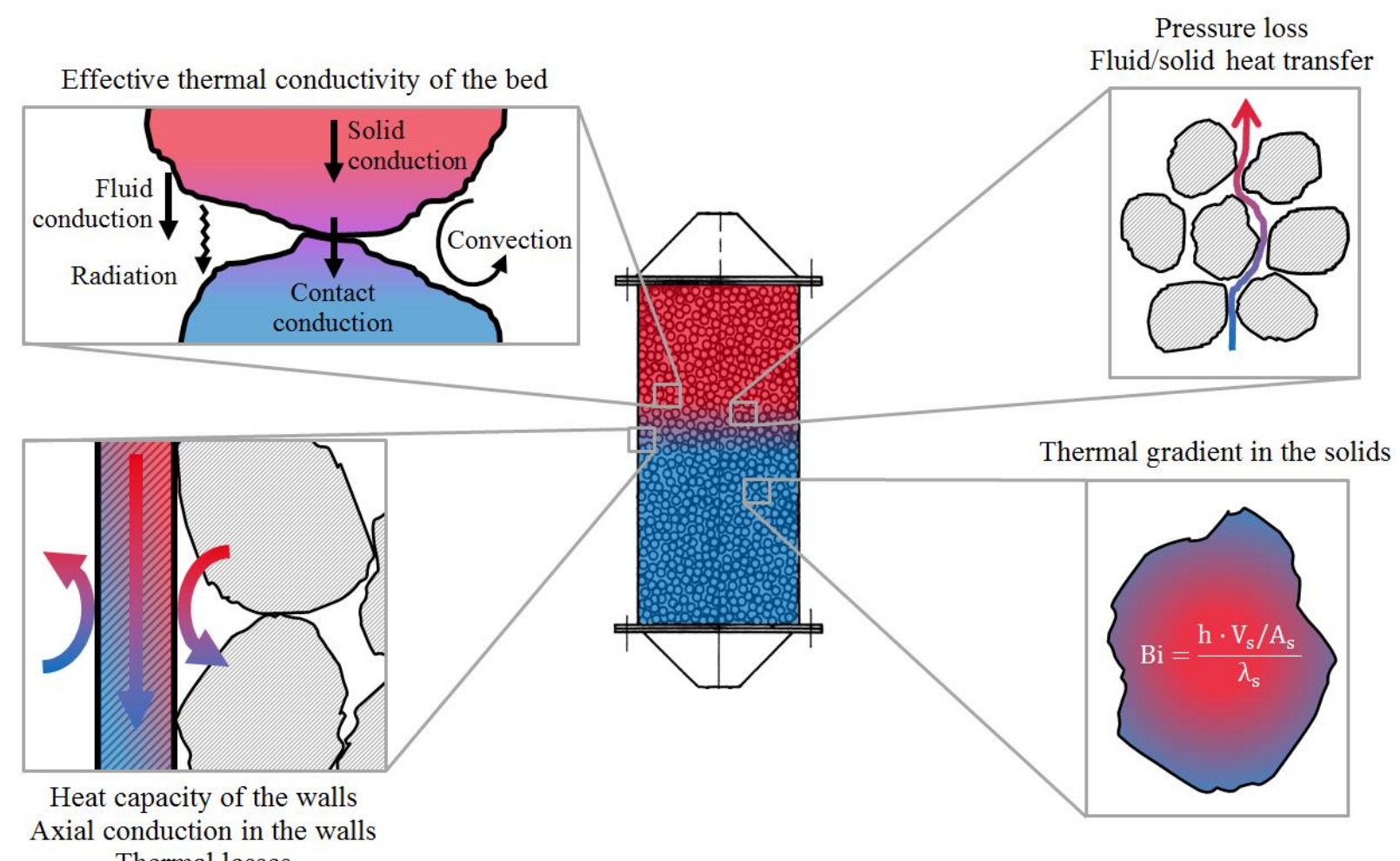

Thermal losses

Fig. 17. Diagram of some physical phenomena involved in the packed-bed storage behavior.

\subsection{Fluid/solid heat transfer coefficient}

The fluid/solid HTC is a key parameter which governs the charge and discharge power and the thermal stratification of the storage. This parameter may be expressed either in volume form $\left(h_{v}\right.$ in $\left.\mathrm{W} \cdot \mathrm{m}^{-3} \cdot \mathrm{K}^{-1}\right)$ or in classical surface form $\left(h\right.$ in W $\cdot \mathrm{m}^{-}$ ${ }^{2} \cdot \mathrm{K}^{-1}$ ). These two forms are related by the shape factor $a_{s}$ defined in equation (4) (Chandra and Willits, 1981):

$$
\frac{\mathrm{h}_{\mathrm{v}}}{\mathrm{h}}=\mathrm{a}_{\mathrm{s}}=\frac{\mathrm{A}_{\mathrm{s}, \mathrm{tot}}}{\mathrm{V}_{\mathrm{b}}}
$$

\subsubsection{Determination methods}

There are several ways to determine the HTC and the corresponding correlations. As pointed out by Balakrishnan and Pei, 1979a, the method used determines the heat transfer modes included in the HTC. When the methodology doesn't enable to isolate fluid/solid convection from the other heat transfer modes (e.g. conduction and radiation between solids), the determined HTC corresponds to the total heat transfer rate. Given that total heat transfer is influenced by physical and transport properties of the bed materials, these correlations, although reliable, are only applicable to the particular bed materials for which they were developed.

The first determination method consists in using temperature measurements and energy balance between the fluid and the solids. This method, which in principle correlates the total heat transfer, was introduced by Furnas, 1930, and used by several authors (Achenbach, 1995; Inaba and Fukuda, 1984; Schröder et al., 2006; Singh et al., 2006).

The second determination method consists in comparing experimental results with the ones of a numerical model. The HTC is fitted so that experimental and numerical results correspond. With this method, the heat transfer modes included in the HTC depend on the phenomena accounted for by the model: the transfer modes which are not considered separately in the model are actually included in the HTC. This method, introduced by Furnas, 1932, is often based on the Schumann model (Alanís et al., 1977; Chandra and Willits, 1981; Handley and Heggs, 1968; Löf and Hawley, 1948; Morgan, 1980; Sagara and Nakahara, 1991). More complete models were used by Coutier and Farber, 1982, and Beasley and Clark, 1984. An 
intraparticle conduction model, i.e. one of the most complete models, was used by Wakao et al., 1979, to correlate numerous data from the literature.

The third determination method is based on the Chilton-Colburn analogy which links convective heat transfer and mass transfer phenomena through characterization of the boundary layer. Several authors used this method (Acetis and Thodos, 1960; Achenbach, 1995; Beek, 1962; Gupta and Thodos, 1962; Khan et al., 1991; Satterfield et al., 1954), but some of them (Acetis and Thodos, 1960; Satterfield et al., 1954) obtained a heat transfer coefficient superior to the corresponding mass transfer coefficient, which is in contradiction with the Chilton-Colburn analogy. According to Balakrishnan and Pei, 1979a, this is due to interaction of additional heat transfer modes and methodology issues. These biases were corrected by Gupta and Thodos, 1962, who obtained very similar heat and mass transfer coefficients. The developed correlation is therefore likely to be general.

In addition to the three main methods mentioned above, other interesting approaches were developed in the literature. Galloway and Sage, 1970, used a boundary layer model based on the behavior of heat and mass transfer from single particle and determined empirically some constants from local heat transfer measurements in packed beds. Whitaker, 1972, and Gunn, 1978, used statistical method on numerous data from the literature to correlate the influence of several parameters. Ranz, 1952, and Pfeffer, 1964, estimated the heat transfer coefficient in a packed bed of spheres from the heat transfer coefficient around an isolated sphere. Martin, 2005, used the theory of Lévêque, 1928, which correlates the frictional pressure drop with heat or mass transfer, to build a general correlation for heat transfer coefficient in packed beds comprised of particles of various shapes.

\subsubsection{Comparison of selected correlations}

Regarding to their determination method, some correlations of the literature were selected and detailed in Table 6. Whatever the experimental conditions in which these correlations were developed and validated, it should be noticed that the column "scope of validity" in Table 6 only indicates what have been explicitly mentioned by the authors. The correlations are compared in Fig. 18 on a case study with a packed bed of uniform spheres and thermal oil. For readability issues, only the most representative of them are plotted. All the correlations of Table 6 which were not plotted give results approximately situated in the envelop formed by the correlations of Whitaker, 1972, Galloway and Sage, 1970, Ranz, 1952, and Gunn, 1978. Fig. 18 shows that Nusselt number increases with Reynolds number. As a consequence, other things equal, convective heat transfer coefficient increases with fluid velocity. Similar evolutions of the Nusselt number with Reynolds number are observed when case studies with molten salts or air at higher temperature are considered. Given that the correlation of Wakao et al., 1979, was developed on a large range of experimental data from different setups, is easy to implement, widely used in the literature and in the average of the other correlations, it seems to be a relevant choice to calculate the HTC in packed beds, at least in a first approach.

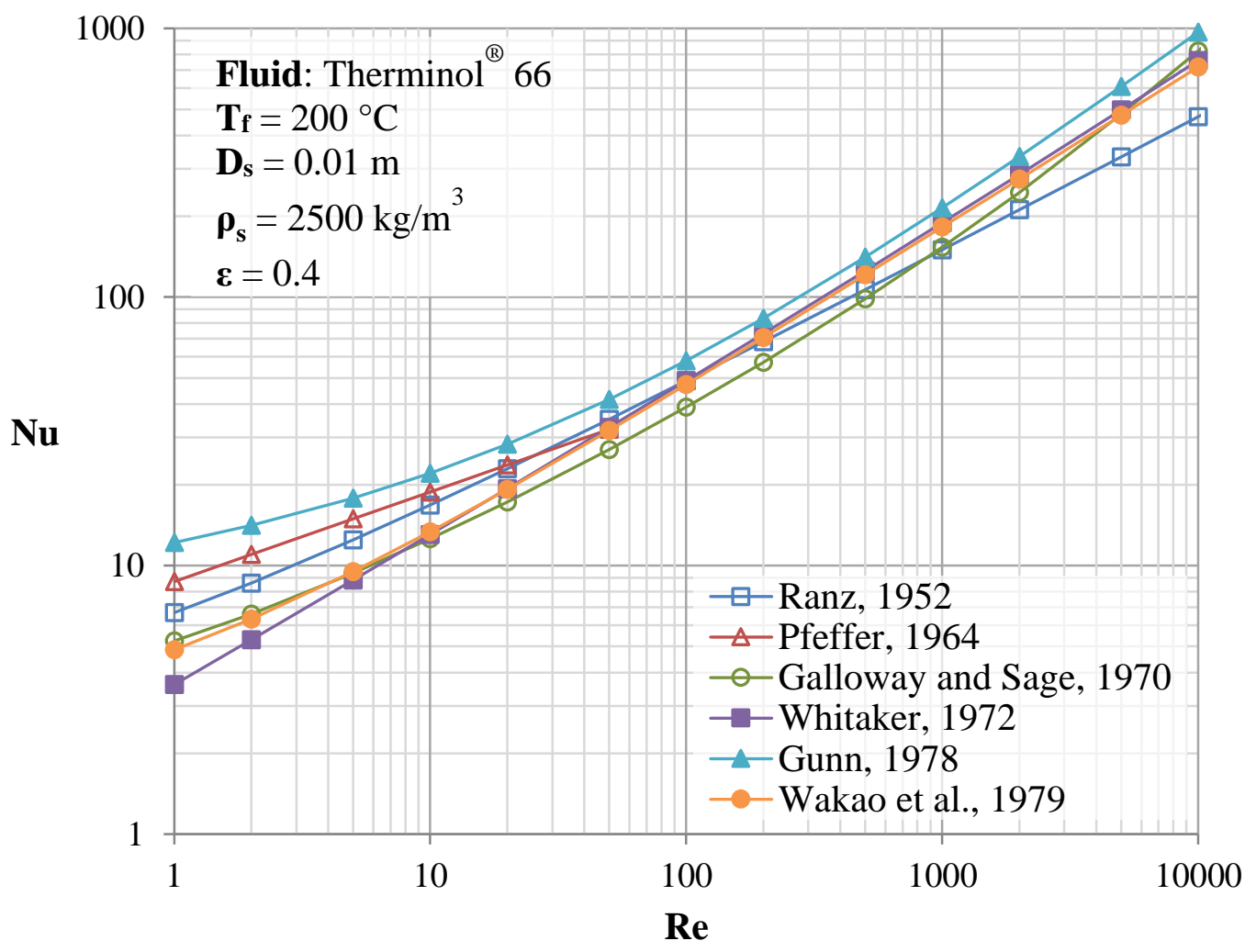

Fig. 18. Influence of the Reynolds number on a given set of fluid/solid HTC correlations. 
As mentioned in 3.2, when the thermal gradient in the solids cannot be reasonably neglected, it may be convenient to use an effective HTC which accounts for conduction resistance of the solid. This method introduced by the work of Stuke, 1948, enables to calculate the effective average temperature of solids. The effective HTC is calculated as:

$$
\frac{1}{\mathrm{~h}_{\mathrm{eff}}}=\frac{1}{\mathrm{~h}}+\frac{\mathrm{D}_{\mathrm{s}}}{\lambda_{\mathrm{s}} \cdot \mathrm{k}}
$$

The value of the coefficient $k$ in (26) depends on the shape of the solids and is 10,8 and 6 for spheres, cylinders and slabs respectively, with $D_{s}$ the sphere or cylinder diameter or slab thickness (Dixon and Cresswell, 1979). Compared to analytical exact solution, the effective HTC method gives very good results (Xu et al., 2012a). 


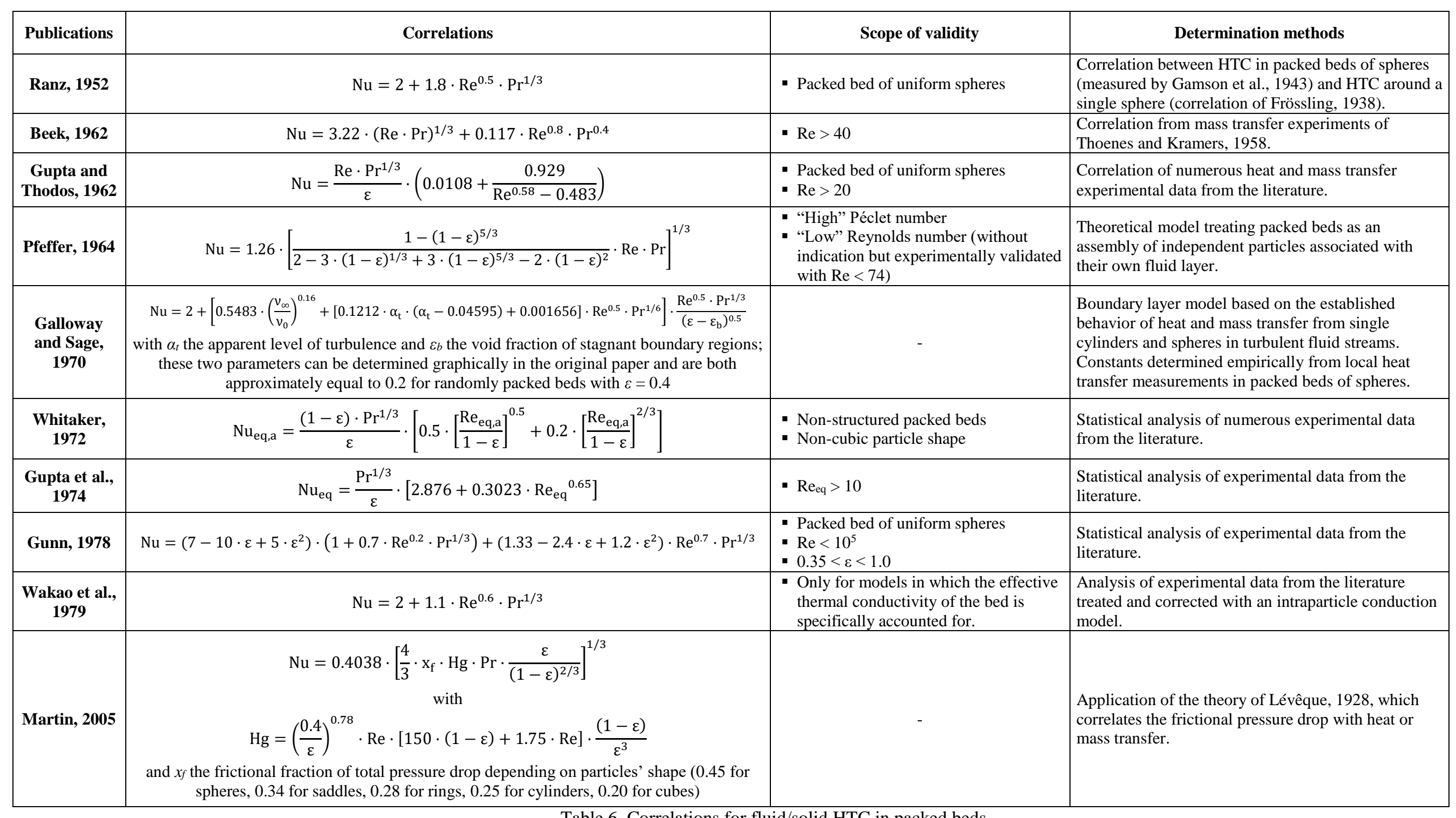




\subsection{Fluid/wall heat transfer coefficient}

In order to determine the influence of the walls on the packed bed storage (thermal losses, heat capacity and axial conduction through the walls), the HTC between the walls and the bed has to be estimated. As shown by Yagi and Kunii, 1960, several heat transfer modes which interact with each other govern the heat transfer near wall surfaces in packed beds: heat transfer through the thin fluid film near contact points, radiative heat transfer from solid surface to solid surface, thermal conduction in void spaces, radiative heat transfer from void to void (i.e. between solids not directly in front of each other), heat transfer caused by the lateral mixing of the flowing fluid in void spaces, heat transfer through the boundary film.

In the same way as for fluid/solid HTC, temperature measurements (Chu and Storrow, 1952; Colburn, 1931; Leva, 1947; Leva et al., 1948; Leva, 1950; Leva and Grummer, 1948; Yagi and Kunii, 1960), Chilton-Colburn analogy (Beek, 1962; Dixon et al., 1984; Kunii and Suzuki, 1968; Li and Finlayson, 1977; Yagi and Wakao, 1959) or more theoretical approaches (Tsotsas and Schlünder, 1990) may be used to determine the HTC between the packed bed and the walls.

\subsubsection{Comparison of some correlations}

Some correlations from the literature were selected and presented in Table 7. In all of them, the characteristic length for calculation of the Nusselt number is the diameter of solids. As previously mentioned, the column "scope of validity" only indicates what have been explicitly mentioned by the authors. The correlations are compared in a case study in Fig. 19. In spite of discrepancies between the correlations, all of them show increasing wall Nusselt number with Reynolds number. The result of the comparison is similar when case studies with molten salt or air at higher temperature and lower tank-to-particle diameter ratio are considered. Although Dixon et al., 1984, established their correlation for low tank-to-particle diameter ratios, this correlation gives an average of several correlations from the literature over a wide range of conditions (even at large tank-toparticle diameter ratios). This correlation could therefore be used to estimate the fluid/wall HTC in a first approach.

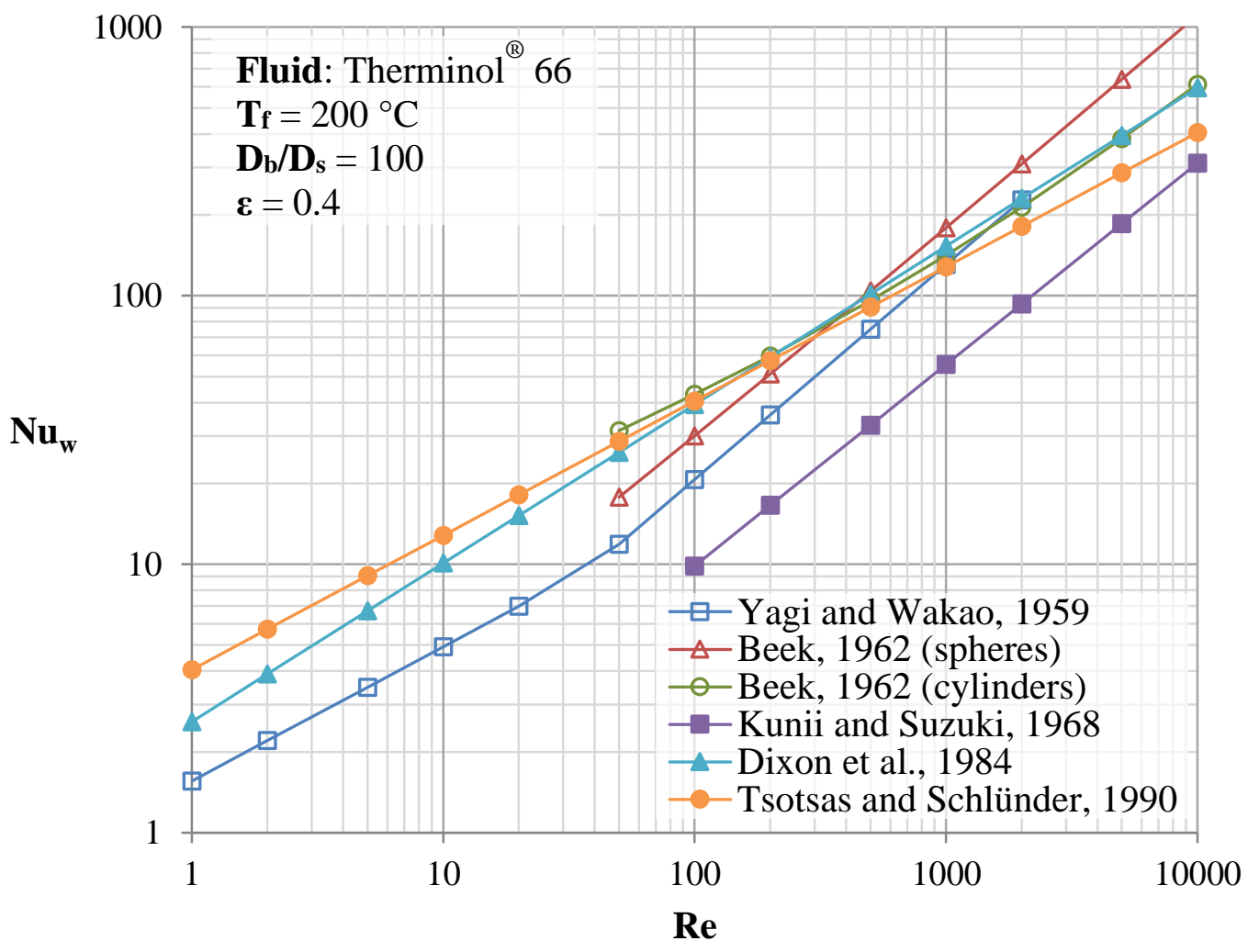

Fig. 19. Influence of the Reynolds number on a given set of correlations of fluid/wall HTC in packed beds. 


\begin{tabular}{|c|c|c|c|}
\hline Publications & Correlations & Scope of validity & Determination methods \\
\hline $\begin{array}{l}\text { Yagi and } \\
\text { Wakao, } \\
1959\end{array}$ & $\begin{array}{l}\mathrm{Nu}_{\mathrm{w}}=0.6 \cdot \operatorname{Pr}^{1 / 3} \cdot \mathrm{Re}^{0.5} \\
\mathrm{Nu}_{\mathrm{w}}=0.2 \cdot \operatorname{Pr}^{1 / 3} \cdot \operatorname{Re}^{0.8}\end{array}$ & $\begin{array}{l}\text { - } 1<\operatorname{Re}<40 \\
\text { - } 40<\operatorname{Re}<2,000\end{array}$ & Correlation from mass transfer experiments. \\
\hline Beek, 1962 & $\begin{array}{c}\mathrm{Nu}_{\mathrm{w}}=0.203 \cdot \operatorname{Pr}^{1 / 3} \cdot \operatorname{Re}^{1 / 3}+0.220 \cdot \operatorname{Pr}^{0.4} \cdot \operatorname{Re}^{0.8} \\
\mathrm{Nu}_{\mathrm{w}}=2.58 \cdot \operatorname{Pr}^{1 / 3} \cdot \operatorname{Re}^{1 / 3}+0.094 \cdot \operatorname{Pr}^{0.4} \cdot \operatorname{Re}^{0.8}\end{array}$ & $\begin{array}{l}\text { - } \text { Packed bed of sphere-like solids } \\
\text { - } \operatorname{Re}>40 \\
\text { - } \text { Packed bed of cylinder-like solids } \\
\text { - } \operatorname{Re}>40\end{array}$ & $\begin{array}{l}\text { Adaptation to the near wall region of } \\
\text { correlations for fluid/solid HTC. }\end{array}$ \\
\hline $\begin{array}{l}\text { Kunii and } \\
\text { Suzuki, } \\
1968\end{array}$ & $\begin{array}{c}\mathrm{Nu}_{\mathrm{w}}=\frac{0.06}{\varepsilon_{\mathrm{w}}^{2}} \cdot \operatorname{Pr}^{1 / 3} \cdot \mathrm{Re}^{0.75} \\
\text { with } \varepsilon_{\mathrm{w}}{ }^{2}=0.5 \text { for packed beds of spheres (Dixon, 1968) }\end{array}$ & $\begin{array}{l}\text { - Packed bed of spheres } \\
\text { - } \operatorname{Re}>100\end{array}$ & Correlation from mass transfer experiments. \\
\hline $\begin{array}{c}\text { Dixon et al., } \\
1984\end{array}$ & $\mathrm{Nu}_{\mathrm{w}}=\left[1-1.5 \cdot\left(\frac{\mathrm{D}_{\mathrm{s}}}{\mathrm{D}_{\mathrm{b}}}\right)^{1.5}\right] \cdot \operatorname{Pr}^{1 / 3} \cdot \operatorname{Re}^{0.59}$ & - $3.0<\mathrm{D}_{\mathrm{b}} / \mathrm{D}_{\mathrm{s}}<12$ & Correlation from mass transfer experiments. \\
\hline $\begin{array}{l}\text { Tsotsas and } \\
\text { Schlüinder, } \\
1990\end{array}$ & $\mathrm{Nu}_{\mathrm{w}}=\left(1.75 \cdot \frac{1-\varepsilon}{\varepsilon^{3}} \cdot \mathrm{Re}\right)^{0.5}$ & $\begin{array}{l}\text { - Gaseous fluids } \\
\text { - "High" Péclet number }\end{array}$ & $\begin{array}{l}\text { Calculation of the thermal boundary layer } \\
\text { considered equivalent to the dynamic boundary } \\
\text { layer. }\end{array}$ \\
\hline
\end{tabular}

Table 7. Correlations for fluid/wall HTC in packed beds. 


\subsection{Effective thermal conductivity}

The effective thermal conductivity of packed beds has been investigated with various approaches by many authors and quite exhaustive reviews can be found in the literature (Kaviany, 1995; Tsotsas and Martin, 1987; Van Antwerpen et al., 2010; Wakao and Kaguei, 1982). This part aims to point out some key aspects and to present some correlations for the estimation of diffusion phenomena in packed beds. Integration of the effective thermal conductivity into numerical models is also treated.

\subsubsection{Effective thermal conductivity contributions}

The effective thermal conductivity of packed beds can be considered as the sum of three contributions (Bauer, 1990): the first one accounts for the effective thermal conductivity of the packed bed with stagnant fluid, the second one accounts for the contribution of fluid mixing and turbulences (braiding effect) which convey heat through the packed bed and similarly the last one accounts for the motion of solids within the bed. The last contribution won't be treated in this paper since the solids are considered motionless in packed-bed storage systems.

The effective conductivity with stagnant fluid embodies four main heat transfer modes (Van Antwerpen et al., 2010): conduction in solids, conduction in stagnant fluid, conduction through contact surfaces of adjacent solids and radiation between solids. The contributions of conduction in each phase, contact conduction and radiation (respectively $\lambda_{\text {eff }}{ }^{\rho}, \lambda_{e f f}{ }^{C}$ and $\lambda_{e f f}^{R}$ ) may be added to determine the overall stagnant effective conductivity, $\lambda_{e f f}{ }^{0, C, R}$ (IAEA, 2000):

$$
\lambda_{\text {eff }}=\lambda_{\text {eff }}^{0, C, R}+\lambda_{\text {mix }}=\left(\lambda_{\text {eff }}^{0}+\lambda_{\text {eff }}^{\mathrm{C}}+\lambda_{\text {eff }}^{R}\right)+\lambda_{\text {mix }}
$$

\subsubsection{Effective thermal conductivity with stagnant fluid}

Various correlations for effective conductivity of isotropic packed beds of spheroidal solids can be found in the literature.

The simplest ones neglect radiative contribution and contact conduction (only $\lambda_{\text {eff }}{ }^{\rho}$ is therefore considered) and enable to assess the value or the bounds of the effective conductivity from the void fraction and the conductivity of the fluid and the solid. The effective medium theory derived from the work of Maxwell, 1873, enables to calculate these bound values when $\lambda_{s} / \lambda_{f} \geq 1$. Less restrictive bound values can be estimated from the correlations of Deissler and Boegli, 1958, who considered the fluid and the solids to be in parallel (upper bound) or in series (lower bound). A very simple correlation from Nield, 1991, enables to roughly assess the effective thermal conductivity of packed beds thanks to a void fraction-weighted geometric average of the conductivity of the fluid and the solid.

More complete models have been implemented to calculate the effective conductivity with stagnant fluid, $\lambda_{e f f}{ }^{0}$. A semiempirical equation derived from numerical calculation of heat transfer through a bundle of cylinders was developed by Krupiczka, 1967, for the effective conductivity of a packed bed of spheres. Zehner and Schlünder, 1970 (ZS), calculated the effective conductivity of a unit cell comprised of fluid and solid and used results from mass transfer experiments to correlate the influence of the void fraction. This so-called ZS model is a reference and is commonly used in the literature. Hadley, 1986, used the Maxwell upper bound and introduced empirically the influence of the void fraction from experiments on packed beds of disks or powder. Similarly, Gonzo, 2002, empirically included the influence of both void fraction and material conductivities in Maxwell equations.

Radiative heat transfer is nonexistent when the HTF is liquid but may become non-negligible and should be taken into account with gasses, particularly at high temperature with large solids (Kunii and Smith, 1960). Several authors included radiative heat transfer contribution $\lambda_{e f f}{ }^{R}$ in the effective conductivity of packed bed. In the correlation of Kunii and Smith, 1960, radiative heat transfer between two neighboring solids and between two neighboring voids (i.e. between solids not directly in front of each other) are accounted for. Breitbach and Barthels, 1980, and Sih and Barlow, 1995, calculated the radiative contribution thanks to the unit cell approach developed by Zehner and Schlünder, 1970.

The contribution of conduction through contact surfaces $\lambda_{e f f}{ }^{C}$ is negligible when $\lambda_{s} / \lambda_{f}<10^{3}$ (Hsu et al., 1994), which is the case for most packed-bed storage. However some correlations enable to estimate this contribution if needed. Bauer and Shlünder, 1978, completed the ZS model by adding both radiative and contact surfaces contributions. The resulting Zehner, Bauer and Schlünder (ZBS) model, based on an empirical contact area fraction parameter, therefore enables to determine $\lambda_{\text {eff }}^{\rho, C, R}$. Hsu et al., 1994, also proposed a modification of the ZS model by including contact surfaces through an empirical deformation factor. Kaviany, 1995, developed a correlation to estimate the additive contribution of conduction through contact surfaces. While the radius of contact surfaces is calculated according to Hertzian elastic deformation, the number of contact surfaces is calculated by considering randomly packed beds to be a combination of various packing arrangements (simple cubic, body centered cubic or face centered cubic) depending on the void fraction. Hsu et al., 1995, developed three different unit-cell models in which solids are considered to be square cylinders, circular cylinders or cubes with connecting plate or connecting columns to account for conduction through contact surfaces. The authors found that the cube model agrees best with experimental data of a packed-sphere bed. Some of the above mentioned correlations for contact conduction contribution are relatively complex to implement and require many input parameters which can be difficult to know and may introduce additional uncertainties. That's why only the model of Hsu et al., 1994, and the cubic model of Hsu et al., 1995, are developed here. The other models give similar results and further information about them can be found in the review of Van Antwerpen et al., 2010, if needed.

All the above mentioned studies were developed for the core region of a packed bed and can be used in one-dimensional models for packed beds with negligible near-wall effects. For two-dimensional models, a correlation which accounts for radial 
variation of the effective thermal conductivity due to near-wall effects should be used. Van Antwerpen et al., 2009, developed such a correlation which enables to account for radiative contribution and conduction through contact surfaces if needed.

The correlations developed in the above mentioned studies are detailed in Table 8. The correlations which neglect radiative contributions (i.e. which enable to determine $\lambda_{\text {eff }}^{0}$ or $\lambda_{\text {eff }}^{0, C}$ ) are compared in Fig. 20. The correlations of Kunii and Smith, 1960 (with neglected radiative contribution) and Krupiczka, 1967, are not plotted for readability purposes but they both give results close to the ZS model. Experimental results collected in the literature by Kaviany, 1995, are also reproduced. Fig. 20 shows that all the selected correlations and most of the experimental data are within the bound values defined by Maxwell, 1873, and Deissler and Boegli, 1958. At $\lambda_{s} / \lambda_{f}$ ratio lower than $10^{3}$, experimental data and all the selected correlations show similar trend. At $\lambda_{s} / \lambda_{f}$ ratio larger than $10^{3}$, the models which do not account for contact conduction like the ones of Zehner and Schlünder, 1970, and Gonzo, 2002, show increasing discrepancy with experimental results. On the contrary, the correlations which account for contact conduction like the ones of Hsu et al., 1994, and Hsu et al., 1995, fit quite well with experimental data. It is interesting to note that the correlation of Hadley, 1986, manages to reproduce experimental results at high $\lambda_{s} / \lambda_{f}$ ratio while the contact conduction is a priori not taken into account (since it derives from Maxwell equations). This may be due to the very empirical approach which captured the contact conduction contribution. As a consequence, the relatively simple and well-known ZS model can be used for $\lambda_{s} / \lambda_{f}$ ratio lower than $10^{3}$, while correlations which account for contact conduction should be used for larger $\lambda_{s} / \lambda_{f}$ ratio. In typical rock beds, $\lambda_{s} / \lambda_{f}$ ratio ranges from unity to several tens with liquids and from several tens to several hundred with air.

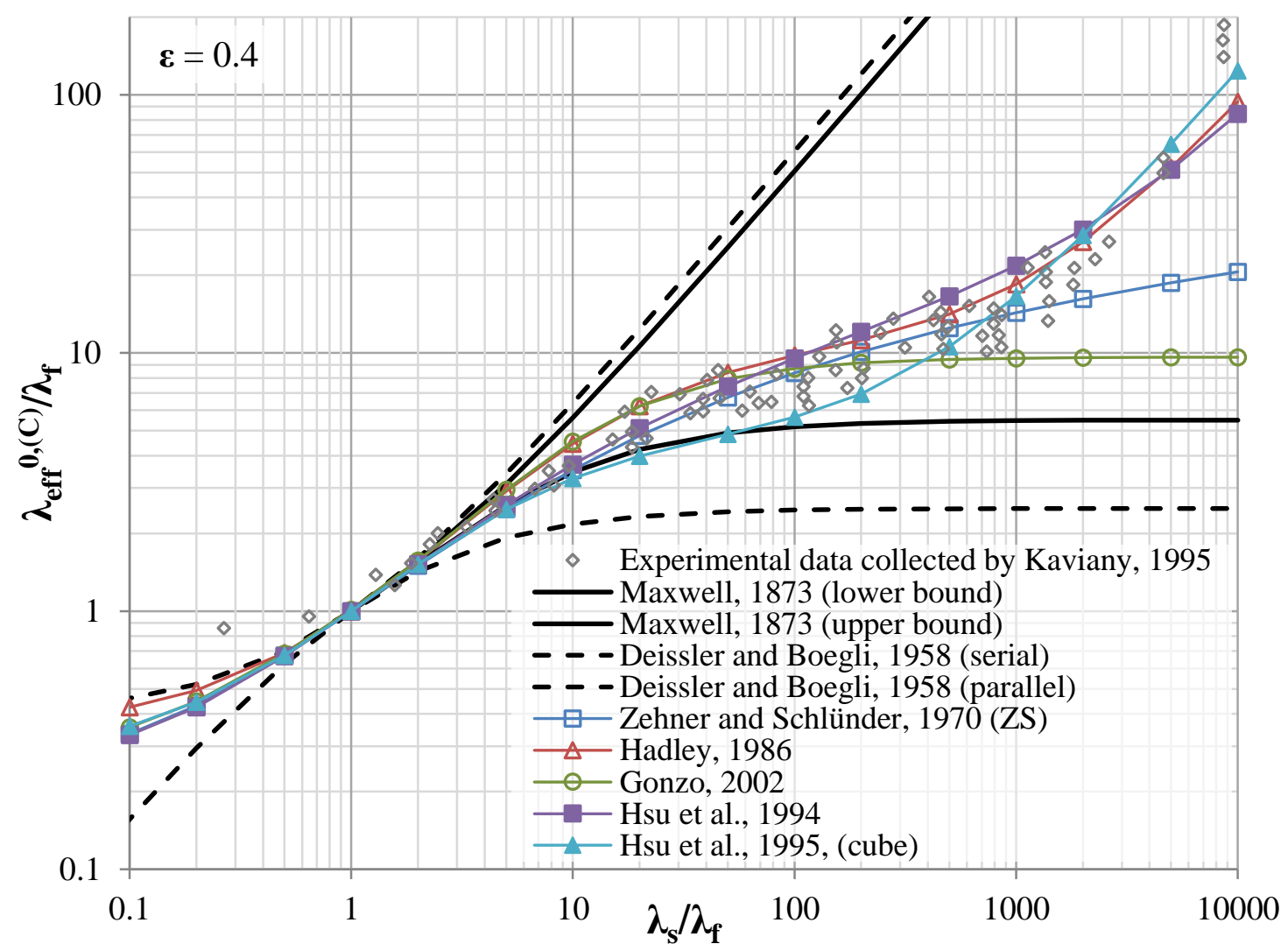

Fig. 20. Comparison of correlations of stagnant effective thermal conductivity of packed-sphere bed without radiative contribution (contact conduction is included or not depending on the correlation).

The relative contribution of radiative heat transfer in various conditions is illustrated in Fig. 21 with the correlation of Breitbach and Barthels, 1980. The correlations of Sih and Barlow, 1995, or Kunii and Smith, 1960, show similar trends (excepted that the latter is insensible to solid conductivity). The figure shows that radiative contribution depends mainly on solid diameter and temperature. Solid conductivity and emissivity also influence the radiative contribution but their influence is smaller since they are unlikely to vary a lot from one packed bed to the other. The influence of void fraction (not plotted) is even lower since it is unlikely to be lower than 0.25 or higher than 0.5 for usual packed beds. 


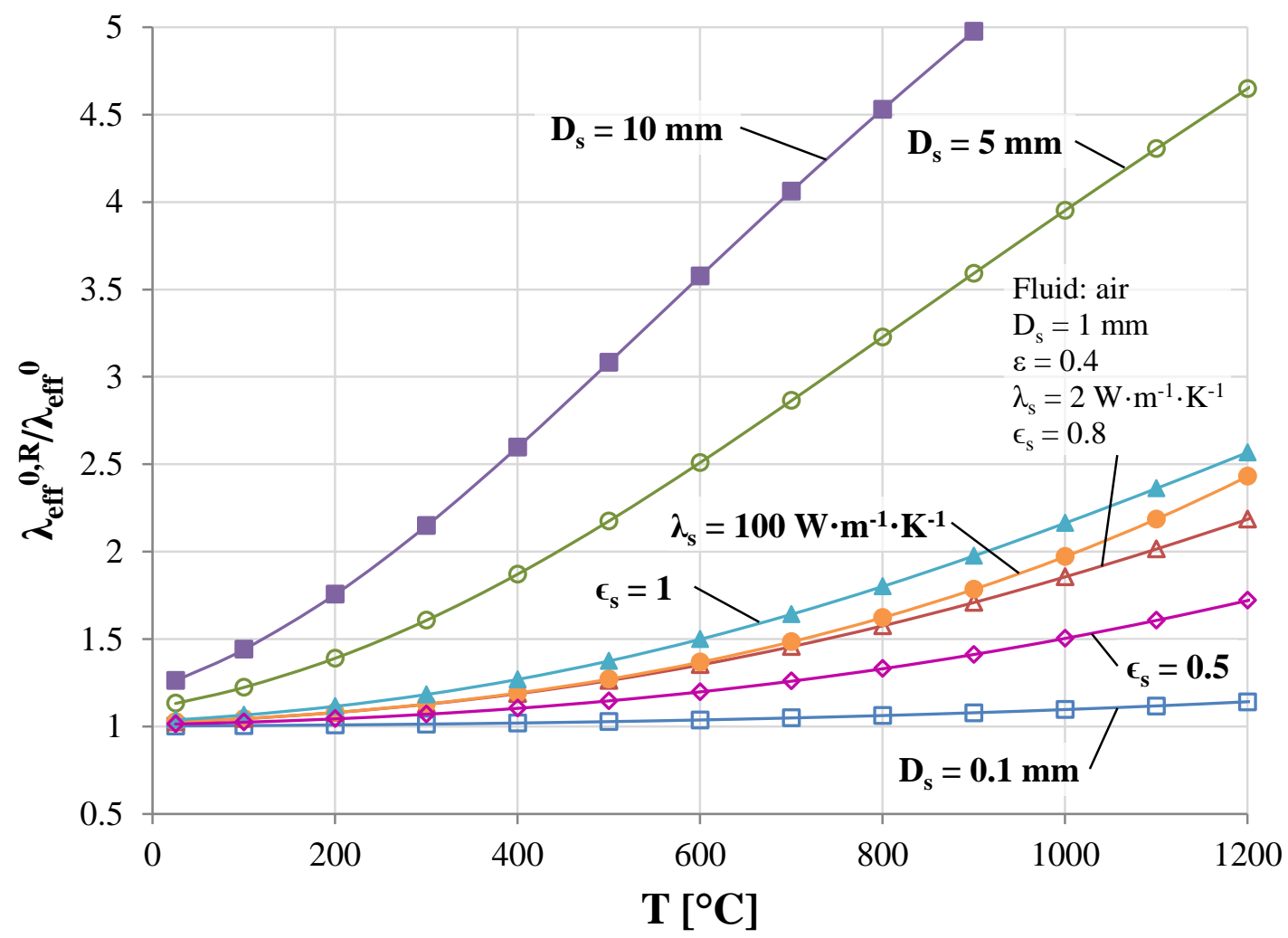

Fig. 21. Influence of various parameters on the relative contribution of radiative heat transfer according to the correlation of Breitbach and Barthels, 1980.

\subsubsection{Contribution of fluid mixing and turbulences}

The contribution of fluid mixing $\lambda_{\text {mix }}$ can be added to the stagnant effective conductivity $\lambda_{e f f}{ }^{0, C, R}$. This contribution is not the same in axial and radial directions (respectively parallel and perpendicular to flow direction) and is given by (Wakao and Kaguei, 1982):

$$
\begin{aligned}
& \frac{\lambda_{\text {mix }, \mathrm{z}}}{\lambda_{\mathrm{f}}}=0,5 \cdot \mathrm{Re} \cdot \operatorname{Pr} \\
& \frac{\lambda_{\mathrm{mix}, \mathrm{r}}}{\lambda_{\mathrm{f}}}=0,1 \cdot \mathrm{Re} \cdot \operatorname{Pr}
\end{aligned}
$$

According to equations (28) and (29), effective conductivity of the mixing contribution can be as high as several dozens of times the fluid conductivity for typical packed-bed storage systems, particularly with molten salts. In two-dimensional models, the inhibition of radial mixing due to the wall should be considered in the near wall-region (i.e. at less than one particle radius from the wall). This inhibition is due to lower fluid velocity caused by the higher local void fraction, the permanent barrier to fluid movement which discourages radial displacement of fluid parcels toward the wall and the viscous boundary layer on the surface of the wall. As a consequence, radial mixing in the near-wall region may be considered to be ten times smaller than in the core region and a coefficient of 0.01 instead of 0.1 can be used in equation (29) (Baddour and Yoon, 1961). Axial mixing in the near-wall region is not clear but it seems that equation (28) can be applied over the whole cross section (Tsotsas and Schlünder, 1990).

\subsubsection{Integration of effective thermal conductivity in models}

Correlations of effective thermal conductivity enable to determine the conductivity of the whole packed bed. This is therefore suitable for intraparticle conduction models (equations (19) and (22)) which require only the whole effective conductivity $\lambda_{\text {eff. }}$ This is also appropriate for single-phase models (equations (8) and (9)), in which the second space derivatives of the fluid and the solid temperatures are considered equal, since the conductivity of the whole media can be reasonably considered to be the sum of the effective conductivity of the fluid phase $\lambda_{\text {eff. } f}$ and the effective conductivity of the solid phase $\lambda_{\text {eff,s: }}$ 


$$
\lambda_{\text {eff }}=\lambda_{\text {eff,f }}+\lambda_{\text {eff,s }}
$$

For two-phase models, two methods can be applied. Since second space derivatives of the fluid and the solid temperatures can be assumed close to each other, the simplest method consists in simply including a single diffusion term, either in the fluidphase or the solid-phase equation with the whole effective thermal conductivity $\lambda_{\text {eff }}$ of the bed (Gunn and Vortmeyer, 1982). This approach is similar to what proposed Wakao et al., 1979, for intraparticle conduction models (cf. 3.2).

The second method consists in sharing out the effective thermal conductivity contributions between the fluid and the solid phases. If conduction through contact surfaces and radiative contribution are accounted for, they should be included in the solid effective conductivity since these contributions depend on the solid thermal gradient. Conversely, the contribution of fluid mixing $\lambda_{\text {mix }}$ has to be included in the fluid effective conductivity. Single conduction in each phase modeled by $\lambda_{e f f}{ }^{p}$ is more difficult to separate since it accounts for the combination of conduction in solid and fluid phases. As shown by Hueppe, 2011, the effective conductivity due to single conduction in each phase can be expressed as:

$$
\begin{gathered}
\lambda_{\mathrm{eff}, \mathrm{f}}^{0}=\varepsilon \cdot \lambda_{\mathrm{f}}+\mathrm{f} \cdot \lambda_{\mathrm{f}} \\
\lambda_{\text {eff,s }}^{0}=(1-\varepsilon) \cdot \lambda_{\mathrm{s}}-\mathrm{f} \cdot \lambda_{\mathrm{s}}
\end{gathered}
$$

The coefficient $f$ accounts for the tortuosity of the bed and depends on many parameters. This term can be used to share out the whole effective conductivity between the two phases. Since equation (30) can be reasonably assumed true even in twophase models, then:

$$
\mathrm{f}=\frac{\left(\lambda_{\text {eff } \mathrm{f}}^{0}+\lambda_{\text {eff,s }}^{0}\right)-\varepsilon \cdot \lambda_{\mathrm{f}}-(1-\varepsilon) \cdot \lambda_{\mathrm{s}}}{\lambda_{\mathrm{f}}-\lambda_{\mathrm{s}}} \cong \frac{\lambda_{\text {eff }}^{0}-\varepsilon \cdot \lambda_{\mathrm{f}}-(1-\varepsilon) \cdot \lambda_{\mathrm{s}}}{\lambda_{\mathrm{f}}-\lambda_{\mathrm{s}}}
$$

As a result, the effective conductivity of each phase may be expressed as follows:

$$
\begin{gathered}
\lambda_{\text {eff, }} \cong\left[\varepsilon \cdot \lambda_{\mathrm{f}}+\mathrm{f} \cdot \lambda_{\mathrm{f}}\right]+\lambda_{\text {mix }} \\
\lambda_{\text {eff,s }} \cong\left[(1-\varepsilon) \cdot \lambda_{\mathrm{s}}-\mathrm{f} \cdot \lambda_{\mathrm{s}}\right]+\lambda_{\text {eff }}^{\mathrm{R}}+\lambda_{\text {eff }}^{\mathrm{C}}
\end{gathered}
$$

The coefficient $f$ is determined thanks to equation (33) and correlations of $\lambda_{e f f}{ }^{0}$ like the ZS model. The mixing contribution $\lambda_{\text {mix }}$ may be calculated with equations (28) or (29) according to the direction considered. The radiative contribution $\lambda_{\text {eff }}^{R}$ may be determined thanks to the correlations of Sih and Barlow, 1995 or Breitbach and Barthels, 1980. The single contribution of contact conduction may be determined thanks to the correlation from Kaviany, 1995, or by subtracting $\lambda_{\text {eff }}^{0}$ from $\lambda_{\text {eff }}^{0, C}$. (determined with correlations like the ones of Bauer and Shlünder, 1978, Hsu et al., 1994, or Hsu et al., 1995). It should be noticed that radiative contribution $\lambda_{\text {eff }}^{R}$ in equation (35) disappears if liquid HTF are considered.

The two above mentioned methods for integration of the effective thermal conductivity must lead to similar results since heat exchange between the fluid and the solids generally prevails over heat exchange inside each phase (i.e. diffusion) as assumed by Schumann, 1929. However this point should be validated with dedicated simulations. 


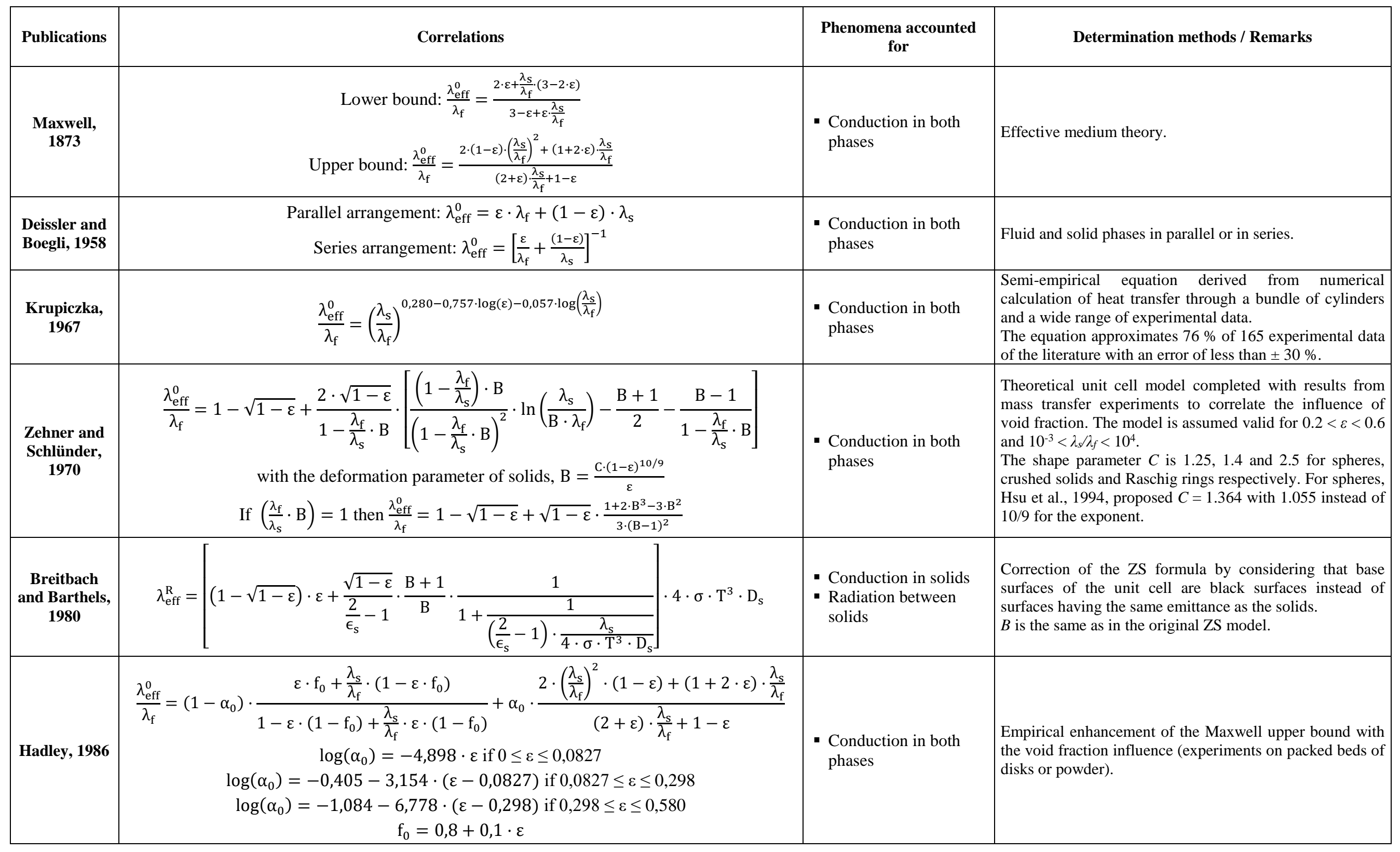




\begin{tabular}{|c|c|c|c|}
\hline $\begin{array}{l}\text { Hsu et al., } \\
1994\end{array}$ & $\begin{aligned} \frac{\lambda_{\text {eff }}^{0, C}}{\lambda_{f}}=(1-\sqrt{1-\varepsilon})+\frac{\lambda_{s}}{\lambda_{f}} \cdot \sqrt{1-\varepsilon} \cdot\left(1-\frac{1}{(1+\alpha \cdot B)^{2}}\right)+\frac{2 \cdot \sqrt{1-\varepsilon}}{1-\frac{\lambda_{f}}{\lambda_{s}} \cdot B+\left(1-\frac{\lambda_{f}}{\lambda_{s}}\right) \cdot \alpha \cdot B} \\
\quad \cdot\left[\frac{\left(1-\frac{\lambda_{f}}{\lambda_{s}}\right) \cdot(1+\alpha) \cdot B}{\left[1-\frac{\lambda_{f}}{\lambda_{s}} \cdot B+\left(1-\frac{\lambda_{f}}{\lambda_{s}}\right) \cdot \alpha \cdot B\right]^{2}} \cdot \ln \left[\frac{1+\alpha \cdot B}{\left.(1+\alpha) \cdot B \cdot \frac{\lambda_{f}}{\lambda_{s}}\right]-\frac{B+1+2 \cdot \alpha \cdot B}{2 \cdot(1+\alpha \cdot B)^{2}}}\right.\right. \\
\left.\quad-\frac{(B-1)}{\left[1-\frac{\lambda_{f}}{\lambda_{s}} \cdot B+\left(1-\frac{\lambda_{f}}{\lambda_{s}}\right) \cdot \alpha \cdot B\right] \cdot(1+\alpha \cdot B)}\right] \\
\text { with } \alpha=0.002 \text { and B so that: } 1-\varepsilon-\frac{B^{2}}{(1-B)^{6} \cdot(1+\alpha \cdot B)^{2}} \cdot\left[\left(B^{2}-4 \cdot B+3\right)+2 \cdot(1+\alpha) \cdot\right. \\
\left.(1+\alpha \cdot B) \cdot \ln \left[\frac{(1+\alpha) \cdot B}{1+\alpha \cdot B}\right]+\alpha \cdot(B-1) \cdot\left(B^{2}-2 B-1\right)\right]^{2}=0\end{aligned}$ & $\begin{array}{l}\text { - Conduction in both } \\
\text { phases } \\
\text { - Conduction through } \\
\text { contact surfaces } \\
\text { between solids }\end{array}$ & $\begin{array}{l}\text { Enhancement of the ZS unit cell model by addition of } \\
\text { contact surfaces between solids which are taken into } \\
\text { account through the empirical deformed factor } \alpha \text {. }\end{array}$ \\
\hline $\begin{array}{l}\text { Hsu et al., } \\
1995\end{array}$ & 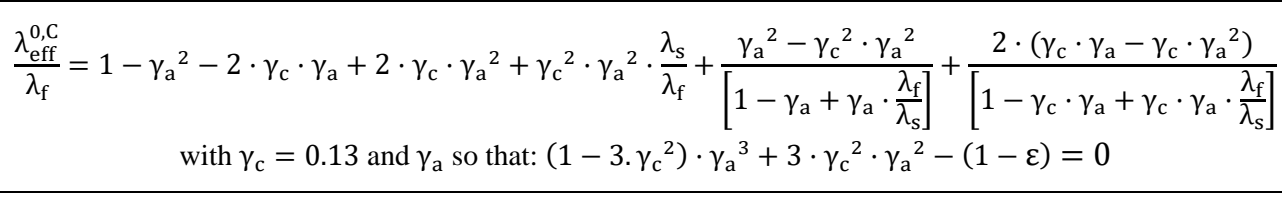 & $\begin{array}{l}\text { - Conduction in both } \\
\text { phases } \\
\text { - Conduction through } \\
\text { contact surfaces } \\
\text { between solids }\end{array}$ & $\begin{array}{l}\text { Theoretical unit cell model in which solids are assumed } \\
\text { cubic and contact surfaces are modeled with square } \\
\text { connecting column, the relative dimensions of which ( } \gamma_{a} \\
\text { and } \gamma_{c} \text { ) are empirically determined. }\end{array}$ \\
\hline $\begin{array}{c}\text { Sih and } \\
\text { Barlow, } 1995\end{array}$ & $\lambda_{\mathrm{eff}}^{\mathrm{R}}=[(1-\sqrt{1-\varepsilon}) \cdot \varepsilon+\sqrt{1-\varepsilon}] \cdot 4 \cdot\left(\frac{2}{\frac{2}{\epsilon_{\mathrm{s}}}-0.264}\right) \cdot \sigma \cdot \mathrm{T}^{3} \cdot \mathrm{D}_{\mathrm{s}}$ & $\begin{array}{l}\text { - Conduction in solids } \\
\text { - Radiation between } \\
\text { solids }\end{array}$ & $\begin{array}{l}\text { Addition in the ZS model of radiation term from } \\
\text { Damköhler, 1937, with the view factor calculated } \\
\text { according to Wakao and Kato, } 1969 \text {. }\end{array}$ \\
\hline Gonzo, 2002 & $\begin{array}{c}\frac{\lambda_{\text {eff }}^{0}}{\lambda_{\mathrm{f}}}=\frac{1+2 \cdot \beta \cdot(1-\varepsilon)+\left(2 \cdot \beta^{3}-0,1 \cdot \beta\right) \cdot(1-\varepsilon)^{2}+(1-\varepsilon)^{3} \cdot 0,05 \cdot \exp (4,5 \cdot \beta)}{1-\beta \cdot(1-\varepsilon)} \\
\text { with } \beta=\frac{\lambda_{s}-\lambda_{f}}{\lambda_{s}+2 \cdot \lambda_{f}}\end{array}$ & $\begin{array}{l}\text { - Conduction in both } \\
\text { phases }\end{array}$ & $\begin{array}{l}\text { Empirical enhancement of the Maxwell equation with the } \\
\text { void fraction and the conductivity influences. The model is } \\
\text { assumed valid for } 0.15<\varepsilon<0.85 \text { and } 10^{-3}<\lambda_{s} / \lambda_{f}<10^{4} \text {. } \\
\text { Compared to } 35 \text { experimental data of the literature, the } \\
\text { mean deviation is } 10.6 \%(+55 \% /-23 \%) \text {. }\end{array}$ \\
\hline
\end{tabular}

Table 8. Correlations of stagnant effective thermal conductivity in packed beds. 


\subsection{Pressure losses}

Fluid flow through a packed bed induces pressure losses. It could be useful to calculate pressure losses to size the installation or to estimate pumping costs. This issue should be carefully addressed when gas is used as HTF since high pressure losses may require the use of compressors instead of fans and hence pressure resistant equipment, which means a significant installation cost increase.

\subsubsection{The Ergun equation}

The Ergun equation (Ergun, 1952) is a reference for calculation of pressure losses through packed beds. This equation associates the Kozeny-Carman equation which was developed by Carman, 1937, from the work of Kozeny, 1927, for lowly to moderately porous media, and the Burke-Plummer equation (Burke and Plummer, 1928) which was developed for highly porous media. The Ergun equation is the sum of a viscous term, corresponding to the Kozeny-Carman equation, and an inertial term, corresponding to the Burke-Plummer equation. They are respectively represented by the left-hand term and the righthand term in (36). Each term corresponds to an asymptotic behavior of the Ergun equation and their combination enables to treat intermediate cases.

$$
\frac{\Delta \mathrm{P}}{\mathrm{L}}=\mathrm{A} \cdot \frac{(1-\varepsilon)^{2}}{\varepsilon^{3}} \cdot \frac{\mu_{\mathrm{f}} \cdot \mathrm{u}_{\mathrm{sup}}}{\mathrm{D}_{\mathrm{s}}{ }^{2}}+\mathrm{B} \cdot \frac{(1-\varepsilon)}{\varepsilon^{3}} \cdot \frac{\rho_{\mathrm{f}} \cdot \mathrm{u}_{\mathrm{sup}}{ }^{2}}{\mathrm{D}_{\mathrm{s}}}
$$

$A$ and $B$ are empirical constants determined by Ergun:

$$
\begin{array}{ll}
\mathrm{A}=150 \quad \mathrm{~B}=1.75
\end{array}
$$

\subsubsection{Enhancement of the Ergun equation}

For packed beds of spherical solids, the validity of the Ergun equation has been confirmed by several authors (Lakota et al., 2002; Nemec and Levec, 2005). However numerous authors disputed the value or the constancy of parameters $A$ and $B$, particularly when the solids are not spherical. While several authors fitted the value of the constants with experimental results (Handley and Heggs, 1968; Lakota et al., 2002; Yu et al., 2002), others give correlations to calculate $A$ and $B$ according to various parameters (Achenbach, 1995; Foumeny et al., 1996; Hicks, 1970; Macdonald et al., 1979; Nemec and Levec, 2005). Particularly, the inertial parameter $B$ seems to depend on the shape of the solids, since it accounts for pressure losses due to the tortuosity of the flow (Handley and Heggs, 1968; Lakota et al., 2002). This affirmation was strengthened by several experimental results (Achenbach, 1995; Allen et al., 2015; Foumeny et al., 1996; Macdonald et al., 1979). Du Plessis and Woudberg, 2008, theoretically validated the empirical Ergun equation for packed beds of uniform spherical granules with a unit cell model. This model is therefore applicable over the entire void fraction range. Some correlations were specifically developed for rock beds (Allen et al., 2015; Chandra and Willits, 1981; Dunkle and Ellul, 1972; Hollands and Sullivan, 1984) but they may be limited to the experimental conditions for which they were established.

In accordance with what proposed Ergun, 1952, when the solids are not spherical and/or not uniform in size, most authors implement the Ergun equation and calculate the Reynolds number with the diameter of the sphere of equivalent specific area $D_{\text {eq,a }}$ as expressed by equation (37) (Allen et al., 2015; Du Plessis and Woudberg, 2008; Foumeny et al., 1996; Hollands and Pott, 1971; Lakota et al., 2002; Macdonald et al., 1979; Martin, 2005; Nemec and Levec, 2005; Rose and Rizk, 1949). However, for irregular solids like gravels, the external surface area is difficult to measure. That's why some authors use the diameter of the sphere of equivalent volume $D_{e q, V}$ which is easier to determine and is expressed by equation (38) (Allen et al., 2015; Chandra and Willits, 1981; Dunkle and Ellul, 1972; Singh et al., 2006). An alternative approach expressed by equation (39) and based on masses of solids was proposed by Hollands and Sullivan, 1984. According to the authors, this representative diameter $D_{e q, a}$ ' is similar to the diameter of equivalent specific area defined in (37) but altered from that one to simplify its determination. Ideally, the sums in equations (37), (38) and (39) should be taken over all solids in the bed, but may be taken only over a representative number $N$ (Hollands and Pott, 1971).

$$
\begin{gathered}
\mathrm{D}_{\mathrm{eq}, \mathrm{a}}=6 \cdot \frac{\sum_{\mathrm{i}}^{\mathrm{N}} \mathrm{V}_{\mathrm{s}, \mathrm{i}}}{\sum_{\mathrm{i}}^{\mathrm{N}} \mathrm{A}_{\mathrm{s}, \mathrm{i}}} \\
\mathrm{D}_{\mathrm{eq}, \mathrm{V}}=\left(\frac{6}{\pi} \cdot \frac{\sum_{\mathrm{i}}^{\mathrm{N}} \mathrm{V}_{\mathrm{s}, \mathrm{i}}}{\mathrm{N}}\right)^{1 / 3} \\
\mathrm{D}_{\mathrm{eq}, \mathrm{a}}^{\prime}=\left(\frac{6}{\pi} \cdot \frac{1}{\rho_{\mathrm{s}}}\right)^{1 / 3} \cdot \frac{\sum_{\mathrm{i}}^{\mathrm{N}} \mathrm{m}_{\mathrm{s}, \mathrm{i}}}{\sum_{\mathrm{i}}^{\mathrm{N}} \mathrm{m}_{\mathrm{s}, \mathrm{i}}{ }^{2 / 3}}
\end{gathered}
$$


An enhanced Ergun-type equation was proposed by Bruch et al., 2014a, for packed beds with two very different sizes of solids. For example, when a packed bed is comprised of stones with void spaces completely filled with sand, they assumed that both the stones and the sand influence the interstitial velocity $\left(u_{s u p} / \varepsilon\right)$ of the fluid by reduction of the available cross section but only the sand is directly responsible for pressure losses. As a consequence, the interstitial velocity is calculated with the global void fraction ( $\left.\varepsilon_{\text {global }}\right)$ of the bed comprised of stones and sand, while the void fraction of the sand only $\left(\varepsilon_{\text {sand }}\right)$ is used in the Ergun equation. Without changing the original values of $A$ and $B$, the resulting equation (40) predicted experimental pressure losses of a packed bed of $3-\mathrm{mm}$ sand and 30-mm rocks with an error less than $+5 \% /-15 \%$.

$$
\frac{\Delta \mathrm{P}}{\mathrm{L}}=\mathrm{A} \cdot \frac{\left(1-\varepsilon_{\text {sand }}\right)^{2}}{\varepsilon_{\text {sand }}{ }^{2}} \cdot \frac{\mu_{\mathrm{f}}}{\mathrm{D}_{\text {sand }}{ }^{2}} \cdot\left(\frac{\mathrm{u}_{\text {sup }}}{\varepsilon_{\text {global }}}\right)+\mathrm{B} \cdot \frac{\left(1-\varepsilon_{\text {sand }}\right)}{\varepsilon_{\text {sand }}} \cdot \frac{\rho_{\mathrm{f}}}{\mathrm{D}_{\text {sand }}} \cdot\left(\frac{\mathrm{u}_{\text {sup }}}{\varepsilon_{\text {global }}}\right)^{2}
$$

Ergun-type equations don't enable to account for near-wall effects due to higher local void fraction close to the walls, and which may affect overall pressure losses of the bed. In order to account for near-wall effects, Rose and Rizk, 1949, constructed a chart (Fig. 22) to determine the correction factor which should be applied to pressure losses of an infinite bed according to the tank-to-particle diameter ratio and the Reynolds number. The influence of near-wall effects on pressure drops was also pointed out by Foumeny et al., 1996, while Nemec and Levec, 2005, considered it to be negligible when the tank-to-particle diameter ratio is larger than 10, which was already suggested by Ergun, 1952.

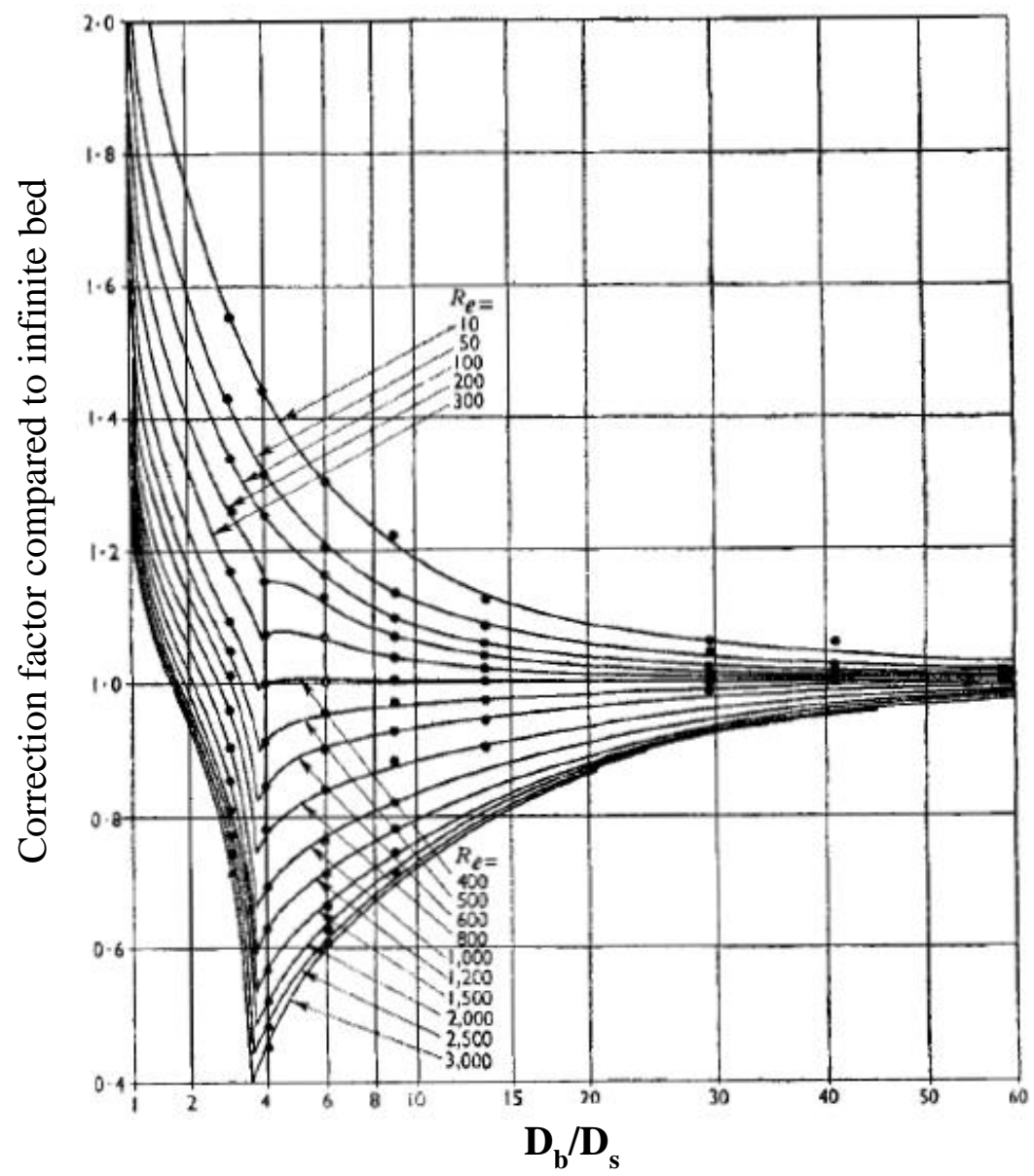

Fig. 22. Correction factor to account for near-wall effects on pressure losses according to the tank-to-particle diameter ratio and the particle Reynolds number. Established for packed bed of spheres but valid for other particle shapes according to the authors (Rose and Rizk, 1949).

\subsubsection{Particular considerations for rock beds}

Hollands and Sullivan, 1984, pointed out the influence of dust on pressure losses in air/rock beds: with unwashed gravels, they measured pressure losses more than twice as high as pressure losses with washed gravels. The presence of dust should therefore be taken into account in air/rock beds and could be responsible for some large scattering in experimental results of the literature. In addition, even with washed gravels, dust may be generated over the storage utilization due to friction caused by thermal expansion and contraction of the solids. 
Allen et al., 2015, showed the influence of the direction in which the rocks were poured into the test section relative to the fluid flow direction. When rocks are not perfectly spherical, ellipsoidal rocks tend to get into position parallel to the bottom of the tank. As a consequence, if the flow direction is the same as the one in which the rocks were poured (co/counter-current), pressure losses may be as $80 \%$ higher as if a perpendicular flow direction is adopted (cross-current). Moreover, the experimental data of the authors tend to show that rearrangement of the rocks due to their expansion/shrinkage caused by thermal solicitations can irreversibly increase pressure losses of the bed (by about 15-20\%).

\subsubsection{Comparison of some correlations}

Some correlations of pressure drop in packed beds are detailed in Table 9. To simplify the writing, they are given in the form of friction factor, $f_{v}$. The column "scope of validity" only indicates what have been explicitly mentioned by the authors. Some of the selected correlations are plotted versus the Reynolds number in Fig. 23. The figure shows that the Ergun equation and the correlation of Du Plessis and Woudberg, 2008, (which aims to generalize the Ergun equation), give very similar results. The correlations of Achenbach, 1995, Lakota et al., 2002, for spheres and Yu et al., 2002, (which were not plotted for readability purposes) also give similar results. Almost all the other correlations which were developed for non-spherical solids result in higher friction factor than the Ergun equation. The correlation of Chandra and Willits, 1981, is not plotted but gives results very similar to the correlation of Dunkle and Ellul, 1972. Correlations given by Lakota et al., 2002, for porous cylinders and Raschig rings give friction factor between the one for porous extrudates and the Ergun equation.

In Fig. 23, it should be noticed that the correlations are compared only for a given void fraction $(\varepsilon=0.4)$. According to the Ergun equation, pressure drop increases with the decrease in void fraction. This trend is represented by all correlations with varying degree except for the one of Dunkle and Ellul, 1972, which is not related at all with void fraction, which is unlikely to be physically correct.

To sum up, pressure losses can be estimated thanks to the Ergun equation in a first approach for spherical granules of uniform size with "standard" void fractions $(0.35<\varepsilon<0.5)$. When the shape of solids is very irregular the correlations of Macdonald et al., 1979, which were tested over a wide range of shape and void fraction may be used. Finally, when solids of two very different sizes are used, the approach developed by Bruch et al., 2014a, should be considered.

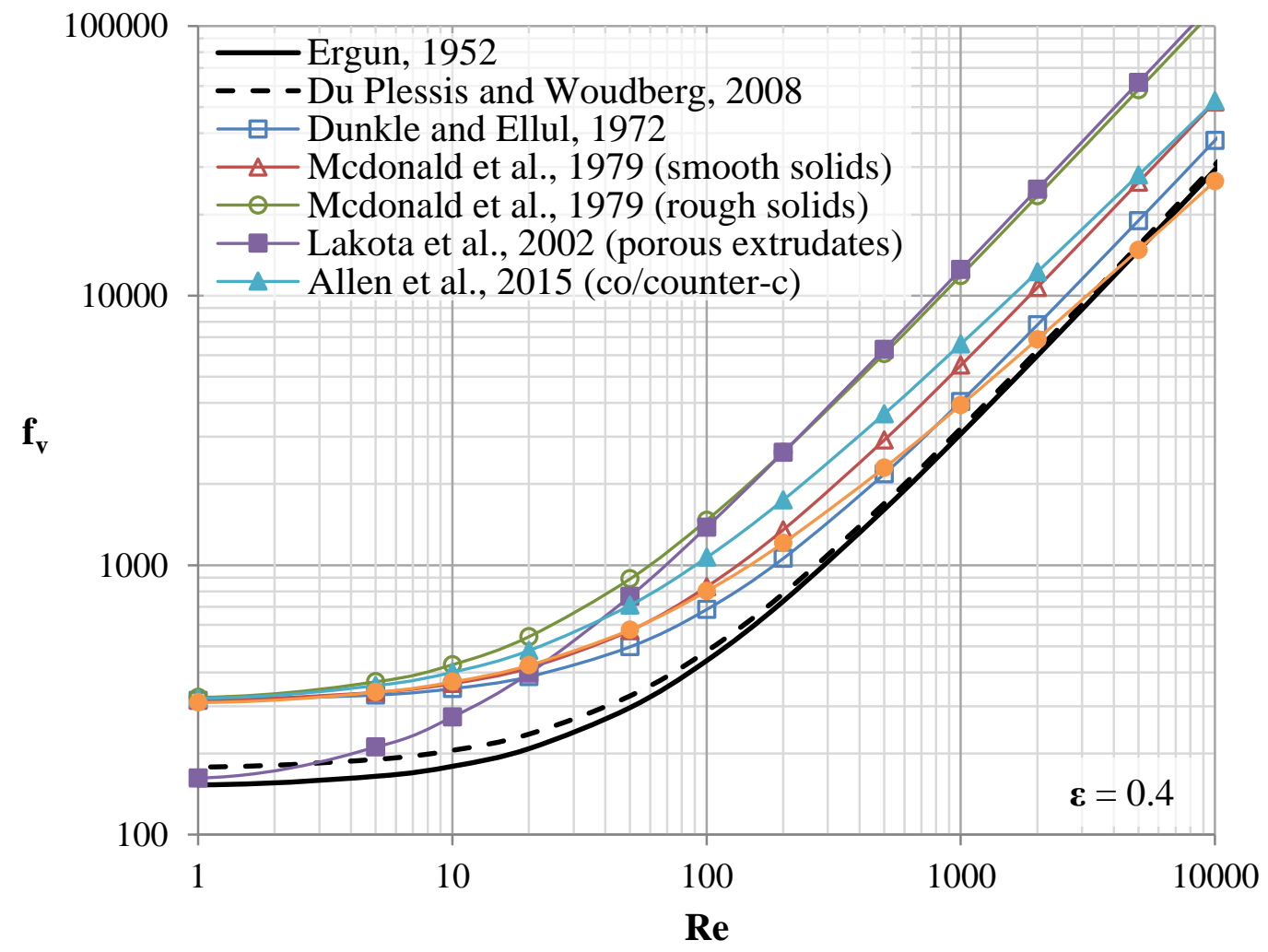

Fig. 23. Comparison of several correlations of pressure losses in packed beds. 


\begin{tabular}{|c|c|c|c|}
\hline Publications & Correlations & Scope of validity & Determination methods / Remarks \\
\hline Ergun, 1952 & $f_{v}=150+1.75 \cdot\left[\frac{\operatorname{Re}_{e q, a}}{1-\varepsilon}\right]$ & - & $\begin{array}{l}\text { Combination of the Kozeny-Carman and the Burke- } \\
\text { Plummer equations with empirical determination of the } \\
\text { constants } A \text { and } B \text { from } 640 \text { experiments with various- } \\
\text { sized spheres, sand, pulverized coke, and } \mathrm{CO}_{2}, \mathrm{~N}_{2}, \mathrm{CH}_{4} \\
\text { and } \mathrm{H}_{2} \text {. }\end{array}$ \\
\hline $\begin{array}{c}\text { Dunkle and } \\
\text { Ellul, } 1972\end{array}$ & $f_{v}=1750 \cdot \frac{\varepsilon^{3}}{(1-\varepsilon)^{2}}+21 \cdot \frac{\varepsilon^{3}}{(1-\varepsilon)} \cdot\left[\frac{\operatorname{Re}_{e q, v}}{1-\varepsilon}\right]$ & $\begin{array}{l}\text { - Rock beds } \\
\text { - } 1<\operatorname{Re}_{\mathrm{eq}, \mathrm{V}}<10^{5}\end{array}$ & Experimental data on air/rock bed. \\
\hline $\begin{array}{l}\text { Chandra and } \\
\text { Willits, } 1981\end{array}$ & $\mathrm{f}_{\mathrm{v}}=185 \cdot \frac{\varepsilon^{0.4}}{(1-\varepsilon)^{2}}+1.7 \cdot \frac{\varepsilon^{0.4}}{(1-\varepsilon)} \cdot\left[\frac{\mathrm{Re}_{\mathrm{eq}, \mathrm{v}}}{1-\varepsilon}\right]$ & $\begin{array}{l}\text { - } 0.3<\varepsilon<0.5 \\
\text { - } 1<\operatorname{Re}_{\mathrm{eq}, \mathrm{V}}<1000\end{array}$ & $\begin{array}{l}\text { Experimental data with air and washed river gravel and } \\
\text { crushed granite }(0.38<\varepsilon<0.46 \text { and } \\
\left.9.9 \mathrm{~mm}<D_{e q, V}<26.9 \mathrm{~mm}\right) \text {. } \\
\text { Mean deviation of } 8 \% \text { between the correlation and } \\
\text { experimental data. }\end{array}$ \\
\hline $\begin{array}{c}\text { Lakota et al., } \\
2002\end{array}$ & $\begin{array}{c}\text { Spheres: } f_{v}=150+1.75 \cdot\left[\frac{R e_{e q, a}}{1-\varepsilon}\right] \\
\text { Porous cylinders: } f_{v}=150+3 \cdot\left[\frac{R e_{e q, a}}{1-\varepsilon}\right] \\
\text { Porous extrudates: } f_{v}=150+7.4 \cdot\left[\frac{R e_{e q, a}}{1-\varepsilon}\right] \\
\text { Raschig rings: } f_{v}=150+6 \cdot\left[\frac{R_{e} e_{e, a}}{1-\varepsilon}\right]\end{array}$ & - & $\begin{array}{l}\text { Experimental data with air and spheres, cylinders, } \\
\text { extrudates, and Raschig rings }(0.375<\varepsilon<0.580 \text { and } \\
\left.3 \mathrm{~mm}<D_{e q, a}<6 \mathrm{~mm}\right) \text {. } \\
\text { Mean deviation between } 5.3 \% \text { and } 10.5 \% \text { for spheres, } \\
\text { and } 4.4 \% \text { and } 15.3 \% \text { for the other shapes compared to } \\
\text { experimental data. }\end{array}$ \\
\hline $\begin{array}{l}\text { Du Plessis } \\
\text { and } \\
\text { Woudberg, } \\
2008\end{array}$ & $\mathrm{f}_{\mathrm{v}}=25.4 \cdot \frac{\varepsilon^{3}}{(1-\varepsilon)^{\frac{2}{3}} \cdot\left[1-(1-\varepsilon)^{\frac{1}{3}}\right] \cdot\left[1-(1-\varepsilon)^{\frac{2}{3}}\right]^{2}}+1.9 \cdot \frac{\varepsilon^{2}}{2 \cdot\left[1-(1-\varepsilon)^{\frac{2}{3}}\right]^{2}} \cdot\left[\frac{\operatorname{Re}_{\text {eq,a }}}{1-\varepsilon}\right]$ & $\begin{array}{l}\text { - Uniformly sized } \\
\text { spherical granules }\end{array}$ & $\begin{array}{l}\text { Modeling of the bed with representative unit cells } \\
\text { composed of fluid volumes occupied by a cubic solid } \\
\text { particle. }\end{array}$ \\
\hline $\begin{array}{l}\text { Allen et al., } \\
2015\end{array}$ & $\begin{array}{c}\text { Co/counter-current (cf. 4.4.3) with } 9 \mathrm{~mm}<D_{e q, V}<49 \mathrm{~mm} \text { : } \\
\mathrm{f}_{\mathrm{v}}=310+6.85 \cdot\left[\frac{1-\varepsilon}{\mathrm{Re}_{\mathrm{eq}, \mathrm{V}}}\right]^{0.08} \cdot\left[\frac{\mathrm{Re}_{\mathrm{eq}, \mathrm{V}}}{1-\varepsilon}\right] \\
\text { Cross-current (cf. 4.4.3) with } 9 \mathrm{~mm}<D_{e q, V}<30 \mathrm{~mm}: \\
\mathrm{f}_{\mathrm{v}}=300+6.15 \cdot\left[\frac{1-\varepsilon}{\operatorname{Re}_{\mathrm{eq}, \mathrm{V}}}\right]^{0.14} \cdot\left[\frac{\mathrm{Re}_{\mathrm{eq}, \mathrm{V}}}{1-\varepsilon}\right]\end{array}$ & $\begin{array}{l}\text { - Crushed rocks } \\
\text { - Negligible buoyancy } \\
\text { effects }\end{array}$ & $\begin{array}{l}\text { Experimental data with air and crushed rock in } \\
\text { co/counter- or cross-current configuration } \\
\left(0.38<\varepsilon<0.46 \text { and } 9 \mathrm{~mm}<D_{e q, V}<49 \mathrm{~mm}\right) \text {. } \\
\text { On their experimental data, the coefficient of } \\
\text { determination }\left(\mathrm{R}^{2}\right) \text { is } 0.93 \text { for the co/counter-current } \\
\text { configuration and } 0.96 \text { for the cross-current } \\
\text { configuration. }\end{array}$ \\
\hline
\end{tabular}

Table 9. Correlations of pressure drop in packed beds expressed in the form of friction factor. 


\section{Conclusion}

In the short to medium term, packed-bed energy storage is a promising technology to enhance the development of solar thermal energy. However, few studies have been carried out on setups large enough to be fully representative of commercialscale systems in which edge effects are second order phenomena. The studies performed so far showed that thermal stratification of the storage system is a key parameter which strongly influences storage efficiency and operation. Thermal stratification of the storage depends on many parameters like the aspect ratio of the storage tank, the fluid and solid physical properties, the solid filler geometry and the charging and discharging operating conditions. Experimental and numerical studies showed that long-term operation of packed-bed storage under cyclic conditions leads to a stabilized state which can be controlled by the operator and is able to withstand punctual perturbations. Packed-bed storages may work with either liquid or gaseous heat transfer fluid. Liquid heat transfer fluids have good physical properties and enable to reach high efficiency whereas air used as gaseous heat transfer fluids is free, enables to operate at very high temperature and is free from chemical issues.

Since packed-bed storage performances depend on operating conditions and many interacting physical phenomena, numerical modeling is a good way to investigate and optimize packed-bed storage design and operation. Several numerical models from the literature have been presented. All of them are based on energy equations applied to the components of the system. Numerical models differ mainly as a result of the assumptions made and the degree of simplification. Assumptions and simplifications should be a trade-off between the desired accuracy and the available computing power, and depend on the studied system. Numerical models should be considered with precaution when they are used for extrapolation and parametric studies since the scope of validity of each simplifying assumption is not precisely known.

Many correlations are available in the literature to model and compute fluid/solid and fluid/wall heat transfer coefficients, thermal diffusion and pressure drop in packed beds. Some of them were presented, compared and advocated. However, these are only general recommendations and the correlations should be chosen depending on each specific case.

In addition to better understanding of the physical mechanisms which govern packed-bed storage behavior and performances, some mechanical issues like thermal ratcheting should be further investigated to enable wide spread of this storage technology. 


\section{References}

Acetis, J., Thodos, G., 1960. Mass and Heat Transfer in Flow of Gases Through Spherical Packings, Industrial \& Engineering Chemistry, vol. 52, 1003 - 1006.

Achenbach, E., 1995. Heat and flow characteristics of packed beds, Exp.Therm.Fluid Sci., vol. 10, 17 - 27.

Adeyanju, A.A., Manohar, K., 2009. Theoretical and experimental investigation of heat transfer in packed beds, Res.J.Appl.Sci., vol. 4, 166 - 177.

Airlight Energy. Aït-Baha CSP pilot plant. http://www.airlightenergy.com/ait-baha-csp-pilot-plant/, Apr. 2016.

Akinyele, D.O., Rayudu, R.K., 2014. Review of energy storage technologies for sustainable power networks, Sustainable Energy Technol.Assess., vol. 8, 74 - 91.

Alanís, E., Saravia, L., Rovetta, L., 1977. Measurement of rock pile heat transfer coefficients, Sol.Energy, vol. 19, 571 - 572.

Allen, K.G., von Backström, T.W., Kröger, D.G., 2015. Rock bed pressure drop and heat transfer: Simple design correlations, Sol.Energy, vol. 115, 525 - 536.

Anderson, R., Shiri, S., Bindra, H., Morris, J.F., 2014. Experimental results and modeling of energy storage and recovery in a packed bed of alumina particles, Appl.Energy, vol. 119, 521 - 529.

Baddour, R.F., Yoon, C.Y., 1961. Local radial effective conductivity and the wall effect in packed beds, Chem.Engg.Prog.Symp.Series, vol. 57, 35 - 50.

Balakrishnan, A.R., Pei, D.C.T., 1979a. Heat transfer in gas-solid packed bed systems. 1. A critical review, Ind.Eng.Chem.Process Des.Dev., vol. 18, 30 - 40.

Balakrishnan, A.R., Pei, D.C.T., 1979b. Heat transfer in gas-solid packed bed systems. 2. The conduction mode, Ind.Eng.Chem.Process Des.Dev., vol. 18, 40 - 46.

Bauer, R., 1990. Stagnant packed beds in: Hewitt, G. F., Hemisphere Handbook of Heat Exchanger Design. Hemisphere Pub. Corp., New York.

Bauer, R., Shlünder, E., 1978. Effective radial thermal conductivity of packings in gas flow - 2. Thermal conductivity of the packing fraction without gas flow, Int Chem Eng, vol. 18, 189 - 204.

Bayón, R., Rivas, E., Rojas, E., 2013. Study of thermocline tank performance in dynamic processes and stand-by periods with an analytical function, Energy Procedia, vol. 49, 725 - 734.

Bayón, R., Rojas, E., 2013. Simulation of thermocline storage for solar thermal power plants: From dimensionless results to prototypes and real-size tanks, Int.J.Heat Mass Transf., vol. 60, 713 - 721.

Beasley, D.E., Clark, J.A., 1984. Transient response of a packed bed for thermal energy storage, Int.J.Heat Mass Transf., vol. 27, 1659 - 1669.

Beek, J., 1962. Design of Packed Catalytic Reactors. 203-271.

Bergman, T.L., Lavine, A.S., Incropera, F.P., Dewitt, D.P., 2011. Fundamentals of Heat and Mass Transfer, 7th Edition. John Wiley \& Sons, 1048 p.

Bhavsar, V.C., Balakrishnan, A.R., 1990. Pebble bed-oil thermal energy storage for solar thermo-electric power systems, Int J Energy Res, vol. 14, 233 - 240.

Biencinto, M., Bayón, R., Rojas, E., González, L., 2014. Simulation and assessment of operation strategies for solar thermal power plants with a thermocline storage tank, Sol.Energy, vol. 103, 456 - 472.

Breitbach, G., Barthels, H., 1980. The radiant heat transfer in the HTR core after failure of the afterheat removal systems, Nucl Technol, vol. 49, 392 - 399.

Brosseau, D., Kelton, J.W., Ray, D., Edgar, M., Chisman, K., Emms, B., 2005. Testing of thermocline filler materials and molten-salt heat transfer fluids for thermal energy storage systems in parabolic trough power plants, J Sol Energy Eng Trans ASME, vol. 127, 109 - 116.

Bruch, A., Fourmigué, J.F., Couturier, R., 2014a. Experimental and numerical investigation of a pilot-scale thermal oil packed bed thermal storage system for CSP power plant, Sol.Energy, vol. 105, 116 - 125.

Bruch, A., Fourmigué, J. F., Couturier, R., Molina, S., 2014b. Experimental and numerical investigation of stability of packed bed thermal energy storage for CSP power plant, SolarPACES 2013, Energy Procedia, vol. 49, 743 - 751.

Burke, S.P., Plummer, W.B., 1928. Gas Flow through Packed Columns, J.Ind.Eng.Chem., vol. 20, 1197 - 1200.

Carman, P.C., 1937. Fluid flow through granular beds, Trans.Instn Chem.Engrs, vol. 15, 150 - 166.

Cascetta, M., Cau, G., Puddu, P., Serra, F., 2015. Experimental investigation of a packed bed thermal energy storage system, J.Phys.Conf.Ser., vol. 655.

Chandra, P., Willits, D.H., 1981. Pressure drop and heat transfer characteristics of air-rockbed thermal storage systems, Sol.Energy, vol. 27, 547 - 553.

Chang, Z. S., Li, X., Xu, C., Chang, C., Wang, Z. F., 2015. The Design and Numerical Study of a 2MWh Molten Salt Thermocline Tank, Energy Procedia, vol. 69, 779 - 789.

Charlas, B., Doremus, P., Gillia, O., Imbault, D., 2010. Numerical analysis of a metal hydride powder bed under swelling or lateral compaction by the discrete element method, Proc.World.Powder Metall.Congr.Exhibition, vol. 1.

Chu, Y.C., Storrow, J.A., 1952. Heat transfer to air flowing through packed tubes, Chem.Eng.Sci., vol. 1, 230 - 237.

Close, D.J., 1965. Rock pile thermal storage for comfort air conditioning, Mech.Chem.Eng.Trans., vol. MC-1, 11 - 22.

Cocco, D., Serra, F., 2015. Performance comparison of two-tank direct and thermocline thermal energy storage systems for 1MWe class concentrating solar power plants, Energy, vol. 81, 526 - 536.

Colburn, A.P., 1931. Heat Transfer and Pressure Drop in Empty, Baffled, and Packed Tubes, Industrial \& Engineering Chemistry, vol. 23, 910 - 913.

Coutier, J.P., Farber, E.A., 1982. Two applications of a numerical approach of heat transfer process within rock beds, Sol.Energy, vol. 29, 451 - 462.

CSP Today. CSP Today Global Tracker. http://social.csptoday.com/tracker/projects, Apr. 2016.

CSP World. CSP World Map. http://www.cspworld.org/cspworldmap, Apr. 2016. 
Damköhler, G., 1937. Technische Reaktionsgeschwindigkeit in: Eucken, A. and Jakob, M., Der Chemie-Ingenieur. Akademische Verlagsgesellschaft, Leipzig, pp. 359 - 485.

Deissler, R.G., Boegli, J.S., 1958. An investigation of effective thermal conductivities of powders in various gases, ASME Transactions, vol. 80, 1417 - 1425.

Dixon, A. G., 1968. Heat Transfer in Packed Beds of Low Tube/Particle Diameter Ratio, Univ. Edinburgh, Scotland.

Dixon, A.G., Cresswell, D.L., 1979. Theoretical prediction of effective heat transfer parameters in packed beds, AIChE J, vol. $25,663-676$.

Dixon, A.G., DiCostanzo, M.A., Soucy, B.A., 1984. Fluid-phase radial transport in packed beds of low tube-to-particle diameter ratio, International Journal of Heat and Mass Transfer, vol. 27, 1701 - 1713.

Dogangun, A., Karaca, Z., Durmus, A., Sezen, H., 2009. Cause of damage and failures in silo structures, J.Perform.Constr.Facil., vol. 23, 65 - 71.

Du Plessis, J.P., Woudberg, S., 2008. Pore-scale derivation of the Ergun equation to enhance its adaptability and generalization, Chem.Eng.Sci., vol. 63, 2576 - 2586.

Dunkle, R.V., Ellul, W.M.J., 1972. Randomly packed particulate bed regenerators and evaporative coolers, Inst Eng Aust Mech Chem Eng Trans, vol. MC8, 117 - 121.

EPRI, 2010. Solar thermocline storage systems: preliminary design study, EPRI, 2010.1019581, 188 p.

Ergun, S., 1952. Fluid flow through packed columns, Chem.Eng.Prog., vol. 48, 89 - 94.

Faas, S.E., Thorne, L.R., Fuchs, E.A., Gilbertsen, N.D., 1986. 10 Mwe Solar Thermal Central Receiver Pilot Plant - Thermal storage subsystem evaluation - Final report, SAND86-8212.

Flueckiger, S.M., Iverson, B.D., Garimella, S.V., Pacheco, J.E., 2014. System-level simulation of a solar power tower plant with thermocline thermal energy storage, Appl.Energy, vol. 113, 86 - 96.

Flueckiger, S.M., Yang, Z., Garimella, S.V., 2013. Review of molten-salt thermocline tank modeling for solar thermal energy storage, Heat Transfer Eng, vol. 34, 787 - 800.

Foumeny, E.A., Kulkarni, A., Roshani, S., Vatani, A., 1996. Elucidation of pressure drop in packed-bed systems, Appl Therm Eng, vol. 16, 195 - 202.

Frössling, N., 1938. Über die Verdunstung fallender Teilchen, Gerlands Beitr.Geophys., vol. 52, 170 - 175.

Furnas, C.C., 1930. Heat Transfer from a Gas Stream to a Bed of Broken Solids, Industrial \& Engineering Chemistry, vol. 22, $26-31$.

Furnas, C.C., 1932. Heat Transfer from a Gas Stream to a Bed of Broken Solids, U.S. Department of Commerce, Bulletin 361, $88 \mathrm{p}$.

Galione, P., Pérez-Segarra, C.D., Rodríguez, I., Torras, S., Rigola, J., 2015. Numerical Evaluation of Multi-layered Solid-PCM Thermocline-like Tanks as Thermal Energy Storage Systems for CSP Applications, Energy Procedia, vol. 69,832 - 841.

Galloway, T.R., Sage, B.H., 1970. A model of the mechanism of transport in packed, distended, and fluidized beds, Chem.Eng.Sci., vol. 25, 495 - 516.

Gamson, B.W., Thodos, G., Hougen, O.A., 1943. Trans.AIChE., vol. 39, 1 - 35.

García-Olivares, A., Ballabrera-Poy, J., García-Ladona, E., Turiel, A., 2012. A global renewable mix with proven technologies and common materials, Energy Policy, vol. 41, 561 - 574.

Gil, A., Medrano, M., Martorell, I., Lázaro, A., Dolado, P., Zalba, B., Cabeza, L.F., 2009. State of the art on high temperature thermal energy storage for power generation. Part 1-Concepts, materials and modellization, Renewable Sustainable Energy Rev, vol. 14, 31 - 55 .

Gonzo, E.E., 2002. Estimating correlations for the effective thermal conductivity of granular materials, Chem.Eng.J., vol. 90, $299-302$.

Gunn, D.J., 1978. Transfer of heat or mass to particles in fixed and fluidised beds, Int.J.Heat Mass Transf., vol. 21 , 467 - 476.

Gunn, D. J., Vortmeyer, D., 1982. Heat transfer in fixed bed chemical reactors, Heat Transfer, Proceedings of the International Heat Transfer Conference 7th., vol. 6, 13 - 18.

Gupta, A.S., Thodos, G., 1962. Mass and heat transfer in the flow of fluids through fixed and fluidized beds of spherical particles, AIChE J, vol. 8, 608 - 610.

Gupta, S.N., Chaube, R.B., Upadhyay, S.N., 1974. Fluid-particle heat transfer in fixed and fluidized beds, Chem.Eng.Sci., vol. 29, $839-843$.

Hadley, G.R., 1986. Thermal conductivity of packed metal powders, Int.J.Heat Mass Transf., vol. 29, 909 - 920.

Haller, M.Y., Cruickshank, C.A., Streicher, W., Harrison, S.J., Andersen, E., Furbo, S., 2009. Methods to determine stratification efficiency of thermal energy storage processes - Review and theoretical comparison, Sol.Energy, vol. 83, 1847 $-1860$.

Hallet, R.W.Jr., Gervais, R.L., 1977. Central receiver solar thermal power system - Phase 1 - CDRL ITEM 2 - Pilot Plant Preliminary Design Report - Vol V - Thermal Storage Subsystem, SAN/1108-8/5.

Handley, D., Heggs, P.J., 1968. Momentum and heat transfer mechanisms in regular shaped packings, Trans.Instn Chem.Engrs, vol. 46, T251 - T264.

Handley, D., Heggs, P.J., 1969. The effect of thermal conductivity of the packing material on transient heat transfer in a fixed bed, Int.J.Heat Mass Transf., vol. 12, 549 - 570.

Hicks, R.E., 1970. Pressure drop in packed beds of spheres, Ind.Eng.Chem.Fundam., vol. 9, 500 - 502.

Hoffmann, J.F., Fasquelle, T., Goetz, V., Py, X., 2016. A thermocline thermal energy storage system with filler materials for concentrated solar power plants: Experimental data and numerical model sensitivity to different experimental tank scales, Appl Therm Eng, vol. 100, 753 - 761.

Hohmeyer, O.H., Bohm, S., 2015. Trends toward 100\% renewable electricity supply in Germany and Europe: A paradigm shift in energy policies, Wiley Interdiscip.Rev.Energy Environ., vol. 4, 74 - 97.

Hollands, K.G.T., Pott, P., 1971. Development and testing of evaporative cooler pads, Mechanical and Chemical Engineering Trans., $66-72$. 
Hollands, K.G.T., Sullivan, H.F., 1984. Pressure drops across rock bed thermal storage systems, Sol.Energy, vol. 33, 221 225.

Hollands, K.G.T., Sullivan, H.F., Shewen, E.C., 1984. Flow uniformity in rock beds, Sol.Energy, vol. 32,343 - 348.

Hsu, C.T., Cheng, P., Wong, K.W., 1994. Modified Zehner-Schlunder models for stagnant thermal conductivity of porous media, Int.J.Heat Mass Transf., vol. 37, 2751 - 2759.

Hsu, C.T., Cheng, P., Wong, K.W., 1995. A lumped-parameter model for stagnant thermal conductivity of spatially periodic porous media, J Heat Transfer Trans ASME, vol. 117, 264 - 269.

Hueppe, A., 2011. Heat transfer modeling at an interface between a porous medium and a free region, Ecole Centrale Paris, $180 \mathrm{p}$.

IAEA, 2000. Heat Transport and Afterheat Removal for Gas Cooled Reactors Under Accident Conditions, TECDOC-1163.

Inaba, H., Fukuda, T., 1984. Transient heat transfer behaviors in cylindrical porous beds at relatively large Reynolds numbers, Wärme- und Stoffübertragung, vol. 18, 109 - 116.

Ismail, K.A.R., Stuginsky, J., 1999. A parametric study on possible fixed bed models for pcm and sensible heat storage, Appl Therm Eng, vol. 19, 757 - 788.

Kaviany, M., 1995. Principles of Heat Transfer in Porous Media, 2nd Edition. 709 p.

Khan, J.A., Beasley, D.E., Alatas, B., 1991. Evaporation from a packed bed of porous particles into superheated vapor, Int.J.Heat Mass Transf., vol. 34, 267 - 280.

Klein, P., Roos, T. H., Sheer, T. J., 2013. Experimental investigation into a packed bed thermal storage solution for solar gas turbine systems, SolarPACES 2013, Energy Procedia, vol. 49, 840 - 849.

Kozeny, J., 1927. Uber Kapillare Leitung des Wasser im Boden, Sitzungsbericht der Akademie der Wissenschaften, vol. 136, 271 - 306.

Kraemer, S. CSP with storage propelled by PV growth while regulators build support, CSP Today. http://social.csptoday.com/markets/csp-storage-propelled-pv-growth-while-regulators-build-support, Apr. 2016.

Krupiczka, R., 1967. Analysis of thermal conductivity in granular materials, Int.Chem.Eng., vol. 7, 122 - 144.

Kunii, D., Smith, J.M., 1960. Heat transfer characteristics of porous rocks, AIChE J, vol. 6, 71 - 78.

Kunii, D., Suzuki, M., 1968. Heat and mass transfer from wall surface to packed beds, Symposium on Heat and Mass Transfer.

Kuravi, S., Trahan, J., Goswami, Y., Jotshi, C., Stefanakos, E., Goel, N., 2013. Investigation of a high-temperature packed-bed sensible heat thermal energy storage system with large-sized elements, J Sol Energy Eng Trans ASME, vol. 135.

Kuznetsov, A.V., 1995. An analytical solution for heating a two-dimensional porous packed bed by a non-thermal equilibrium fluid flow, Appl.Sci.Res., vol. 55, 83 - 93.

Lakota, A., Levec, J., Carbonell, R.G., 2002. Hydrodynamics of trickling flow in packed beds: Relative permeability concept, AIChE J., vol. 48, 731 - 738 .

Leva, M., 1947. Heat Transfer to Gases through Packed Tubes - General correlation for smooth spherical particles, Industrial \& Engineering Chemistry, vol. 39, 857 - 862.

Leva, M., 1950. Packed-Tube Heat Transfer, Industrial \& Engineering Chemistry, vol. 42, 2498 - 2501.

Leva, M., Grummer, M., 1948. Heat Transfer to Gases through Packed Tubes - Effect of particle characteristics, Industrial \& Engineering Chemistry, vol. 40, 415 - 419.

Leva, M., Weintraub, M., Grummer, M., Clark, E.L., 1948. Cooling of Gases through Packed Tubes, Industrial \& Engineering Chemistry, vol. 40, $747-752$.

Lévêque, A., 1928. Les lois de la transmission de chaleur par convection, Université de Paris.

Li, C.H., Finlayson, B.A., 1977. Heat transfer in packed beds: a re-evaluation, Chenz.Eng.Sci., vol. 32,1055 - 1066.

Löf, G.O.G., Hawley, R.W., 1948. Unsteady state heat transfer between air and loose solids, Industrial \& Engineering Chemistry, vol. 40, 1061 - 1070.

Mabrouk, M.T., Kheiri, A., Feidt, M., 2015. Using Generalized Integral Transforms to solve a perturbation model for a packed bed thermal energy storage tank, Int.J.Heat Mass Transf., vol. 84, 633 - 641.

Macdonald, I.F., El-Sayed, M.S., Mow, K., Dulllen, F.A.L., 1979. Flow through porous media - The Ergun equation revisited, Ind.Eng.Chem.Fundam., vol. 18, 199 - 208.

Martin, H., 2005. The Lévêque-analogy or How to predict heat and mass transfer from fluid friction, 4th International Conference on Heat Transfer, Fluid Mechanics and Thermodynamics, HEFAT2005.

Mawire, A., McPherson, M., 2009. Experimental and simulated temperature distribution of an oil-pebble bed thermal energy storage system with a variable heat source, Appl Therm Eng, vol. 29, 1086 - 1095.

Mawire, A., McPherson, M., van den Heetkamp, R.R.J., Mlatho, S.J.P., 2009. Simulated performance of storage materials for pebble bed thermal energy storage (TES) systems, Appl.Energy, vol. 86, 1246 - 1252.

Mawire, A., McPherson, M., van den Heetkamp, R.R.J., Taole, S.H., 2010. Experimental volumetric heat transfer characteristics between oil and glass pebbles in a small glass tube, Energy, vol. 35, 1256 - 1263.

Mawire, A., Taole, S.H., 2011. A comparison of experimental thermal stratification parameters for an oil/pebble-bed thermal energy storage (TES) system during charging, Appl.Energy, vol. 88, 4766 - 4778.

Maxwell, J.C., 1873. A Treatise on Electricity and Magnetism. Clarendon Press, Oxford, 425 p.

McDonnell Douglas Astronautics Company, 1986. 10 MWe Solar Thermal Central Receiver Pilot Plant Mode 5 (Test 1150) and Mode 6 (Test 1160) Test report, Sandia National Laboratories, SAND86-8175.

Meier, A., Winkler, C., Wuillemin, D., 1991. Experiment for modelling high temperature rock bed storage, Solar Energy Materials, vol. 24, 255 - 264.

Melanson, M.M., Dixon, A.G., 1985. Solid conduction in low dt/dp beds of spheres, pellets and rings, Int.J.Heat Mass Transf., vol. 28, 383 - 394 .

Mertens, N., Alobaid, F., Frigge, L., Epple, B., 2014. Dynamic simulation of integrated rock-bed thermocline storage for concentrated solar power, Sol.Energy, vol. 110, 830 - 842.

Morgan, G.R., 1980. 10 Mwe Pilot Plant Thermal Storage Subsystem - Analysis Report, RADL ITEM 5-1. 
Nellis, G., Klein, S., 2009. Heat Transfer. Cambridge, 1107 p.

Nemec, D., Levec, J., 2005. Flow through packed bed reactors: 1. Single-phase flow, Chem.Eng.Sci., vol. 60 , 6947 - 6957.

Nield, D.A., 1991. Estimation of the stagnant thermal conductivity of saturated porous media, Int.J.Heat Mass Transf., vol. 34, $1575-1576$

NREL. Concentrating Solar Power Projects. http://www.nrel.gov/csp/solarpaces/, Apr. 2016.

Okello, D., Nydal, O.J., Banda, E.J.K., 2014. Experimental investigation of thermal de-stratification in rock bed TES systems for high temperature applications, Energy Convers.Manage., vol. 86, 125 - 131.

Pacheco, J.E., Showalter, S.K., Kolb, W.J., 2002. Development of a molten-salt thermocline thermal storage system for parabolic trough plants, J Sol Energy Eng Trans ASME, vol. 124, 153 - 159.

Pardo, P., Deydier, A., Anxionnaz-Minvielle, Z., Rougé, S., Cabassud, M., Cognet, P., 2014. A review on high temperature thermochemical heat energy storage, Renewable Sustainable Energy Rev, vol. 32, 591 - 610.

Pfeffer, R., 1964. Heat and mass transport in multiparticle systems, I\&EC Fundamentals, vol. 3, 380 - 383.

Philibert, C., 2011. Renewable Energy Technologies. Solar Energy Perspectives. OECD, IEA, Paris, France, 228 p.

Pudjianto, D., Aunedi, M., Djapic, P., Strbac, G., 2014. Whole-systems assessment of the value of energy storage in lowcarbon electricity systems, IEEE Trans.Smart Grid, vol. 5, 1098 - 1109.

Qin, F.G.F., Yang, X., Ding, Z., Zuo, Y., Shao, Y., Jiang, R., Yang, X., 2012. Thermocline stability criterions in single-tanks of molten salt thermal energy storage, Appl.Energy, vol. 97, 816 - 821.

Ranz, W.E., 1952. Friction and transfer coefficients for single particles and packed beds, Chem.Eng.Progr., vol. 48, 247 - 253.

Rodat, S., Bruch, A., Dupassieux, N., Mourchid, N. E., 2015. Unique Fresnel Demonstrator Including ORC and Thermocline Direct Thermal Storage: Operating Experience, Energy Procedia, vol. 69, 1667 - 1675.

Rose, H.E., Rizk, A.M.A., 1949. Further Researches in Fluid Flow through Beds of Granular Material, Proc.Inst.Mech.Eng., vol. 160, 493 - 503.

Sabihuddin, S., Kiprakis, A.E., Mueller, M., 2015. A numerical and graphical review of energy storage technologies, Energies, vol. 8,172 - 216 .

Saez, A.E., McCoy, B.J., 1982. Dynamic response of a packed bed thermal storage system - a model for solar air heating, Sol.Energy, vol. 29, $201-206$.

Sagara, K., Nakahara, N., 1991. Thermal performance and pressure drop of rock beds with large storage materials, Sol.Energy, vol. 47, $157-163$.

Satterfield, C.N., Resnick, H., Wentworth, R.L., 1954. Simultaneous heat and mass transfer in a diffusion-controlled chemical reaction, Chem.Eng.Progr., vol. 50, 460 - 466.

Schröder, E., Class, A., Krebs, L., 2006. Measurements of heat transfer between particles and gas in packed beds at low to medium Reynolds numbers, Exp.Therm.Fluid Sci., vol. 30, 545 - 558.

Schumann, T.E.W., 1929. Heat transfer: A liquid flowing through a porous prism, J Franklin Inst, vol. 208, 405 - 416.

Shewen, E.C., Sullivan, H.F., Hollands, K.G.T., Balakrishnan, A.R., 1978. A heat storage subsystem for solar energy - Final report - Phase 2, STOR - 6.

Shitzer, A., Levy, M., 1983. Transient Behavior of a Rock-Bed Thermal Storage System Subjected to Variable Inlet Air Temperatures - Analysis and Experimentation, J Sol Energy Eng Trans ASME, vol. 105, 200 - 206.

Sih, S. S., Barlow, J. W., 1995. The prediction of the thermal conductivity of powders, 6th SFF Symposium, 397 - 401.

Singh, R., Saini, R.P., Saini, J.S., 2006. Nusselt number and friction factor correlations for packed bed solar energy storage system having large sized elements of different shapes, Sol.Energy, vol. 80, 760 - 771.

Stuke, B., 1948. Berechnung des Wärmeaustausches in Regeneratoren mit zylindrischen und kugelförmigen Füllmaterial, Angewandte Chemie, vol. B20, 262.

Szekely, J., Poveromo, J.J., 1975. Flow maldistribution in packed beds: a comparison of measurements with predictions, AIChE J, vol. 21, 769 - 775.

Thoenes, D.J., Kramers, H., 1958. Mass transfer from spheres in various regular packings to a flowing fluid, Chemical Engineering Science, vol. 8, 271 - 283.

Tsotsas, E., Martin, H., 1987. Thermal conductivity of packed beds: A review, Chem.Eng.Proc., vol. 22,19 - 37.

Tsotsas, E., Schlünder, E.U., 1990. Heat transfer in packed beds with fluid flow: remarks on the meaning and the calculation of a heat transfer coefficient at the wall, Chem.Eng.Sci., vol. 45, 819 - 837.

Van Antwerpen, W., Du Toit, C.G., Rousseau, P.G., 2010. A review of correlations to model the packing structure and effective thermal conductivity in packed beds of mono-sized spherical particles, Nucl Eng Des, vol. 240,1803 - 1818.

Van Antwerpen, W., Rousseau, P. G., Du Toit, C. G., 2009. Accounting for porous structure in effective thermal conductivity calculations in a pebble bed reactor, Int.Congr.Adv.Nuc.Power Plants, ICAPP, vol. 1, 258 - 269.

Van Lew, J.T., Li, P., Chan, C.L., Karaki, W., Stephens, J., 2011. Analysis of heat storage and delivery of a thermocline tank having solid filler material, J Sol Energy Eng Trans ASME, vol. 133, 021003-1 - 021003-10.

Vortmeyer, D., 1989. Packed bed thermal dispersion models and consistent sets of coefficients, Chem.Eng.Proc., vol. 26, 263 268.

Vortmeyer, D., Schaefer, R.J., 1974. Equivalence of one- and two-phase models for heat transfer processes in packed beds: one dimensional theory, Chem.Eng.Sci., vol. 29, 485 - 491.

Votyakov, E.V., Bonanos, A.M., 2014. A perturbation model for stratified thermal energy storage tanks, Int.J.Heat Mass Transf., vol. 75, 218 - 223.

Votyakov, E.V., Bonanos, A.M., 2015. Algebraic model for thermocline thermal storage tank with filler material, Sol.Energy, vol. 122, 1154 - 1157.

Wakao, N., Kaguei, S., 1982. Heat and mass transfer in packed beds. Gordon and Breach Science Publishers, New York, 364 p.

Wakao, N., Kaguei, S., Funazkri, T., 1979. Effect of fluid dispersion coefficients on particle-to-fluid heat transfer coefficients in packed beds. Correlation of nusselt numbers, Chem.Eng.Sci., vol. 34, 325 - 336. 
Wakao, N., Kato, K., 1969. Effective thermal conductivity of packed beds, J.Chem.Eng.Jpn, vol. 2, 24 - 33.

Weidenfeld, G., Weiss, Y., Kalman, H., 2004. A theoretical model for effective thermal conductivity (ETC) of particulate beds under compression, Granular Matter, vol. 6, 121 - 129.

Whitaker, S., 1972. Forced convection heat transfer correlations for flow in pipes, past flat plates, single cylinders, single spheres, and for flow in packed beds and tube bundles, AIChE J, vol. 18, 361 - 371.

Xu, B., Li, P., Chan, C., 2015. Application of phase change materials for thermal energy storage in concentrated solar thermal power plants: A review to recent developments, Appl.Energy, vol. 160, 286 - 307.

Xu, B., Li, P.W., Chan, C.L., 2012a. Extending the validity of lumped capacitance method for large Biot number in thermal storage application, Sol.Energy, vol. 86, 1709 - 1724.

Xu, C., Wang, Z., He, Y., Li, X., Bai, F., 2012b. Sensitivity analysis of the numerical study on the thermal performance of a packed-bed molten salt thermocline thermal storage system, Appl.Energy, vol. 92, 65 - 75.

Yagi, S., Kunii, D., 1960. Studies on heat transfer near wall surfaces in packed beds, AIChE J, vol. 6, 97 - 104.

Yagi, S., Wakao, N., 1959. Heat and Mass Transfer from Wall to Fluid in Packed Beds, AIChE J, vol. 5, 79 - 85.

Yang, X., Qin, F.G.F., Jiang, R., 2014. Experimental investigation of a molten salt thermocline storage tank, Int.J.Sustainable Energy.

Yang, Z., Garimella, S.V., 2010a. Molten-salt thermal energy storage in thermoclines under different environmental boundary conditions, Appl.Energy, vol. 87, 3322 - 3329.

Yang, Z., Garimella, S.V., 2010b. Thermal analysis of solar thermal energy storage in a molten-salt thermocline, Sol.Energy, vol. 84, 974 - 985.

Yu, J., Zhang, M., Fan, W., Zhou, Y., Zhao, G., 2002. Study on performance of the ball packed-bed regenerator: Experiments and simulation, Appl Therm Eng, vol. 22, 641 - 651.

Zanganeh, G., Ambrosetti, G., Pedretti, A., Zavattoni, S., Barbato, M., Good, P., Haselbacher, A., Steinfeld, A., 2014. A 3 MWth parabolic trough CSP plant operating with air at up to $650{ }^{\circ} \mathrm{C}$, Proc.Int.Renew.Sustain.Energy Conf., 108 - 113.

Zanganeh, G., Pedretti, A., Zavattoni, S., Barbato, M., Steinfeld, A., 2012. Packed-bed thermal storage for concentrated solar power - Pilot-scale demonstration and industrial-scale design, Sol.Energy, vol. 86, 3084 - 3098.

Zavattoni, S.A., Barbato, M.C., Pedretti, A., Zanganeh, G., Steinfeld, A., 2014. High Temperature Rock-bed TES System Suitable for Industrial-scale CSP Plant - CFD Analysis Under Charge/Discharge Cyclic Conditions, Energy Procedia, vol. 46, $124-133$.

Zehner, P., Schlünder, E.U., 1970. Wärmeleitfähigkeit von Schüttungen bei mäßigen Temperaturen, Chemie Ingenieur Technik, vol. 42, 933 - 941. 